UNIVERSIDADE FEDERAL DA PARAÍBA CENTRO DE CIÊNCIAS SOCIAIS APLICADAS

PROGRAMA DE PÓS-GRADUAÇÃO EM CIÊNCIA DA INFORMAÇÃO

LUCIANA DUMER

\title{
REPRESENTAÇÃO DESCRITIVA DA INFORMAÇÃO EM BIBLIOTECAS: UM ESTUDO SOBRE OS FORMATOS DE INTERCÂMBIO
}

JOÃO PESSOA

2019 


\section{REPRESENTAÇÃO DESCRITIVA DA INFORMAÇÃO EM BIBLIOTECAS: UM ESTUDO SOBRE OS FORMATOS DE INTERCÂMBIO}

Dissertação apresentada ao Programa de Pós-Graduação em Ciência da Informação (PPGCI) da Universidade Federal da Paraíba (UFPB) em nível de Mestrado Acadêmico, como requisito para obtenção do título de Mestre em Ciência da Informação.

Orientadora: Prof. ${ }^{a}$ Dr. $^{a}$ Maria Elizabeth Baltar Carneiro de Albuquerque.

Área de Concentração:

Informação, Conhecimento e Sociedade

Linha de Pesquisa:

Organização, Acesso e Uso da Informação

JOÃO PESSOA

2019 


\section{Catalogação na publicação \\ Seção de Catalogação e Classificação}

D888r Dumer, Luciana.

Representação descritiva da informação em bibliotecas: um estudo sobre os formatos de intercâmbio / Luciana

Dumer. - João Pessoa, 2019.

$144 \mathrm{f}$. : il.

Orientação: Maria Elizabeth Baltar Carneiro de Albuquerque.

Dissertação (Mestrado) - UFPB/CCSA.

1. Bibliotecas - Organização da informação. 2 . Representação descritiva. 3. Intercâmbio de informações bibliográficas. 4. MARC 21. I. Albuquerque, Maria Elizabeth Baltar Carneiro de. II. Título.

UFPB / BC 


\section{REPRESENTAÇÃO DESCRITIVA DA INFORMAÇÃO EM BIBLIOTECAS: UM ESTUDO SOBRE OS FORMATOS DE INTERCÂMBIO}

Dissertação apresentada ao Programa de Pós-Graduação em Ciência da Informação (PPGCI) da Universidade Federal da Paraíba (UFPB) em nível de Mestrado Acadêmico, como requisito para obtenção do título de Mestre em Ciência da Informação.

Aprovado em 26 de março de 2019.

\section{BANCA EXAMINADORA}

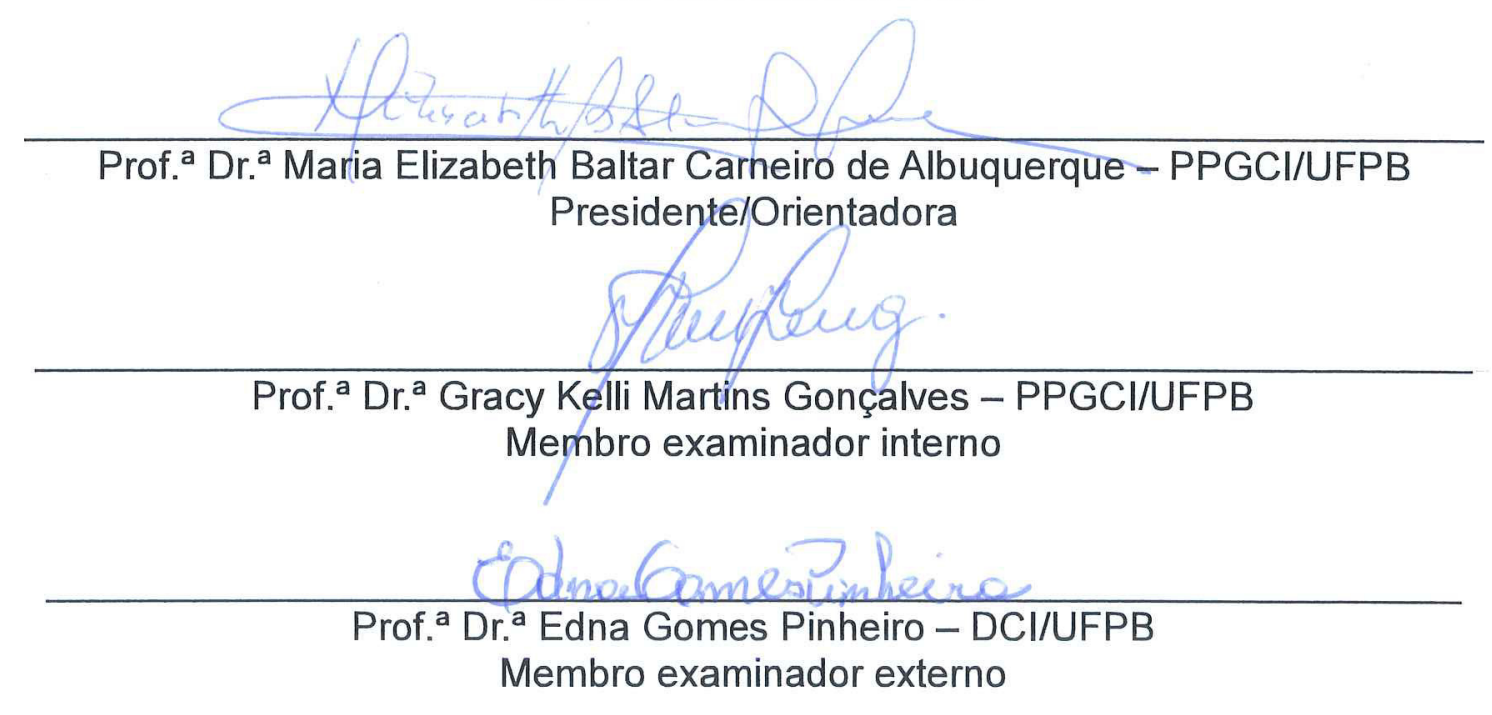
Prof. ${ }^{a}$ Dr. ${ }^{a}$ Bernardina Maria Juvenal de Oliveira Freire - PPGCI/UFPB Membro examinador interno (suplente)
Prof. ${ }^{\circ}$ Dr. Fabio Assis Pinho - PPGCI/UFPE Membro examinador externo (suplente)


Dedico ao meu querido companheiro de vida, Messias Azevedo de Almeida. 


\section{AGRADECIMENTOS}

Agradeço, antes de tudo, ao Pai Celestial pela vida e por ter me proporcionado a oportunidade de trilhar esse caminho.

Agradeço aos meus pais por tudo. À minha mãe querida, Adélia Bauser, por me apoiar e por suportar a distância física e a saudade nestes dois anos de estudos na encantadora cidade de João Pessoa, tão longe de casa.

Ao meu companheiro Messias de Almeida, o meu agradecimento de coração por embarcar comigo nessa aventura, por estar ao meu lado nos bons e nos maus momentos, por todo amor, paciência e carinho.

Sou muito grata a toda minha família em especial à minha irmã Vanessa Dumer e meu cunhado Lenon Neves, que me ajudaram e cuidaram de tantas coisas para que tudo desse certo.

Agradeço ao Instituto Federal do Espírito Santo, instituição onde tenho a oportunidade de exercer a minha profissão de bibliotecária, e que apoia a educação continuada de seus Técnicos Administrativos. Obrigada Maristela Mercandeli, minha amiga de trabalho e de vida, por me incentivar desde o primeiro momento a seguir em busca desta conquista.

Agradeço imensamente à querida professora Dra. Maria Elizabeth Baltar Carneiro de Albuquerque que me acolheu e me recebeu tão carinhosamente, não apenas como minha orientadora, mas também como amiga e incentivadora de todas as horas, pessoa especial a quem aprendi a admirar e respeitar muito.

A todos os professores do PPGCI/UFPB, o meu muito obrigada por compartilharem tanto conhecimento e tantas informações.

Agradeço também aos professores que aceitaram prontamente participar da banca examinadora deste trabalho: Prof ${ }^{a}$ Gracy Kelli Martins, Prof ${ }^{a}$ Edna Gomes Pinheiro, Profa Bernardina Freire e Prof. Fábio Pinho. Não posso deixar de destacar a Professora Gracy e professora Edna pela valiosa contribuição na qualificação e pela carinhosa parceria.

Agradeço também a todos os meus colegas estudantes do PPGCl, que se revelaram pessoas tão especiais e queridas, as quais estarão sempre guardadas no meu coração. Em especial aos meus amigos Larissa, Jayro e Kamilla: obrigada pela sintonia e companheirismo de sempre e também pela parceria durante as disciplinas. 
"Tenho duas armas para lutar contra o desespero, a tristeza e até a morte: o riso a cavalo e o galope do sonho. É com isso que enfrento essa dura e fascinante tarefa de viver."

Ariano Suassuna 


\section{RESUMO}

Situa-se no âmbito da organização da informação em catálogos de bibliotecas com enfoque na representação descritiva e nos formatos de intercâmbio de dados bibliográficos. Tem como objetivo principal conhecer características da trajetória e da estrutura da descrição de livros, em diferentes formatos de intercâmbio, realizando um cotejamento desses formatos com o padrão MARC 21. Para atender o objetivo proposto, foram delimitados os seguintes objetivos específicos: identificar formatos de descrição e intercâmbio de dados bibliográficos entre bibliotecas, bem como suas características e princípios norteadores; enfatizar a importância de se adotar as regras de descrição e os formatos de intercâmbio para a representação descritiva em sistemas de bibliotecas; apresentar as estruturas de dados em formatos de intercâmbio que se assemelham ou se diferenciam do formato MARC 21. Trata-se de pesquisa bibliográfica, de natureza descritiva e abordagem qualitativa. Traz à tona o cenário de consolidação dos principais instrumentos, regras e padrões de descrição bibliográfica utilizados na automatização de catálogos de bibliotecas, a partir de meados da década de 1960 até o início do Século XXI. Enfatiza que, além do amplamente conhecido padrão MARC, outros formatos de intercâmbio bibliográfico foram desenvolvidos ao longo dos anos. Conclui que o padrão MARC desenvolvido na Library of Congress e o Manual de Referência UNISIST, desenvolvido pela UNESCO, guiaram o desenvolvimento dos formatos de intercâmbio de dados bibliográficos entre as décadas de 1970 e 1980, destacando-se nessa época, os seguintes formatos: CALCO, UNIMARC, CCF, LILACS, CEPAL e IBICT. Sendo que alguns destes deixaram de ser utilizados e outros permanecem em vigor. A partir da década de 1990, com a popularização da internet, surgiram os padrões de metadados para diferentes contextos na web, destacando-se o MARC 21 para Dados Bibliográficos e o padrão de metadados Dublin Core que, embora não seja específico do contexto bibliográfico, tem sido também utilizado no âmbito das bibliotecas. $O$ cotejamento de registros bibliográficos com a versão vigente do padrão MARC 21 possibilitou conhecer particularidades de cada um destes formatos de intercâmbio.

Palavras-chave: Bibliotecas - Organização da informação. Representação descritiva. Intercâmbio de informações bibliográficas - Formatos. MARC 21. 


\begin{abstract}
It is part of the organization of information in catalogs of libraries with a focus on descriptive representation and formats for the exchange of bibliographic data. Its main objective is to know the characteristics of the trajectory and the structure of the book description, in different exchange formats, making a comparison of these formats with the MARC 21 standard. In order to meet the proposed objective, the following specific objectives were delineated: identify formats for the interchange of bibliographic data between libraries, as well as their characteristics and guiding principles; emphasize the importance of adopting the rules of description and exchange formats for descriptive representation in library systems; and present the description structure of data in other exchange formats that resemble or differ from the current MARC 21 format. It is a bibliographic research, descriptive in nature and with qualitative approach. It shows that, in addition to the widely known MARC standard, other bibliographic exchange formats have been developed over the years. In addition, it brings out the scenario of consolidation of the main instruments, rules and standards of bibliographic description used in the automation of library catalogs, from the mid-1960s to the beginning of the 21 st Century, revealing the efforts of information professionals in order to offer contemporary society access to bibliographic information in an organized and standardized way. Concludes that the MARC standard developed in the Library of Congress and the UNISIST Reference Manual, developed by UNESCO, guided the development of formats for the exchange of bibliographic data between the 1970s and 1980s. Especially, at this time, the formats: CALCO, UNIMARC, CCF, LILACS, CEPAL and the IBICT. Some of which are no longer used and others remain in force. From the 1990s, with the popularization of the Internet, the metadata standards for different contexts appeared on the web, highlighting the MARC 21 for Bibliographic Data and the Dublin Core metadata standard that, although not specific to the bibliographic context, has also been used in libraries. The comparison of bibliographic records with the current version of the MARC 21 has made it possible to learn about the particularities of each of these exchange formats.
\end{abstract}

Keywords: Libraries - Information organization. Descriptive representation. Exchange of bibliographic information - Formats. MARC 21. 


\section{LISTA DE FIGURAS}

Figura 1 - Registro bibliográfico codificado com a Norma ISO 2709 ........... 27

Figura 2 - Representação descritiva do livro A pena e a Lei no formato MARC 21

Figura 3 - Pontuação para Área de Título e Indicação de Responsabilidade na ISBD (G)

Figura 4 - Pontuação para Área do Título e Indicação de Responsabilidade no AACR2 - Regra 1.1A1.

Figura 5 Registro de um livro nos campos MARC conforme o RDA............ 58

Figura 6 - Exemplo do registro bibliográfico de entrada, conforme as convenções do Manual UNISIST.

Figura 7 - Codificação do registro para o intercâmbio em meio magnético, conforme as convenções do Manual UNISIST..

Figura 8 - Formulário usado para catalogação no formato CALCO.

Figura 9 - Registro de livro no Formato UNIMARC no catálogo da Biblioteca Nacional de Portugal.

Figura 10 - Registro de material informacional em Formato CCF.

Figura 11 - Registro de material informacional em Formato LILACS 75

Figura 12 - Definição dos Campos do Formato CEPAL 77

Figura 13 - Registro de um livro nos Campos do Formato IBICT 78

Figura 14 - Resultado de busca na página on-line da BNDigital 87

Figura 15 - Registro de um livro eletrônico no padrão de metadados Dublin Core. 


\section{LISTA DE QUADROS}

Quadro 1 - Blocos de Campos do MARC 21 para Dados Bibliográficos ................................................................ 31

Quadro 2 - Divisão básica dos Campos do MARC 21 para Livros Impressos..... 32

Quadro 3 - Exemplo de preenchimento do campo 245 no MARC 21................ 33

Quadro 4 - Atividades do processo de Representação Descritiva em catálogos de bibliotecas.

Quadro 5 - Exemplo de Campos MARC 21 para áreas de descrição de livros impressos

Quadro 6 - Campos para descrição dos Pontos de Acesso no MARC 21 para Dados Bibliográficos

Quadro 7 - Elementos do Padrão de Metadados Dublin Core

Quadro 8 - Bibliografias que apresentam correspondência dos campos do Formato MARC 21 com outros formatos de descrição.

Quadro 9 - Campos variáveis do MARC 21 e do CALCO para a descrição de livros segundo o AACR2

Quadro 10 - Representação descritiva de um livro nos formatos MARC 21 e CALCO

Quadro 11 - Campos variáveis do MARC 21 e do UNIMARC para a descrição de livros segundo o AACR2

Quadro 12 - Representação descritiva de um livro nos formatos MARC 21 e UNIMARC

Quadro 13 - Campos variáveis do MARC 21 e do CCF para a descrição de livros segundo o AACR2.

Quadro 14 - Representação descritiva de um livro nos formatos MARC 21 e CCF

Quadro 15 - Campos variáveis do MARC 21 e do LILACS para a descrição de livros segundo o AACR2

Quadro 16 - Representação descritiva de um livro nos formatos MARC 21 e LILACS

Quadro 17 - Campos variáveis do MARC 21 e do formato CEPAL para a descrição de livros segundo o AACR2.

Quadro 18 - Representação descritiva de um livro nos formatos MARC 21 e CEPAL

Quadro 19 - Campos variáveis MARC 21 e do formato IBICT para a descrição de livros segundo o AACR2. 
Quadro 20 - Representação descritiva de um livro nos formatos MARC 21 e IBICT

Quadro 21 - Campos variáveis do MARC 21 e do Dublin Core para a descrição de livros segundo o AACR2

Quadro 22 - Representação descritiva de um livro impresso nos formatos MARC 21 e Dublin Core 


\section{LISTA DE ABREVIATURAS E SIGLAS}

AACR2 Anglo American Cataloguing Rules, second edition (Código de Catalogação Anglo-Americano, segunda edição)

ABCD Automação de Bibliotecas e Centros de Documentação

BDTD Biblioteca Digital de Teses e Dissertações

BIBFRAME Bibliographic Framework Initiative

BN Biblioteca Nacional (Brasil)

BNP Biblioteca Nacional (Portugal)

CALCO Catalogação Legível por Computador

CDD Classificação Decimal de Dewey

DASP Departamento Administrativo do Serviço Público

DCMI Dublin Core Metadata Initiative

DeCS Descritores em Ciências da Saúde

CBU Controle Bibliográfico Universal

CDS/ISIS Computerized Documentation System / Integrated Scientific Information System

CDU Classificação Decimal Universal

CCF Common Comunication Format

CEPAL Comissão Econômica para a América Latina e o Caribe

Cl Ciência da Informação

FGV Fundação Getulio Vargas

FRAD Functional Requirements for Authority Data (Requisitos Funcionais para Dados de Autoridades)

FRBR Functional Requirements for Bibliographic Records (Requisitos Funcionais para Registros Bibliográficos)

HTML HyperText Markup Language

IBBD Instituto Brasileiro de Bibliografia e Documentação

IBICT Instituto Brasileiro de Informação em Ciência e Tecnologia

IBICT (Formato) Formato de Intercâmbio Blbliográfico e CaTalográfico

IFLA International Federation of Library Association (Federação Internacional das Associações e Instituições Bibliotecárias) 


$\begin{array}{ll}\text { ISBD } & \begin{array}{l}\text { International Standard Bibliographic Description } \\ \text { Bibliográfica Internacional Normalizada) }\end{array} \\ \text { ISBN } & \begin{array}{l}\text { International Standard Book Numbero } \\ \text { Normalizado para Livros) }\end{array} \\ \text { ISO } & \begin{array}{l}\text { International Organization for Standardization (Organização } \\ \text { Internacional para Padronização) }\end{array} \\ \text { LC } & \text { Library of Congress (Biblioteca do Congresso) } \\ \text { LILACS } & \text { Literatura Latino-Americana e do Caribe em Ciências da Saúde } \\ \text { MADS } & \text { Metadata Authority Description Schema } \\ \text { MARC } & \text { Machine Readable Cataloging (Catalogação Legível por Máquina) } \\ \text { MODS } & \text { Metadata Object Description Schema } \\ \text { MTD-BR } & \text { Metadados para Teses e Dissertações - Brasil } \\ \text { NCSA } & \text { National Center for Supercomputing Applications } \\ \text { OCLC } & \text { Online Computer Library Center } \\ \text { ONIX } & \text { ONline Information eXchange } \\ \text { RDA } & \text { Resource Description and Access } \\ \text { RDF } & \text { Resource Description Framework } \\ \text { SIC } & \text { Serviço de Intercâmbio de Catalogação } \\ \text { TICs } & \text { Tecnologias de Comunicação e Informação } \\ \text { UNESCO } & \text { United Nations Educational, Scientific and Cultural Organization } \\ & \text { (Organização das Nações Unidas para a Educação, Ciência e } \\ \text { UNIMARC } & \text { Cultura) } \\ \text { UNIversal MAchine Readable Catalogue } \\ \text { USIST } & \text { United Nations Information System in Science and Technology } \\ \text { (Sistema de Informação das Nações Unidas em Ciência e } \\ \text { XMC } & \text { United States MARC } \\ & \text { Wold Wide Web Consortium } \\ \text { Extensible Markup Language }\end{array}$




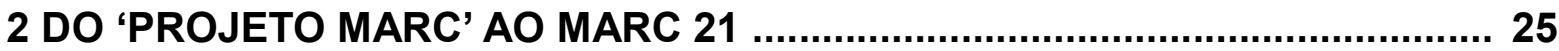

2.1 O MARC 21 PARA DADOS BIBLIOGRÁFICOS ................................. 29

3 A REPRESENTAÇÃO DA INFORMAÇÃO EM BIBLIOTECAS ...................... 37

3.1 O LUGAR DA REPRESENTAÇÃO DESCRITIVA ..................................... 39

4 REPRESENTAÇÃO DESCRITIVA: REGRAS E CONTEXTOS ........................ 43

4.1 REGRAS DE DESCRIÇÃO: DO CONTEXTO IMPRESSO AO

ELETRÔNICO

4.2 REGRAS DE DESCRIÇÃO: AATUALIZAÇÃO PARA O CONTEXTO

DIGITAL

5 CONHECENDO OUTROS FORMATOS DE INTERCÂMBIO 61

5.1 O MANUAL DE REFERÊNCIA UNISIST

5.2 O FORMATO CALCO: IMPLEMENTAÇÃO DO MARC NO BRASIL 66

5.3 O FORMATO UNIMARC: NA ROTA DO CONTROLE BIBLIOGRÁFICO UNIVERSAL

5.4 O FORMATO CCF: UMA “PONTE" ENTRE O MARC E O MANUAL UNISIST 72

5.5 O FORMATO LILACS: UNINDO INFORMAÇÕES BIBLIOGRÁFICAS DA SAÚDE 74

5.6 O FORMATO CEPAL: GERANDO BASES BIBLIOGRÁFICAS NAAMÉRICA LATINA 76

5.7 O FORMATO IBICT: UMA EVOLUÇÃO DO CALCO NO BRASIL 77

6 A ERA DA WEB E OS PADRÕES DE METADADOS 80

6.1 O DUBLIN CORE: UM PADRÃO SIMPLIFICADO 84

6.2 O MARC 21 E SEUS AVANÇOS NA ERA DA WEB 88

7 O PERCURSO METODOLÓGICO 92

7.1 AS ETAPAS DA PESQUISA 92 
8 COTEJANDO O MARC 21 COM OS OUTROS FORMATOS …...................... 95

8.1 O MARC 21 E O FORMATO CALCO …..................................................... 96

8.2 O MARC 21 E O FORMATO UNIMARC .................................................... 100

8.3 O MARC 21 E O FORMATO CCF ….......................................................... 104

8.4 O MARC 21 E O FORMATO LILACS …..................................................... 110

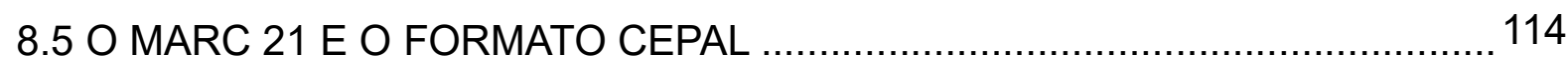

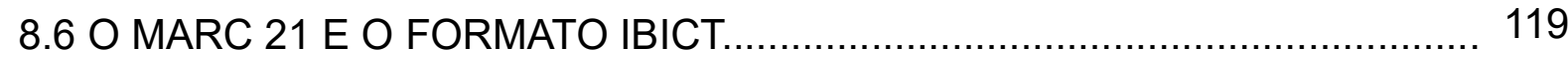

8.7 O MARC 21 E O PADRÃO DUBLIN CORE ……................................... 124

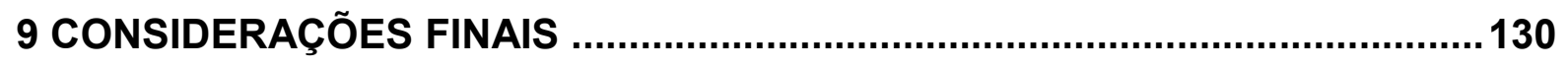

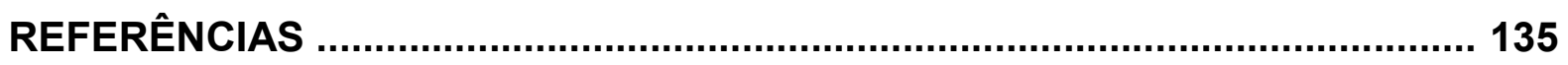




\section{INTRODUÇÃO}

A necessidade de organização e recuperação eficaz e eficiente da informação de qualidade, em meio ao problema da explosão informacional, se constituiu em um dos principais motivos para o desenvolvimento da Ciência da Informação enquanto campo científico. Com a evolução tecnológica e as novas exigências da sociedade contemporânea, a representação da informação em ambientes digitais ganha destaque fundamental nas pesquisas de disciplinas como a Ciência da Informação (Cl) e a Ciência da Computação (SARACEVIC, 1996). Araújo (2014) aponta a representação e a recuperação da informação como sendo uma das subáreas da $\mathrm{Cl}$ em destaque nos dias atuais.

A interdisciplinaridade da $\mathrm{Cl}$ com diferentes áreas, tais como a Biblioteconomia, a Comunicação e a Ciência da Computação, trouxe consigo estudos acerca das Tecnologias de Informação e Comunicação (TICs), bem como das ferramentas, dos recursos e dos padrões que auxiliam no tratamento, na organização, na apresentação e também no intercâmbio de dados nas redes de informações bibliográficas.

De fato, estamos passando por mudanças sociais que são impulsionadas pelas TICs. A qualidade da representação da informação tem impacto direto nos resultados das buscas e na recuperação da informação por parte das comunidades de usuários. Além disso, na era digital, a noção de tempo e espaço já não é mais a mesma. Por consequência de uma nova dinâmica de acesso e uso da informação, os usuários das bibliotecas mudaram as suas formas de fazer pesquisa, já não dispõem de muito tempo para realizá-las, tornaram-se mais exigentes e precisam da informação de imediato.

Diariamente é lançada na internet uma infinidade de informações, nos mais diferentes tipos e suportes, o que torna cada vez mais difícil e demorado o trabalho de extrair aquilo que significativamente servirá para a criação de novos conhecimentos.

Nesse cenário, as bibliotecas digitais, bem como os catálogos on-line de consulta aos acervos, se tornaram ferramentas fundamentais para os pesquisadores na difícil tarefa de "garimpar" a informação relevante. Nessa perspectiva, a atuação das bibliotecas em redes colaborativas desempenha um papel preponderante, porque coloca à disposição dos usuários a busca de materiais bibliográficos, de diferentes unidades de informação, em uma única página na internet, sem que necessitem se 
deslocar para uma biblioteca física. Com este "fenômeno da organização colaborativa" em ambientes digitais, os cuidados com a representação da informação, no que se refere à sua descrição, classificação e organização, ganham um novo destaque no campo da Ciência da Informação (ARAÚJO, 2014).

Outrossim, para que as bibliotecas e unidades de informação possam trabalhar e compartilhar informações de forma organizada em redes digitais, elas precisam adotar sistemas de gerenciamento de acervos que permitam ter qualidade na representação dos recursos informacionais.

Esses sistemas devem, por sua vez, comportar os formatos de intercâmbio de dados bibliográficos bem como as regras de catalogação vigentes com vistas a organizar e a facilitar a troca de informações bibliográficas entre as instituições. Conforme enfatizado por Silva e Baptista (2013, p. 3), para se tornar acessível em redes colaborativas, é necessário que a informação esteja registrada "[...] dentro dos padrões internacionais de catalogação, tanto para realização de um intercâmbio bibliográfico quanto para localização física ou digital de um documento".

Nesse sentido, Okada e Ortega (2009, p. 25) argumentam que "os formatos de registro bibliográfico definem-se em parte pela incorporação de recursos tecnológicos, e seu uso relaciona-se à catalogação cooperativa ou às redes de informação especializada". Entretanto, além de proporcionar meios para o intercâmbio de dados bibliográficos, os formatos relacionam-se ainda a outros usos: como padrão para a entrada de dados, para o armazenamento e para a apresentação da informação (OKADA; ORTEGA, 2009).

Dessa maneira, é possível entender que os formatos de intercâmbio de registros bibliográficos também contribuem de forma significativa para a própria organização dos conteúdos informacionais em sistemas de gerenciamento de bibliotecas. São parte importante no processo de evolução e modernização dos produtos e dos instrumentos voltados para a descrição e organização da informação.

Os catálogos automatizados das bibliotecas proporcionam aos usuários diferentes tipos de busca pela informação e seguem evoluindo trazendo muitas facilidades no acesso aos conteúdos. No entanto, ao realizar a representação dos recursos informacionais no sistema, de modo a tornar possível a recuperação eficaz e eficiente das informações contidas nos acervos, o profissional da informação deve "[...] seguir critérios para o preenchimento dos campos recuperáveis" (OKADA; ORTEGA, 2009, p. 20). Com relação aos "critérios" para o preenchimento desses 
campos, o bibliotecário precisa estar principalmente atento à observação e à aplicação das regras contidas nos códigos de catalogação estabelecidos e consolidados internacionalmente pelas comunidades bibliotecárias. Quanto aos "campos recuperáveis", é função dos formatos de intercâmbio e de descrição bibliográfica munir o sistema de uma estrutura interna adequada, para que o bibliotecário possa fazer o preenchimento exato dos dados, gerando, posteriormente, diferentes possibilidades na recuperação das informações. Nessa perspectiva, Melgaço (1989, p. 350) salienta:

O formato de intercâmbio é aquele que deve ter padronização tal, que torne eficiente e econômico o intercâmbio de informações entre sistemas computadorizados de registros bibliográficos e catalográficos, de modo a prover uma estrutura de registro capaz de contemplar as necessidades de uma grande variedade de sistemas de registro bibliográfico.

No que se refere a essa estrutura dos dados, bibliotecas no mundo todo, têm adotado o padrão Machine Readable Cataloging - MARC (ou Catalogação Legível por Máquina) para a descrição bibliográfica de recursos informacionais e para o intercâmbio de informações.

O formato MARC surgiu na década de 1960, por uma iniciativa da Library of Congress - LC (Biblioteca do Congresso), nos Estados Unidos. Desde a sua criação, o MARC passou por diferentes versões ao longo dos anos, destacando-se, nos dias atuais, por sua ampla aceitação e utilização por parte das comunidades bibliotecárias. Diante desse fato, segundo Okada e Ortega (2009, p. 22), "a literatura sobre formatos de registro bibliográfico está, em geral, centrada nas características do formato MARC", desenvolvido pela Biblioteca do Congresso dos Estados Unidos. Por conseguinte, um grande enfoque é dado ao formato MARC em algumas disciplinas dos cursos de graduação em Biblioteconomia.

Entretanto, há também, na literatura, estudos que abarcam outros formatos para o intercâmbio de registros bibliográficos, desenvolvidos por outras grandes instituições, tais como o Common Comunication Format (CCF), desenvolvido pela Organização das Nações Unidas para a Educação, Ciência e Cultura (UNESCO) e o UNIversal MAchine Readable Catalogue (UNIMARC), desenvolvido pela Federação Internacional das Associações e Instituições Bibliotecárias (IFLA), dentre outros.

Diante desse contexto, a presente pesquisa buscou identificar diferentes tipos de formatos de intercâmbio de registros bibliográficos, bem como suas 
características, de modo que se possa realizar um cotejamento desses com a versão vigente do padrão MARC, a qual é denominada MARC 21.

A história das bibliotecas é marcada pelo surgimento e uso dos formatos para a descrição e para o intercâmbio de dados entre seus sistemas. Mesmo tendo sido iniciado há mais de cinquenta anos, o padrão MARC, hoje chamado de MARC 21, ainda se destaca como referência quando o assunto é Representação Descritiva e Intercâmbio entre bibliotecas.

Levando em consideração que muitos outros formatos de intercâmbio surgiram ao longo dos anos, as seguintes questões impulsionaram a presente pesquisa: Além do padrão MARC 21 para Dados Bibliográficos, criado pela Biblioteca do Congresso nos Estados Unidos, quais são os outros formatos de descrição bibliográfica e de intercâmbio de informações entre bibliotecas? Em que aspectos os outros formatos existentes se assemelham ou se diferenciam do MARC 21? Em que circunstâncias eles surgiram?

Dessa forma, este estudo tem por objetivo geral conhecer as características de diferentes tipos de formatos de Intercâmbio de dados bibliográficos por meio de um cotejamento destes com o formato MARC 21. Para alcançar este objetivo geral, foram delimitados os seguintes objetivos específicos:

- identificar formatos de descrição e intercâmbio de dados utilizados em bibliotecas e seus princípios norteadores;

- enfatizar a importância de adotar as regras de descrição bibliográfica e os formatos de intercâmbio em sistemas de bibliotecas;

- apresentar as estruturas de dados em formatos de intercâmbio que se assemelham ou se diferenciam do formato MARC 21.

Por meio de investigação bibliográfica, buscou-se conhecer aspectos da descrição física de livros impressos em alguns dos diferentes tipos de formatos de intercâmbio, cujas características estão disponíveis para consulta na literatura, destacando-se os seguintes: 
- CAtalogação Legível por COmputador (formato CALCO);

- UNIversal MAchine Readable Catalogue (formato UNIMARC);

- Common Comunication Format (formato CCF);

- Llteratura LAtino-Americana e do Caribe em Ciências da Saúde (formato LILACS);

- Comissão Econômica Para a América Latina e o Caribe (formato CEPAL);

- Formato de Intercâmbio BIbliográfico e CaTalográfico (formato IBICT), e

- Formato Dublin Core (DC).

Por meio de um olhar comparativo entre os campos definidos para a descrição dos itens, planejou-se verificar em que aspectos os outros formatos de intercâmbio se assemelham ou se diferenciam do atual padrão MARC 21 para Dados Bibliográficos. Além disso, foram abordados aspectos da evolução histórica, as diretrizes e normas que nortearam a construção dos formatos de intercâmbio desde o seu surgimento na década de 60 até os dias atuais, bem como conhecer um pouco das tendências futuras.

Destaca-se que, um dos motivos para a escolha deste objeto de estudo os formatos de descrição e intercâmbio - foi o fato de a pesquisadora contar com a experiência profissional de $10(\mathrm{dez})$ anos atuando como bibliotecária e utilizando o formato MARC 21, tendo sido possível familiarizar-se, principalmente, com o processo de representação descritiva e temática de recursos informacionais. Nesse sentido, Gondim e Lima (2006, p. 71) argumentam:

[...] Sem dúvida, o contato prévio do pesquisador com o tema (estudos anteriores, experiência profissional, prática política, vivência pessoal, etc.) constitui fonte importante de ideias que devem ser trabalhadas mediante a organização de notas e documentos por ventura já obtidos. [...]. É indispensável, porém, recorrer a procedimentos mais sistemáticos, em que estão incluídos levantamentos bibliográfico e documental, entrevistas exploratórias e contato com a realidade empírica a ser investigada.

Enquanto facilitadoras do acesso, em meio a infinidades de informações, as bibliotecas precisam ter as TICs como suas aliadas. O trabalho de descrição 
bibliográfica de materiais em diferentes tipos e suportes exige tempo e esforço dos profissionais da informação e a tecnologia é de grande ajuda no sentido de otimizar esses serviços.

$\mathrm{Na}$ era digital, cada vez mais se destaca a catalogação cooperativa entre unidades de informação. O trabalho em rede permite, por exemplo, que determinada biblioteca reutilize a descrição bibliográfica de um item cujo registro já foi realizado por outra unidade de informação, evitando-se, assim, o retrabalho e deixando os profissionais da informação mais livres para resolver outras questões, tendo em vista que não basta organizar e facilitar o acesso a informações, é importante que as bibliotecas possam também utilizar este ambiente de informações organizadas para promover a formação de usuários com competências no acesso e no uso da informação. O trabalho colaborativo possibilita às instituições, a economia de custos e de tempo com a catalogação de seus acervos (SILVA; SOUZA, 2011), e os formatos de intercâmbio e descrição bibliográfica são de fundamental importância nesse processo.

Sistemas de gerenciamento que permitam a criação de redes colaborativas, atrelados aos formatos de registro que viabilizam o intercâmbio de dados entre diferentes instituições, podem facilitar e tornar mais ágil o trabalho de representação descritiva da informação contida em suportes físicos. No entanto,

\begin{abstract}
Ainda que os sistemas gerenciadores de bibliotecas apresentem estes requisitos, de nada adiantará se o profissional bibliotecário desconhecer as vantagens de sua utilização, como por exemplo, a participação em redes de catalogação cooperativa e do estabelecimento de políticas institucionais e interinstitucionais necessárias (STORTI; ZAFALON; LANDGRAF, 2013, p. 7).
\end{abstract}

Além disso, diante do avanço tecnológico e da rapidez com que a informação é disponibilizada, hoje, em ambientes digitais, o profissional da informação precisa estar preparado para a tomada de decisões gerenciais que terão impacto direto na qualidade do acesso e da recuperação da informação por parte dos usuários. Sobre a recuperação da informação em ambientes digitais, Sousa (2012, p. 68, grifo nosso) destaca que,

[...] os usuários nem sempre conseguem encontrar o que desejam, seja pelo fato dos sistemas de busca não realizarem uma recuperação 
de forma satisfatória, seja porque ela não foi concebida para o usuário através de uma representação adequada.

Sendo assim, é importante trazer à tona as questões que englobam esse universo multifacetado que é a representação da informação. De nada adianta uma enorme quantidade de informação se não houver um tratamento adequado e uma representação de qualidade que facilite a sua recuperação por parte dos usuários. Ao longo dos tempos, as bibliotecas são reconhecidas como o lugar onde a informação é organizada. Agora, na era digital, com a rapidez da internet, este desafio se torna ainda maior.

Portanto, os estudos que trazem a temática da Representação Descritiva e formatos de descrição bibliográfica, no Brasil "[...] são necessários por contribuírem com reflexões em torno das vantagens e benefícios que o uso desses padrões pode trazer às bibliotecas e demais unidades de informação" (VETTER; ARAÚJO, 2012, p. 2). Por outro lado, um estudo realizado por Assumpção e Santos (2014) mostra que, quando unidades de informação adotam sistemas que utilizam padrões de descrição de criação própria e não aqueles aceitos internacionalmente, podem ocorrer problemas e dificuldades relativas à conversão de dados e à migração de um sistema para outro, trazendo prejuízos à Instituição.

Outro fator, não menos importante, que justifica a presente pesquisa, é que as discussões que envolvem os instrumentos de representação da informação e as TICs podem ser de ajuda no fortalecimento do diálogo entre os profissionais da área de Ciência da Informação e da Ciência da Computação, sendo este diálogo cada vez mais necessário nos ambientes informacionais contemporâneos.

Além disso, observa-se que na literatura científica das áreas de Biblioteconomia e Ciência da Informação, e no ensino das disciplinas de Representação Descritiva da Informação nos cursos de graduação em Biblioteconomia, um grande destaque é dado às características do padrão MARC para a descrição e intercâmbio de dados bibliográficos. Ao ponderar sobre a padronização da descrição bibliográfica no Brasil, Campello (2006, p. 67) ressalta que, "com relação aos formatos para informatização, pode-se dizer que o MARC tem ampla aceitação; muitas bibliotecas o utilizam e várias publicações em português têm permitido sua introdução em disciplinas de cursos de graduação em biblioteconomia”. 
Entretanto, partindo do pressuposto de que, além do MARC, existem outros formatos criados para a descrição bibliográfica e o intercâmbio de informações entre bibliotecas, acredita-se que a relevância da presente pesquisa reside também no fato de que a mesma poderá servir como um referencial teórico no âmbito das disciplinas de Representação Descritiva da Informação, principalmente no que tange às discussões relativas aos diferentes tipos de formatos de registro bibliográficos e intercâmbios, assim como as peculiaridades deles.

Assim, esta pesquisa encontra-se estruturada em nove seções: na introdução apresenta-se a contextualização, a justificativa e os objetivos do estudo. Na segunda seção é abordada a trajetória do formato MARC, trazendo alguns de seus aspectos históricos e técnicos, tendo em vista que toda a pesquisa gira em torno de um cotejamento com este padrão.

Na terceira e na quarta seção discorre-se acerca da representação da informação com enfoque na representação descritiva, trazendo considerações principalmente sobre a trajetória dos Códigos de Catalogação: Código de Catalogação Anglo-Americano (AACR2) e seu sucessor, o Resource Description and Access (RDA), com destaque especial para o primeiro, por ainda ser o código vigente no Brasil. Ao estudar os formatos de intercâmbio e de descrição bibliográfica se fez necessário abordar também os códigos de catalogação, por serem instrumentos que amiúde caminham juntos na era digital e que se complementam mutuamente no processo de representação descritiva de materiais nos sistemas de gerenciamento de bibliotecas.

Na quinta seção, são apresentados cada um dos seguintes formatos de intercâmbio bibliográfico, surgidos após a criação do MARC entre as décadas de 1970 a 1980: Formato de Catalogação Legível por Computador (CALCO); Formato Universal MARC (UNIMARC); o Formato Comum de Comunicação (CCF); Formato da Literatura Latino-Americana e do Caribe em Ciências da Saúde (LILACS); Formato da Comissão Econômica Para a América Latina e o Caribe (CEPAL); e o Formato de Intercâmbio Bibliográfico e CaTalográfico (IBICT).

$\mathrm{Na}$ sexta seção, apontam-se outras iniciativas que surgiram com a chegada da web, a partir da década de 1990, e apresenta-se o padrão de metadados Dublin Core.

Os aspectos metodológicos da pesquisa são tratados na sétima seção, onde a pesquisa é situada quanto às suas fontes, quanto aos seus objetivos e quanto 
à sua abordagem. Discorre-se também, neste capítulo, sobre o percurso adotado para a realização do presente estudo.

$\mathrm{Na}$ oitava seção são trazidos os resultados alcançados por meio do cotejamento do MARC 21 para Dados Bibliográficos com cada um dos formatos de descrição bibliográfica apontados no capítulo 5 , e também com o padrão de metadados Dublin Core. Esta seção é seguida das considerações finais. 


\section{DO ‘PROJETO MARC’ AO MARC 21}

Na década de 1960 a programadora e analista de sistemas Henriette Avram deu início ao Projeto Machine Readable Cataloging (MARC), ou catalogação legível por máquina, na Library of Congress (LC), nos Estados Unidos. Sendo assim, observa-se que o primeiro formato de descrição bibliográfica surgiu em meados do Século XX, por uma iniciativa da Biblioteca do Congresso Americano. A partir de sua criação, o formato MARC passou por evoluções constantes e, atualmente, é um formato amplamente adotado em sistemas de gerenciamento de bibliotecas.

O formato MARC tornou a representação descritiva, pela primeira vez, legível por computador e teve um impacto revolucionário na comunidade bibliotecária, possibilitando a transição dos registros manuais, feitos em fichas e cartões, para os catálogos e registros automatizados, alavancando, assim, a cooperação e o intercâmbio de informações entre bibliotecas (JOHNSON, 2011). De acordo com Silva e Baptista (2013, p. 2), "o MARC ajustou os recursos tecnológicos da época à catalogação tradicional".

Para Coyle (2016, p. 50, tradução nossa) "depois de Melvil Dewey, a pessoa que teve o maior efeito na tecnologia da biblioteca foi Henriette Avram, criadora do formato Machine Readable Cataloging (MARC)". Embora, durante os seus primeiros trabalhos com o MARC ela não tenha antecipado a criação dos catálogos on-line de acesso público (OPACs), mas foram os anos de catalogação em um formato legível por máquina que os tornaram possíveis (COYLE, 2016). A autora acrescenta que,

\footnotetext{
Em meados da década de 1960, quando o MARC estava em desenvolvimento, as capacidades informáticas para manusear dados textuais eram muito cruas. [...]. No entanto, as bibliotecas precisavam representar títulos reais de documentos e nomes de autores em outros idiomas além do inglês. Isso significava que o registro de dados da biblioteca precisava ter campos de comprimento variável, pontuação completa e marcas diacríticas. Avram entregou um padrão que definitivamente estava à frente de seu tempo (COYLE, 2016, p. 50, tradução nossa).
}

No ano de 1969, dando continuidade ao projeto MARC, a LC lançou o formato MARC II, “[...] e, na década seguinte, já eram encontradas diversas variações do formato original em vários países" (ASSUNPÇÃO; SANTOS; ZAFALON, 
2017 , p. 23, grifo nosso). No entanto, antes de abordar essas variações de formatos que surgiram a partir do MARC, convém destacar que a LC criou também, para o formato MARC, uma estrutura de organização dos dados em fita magnética que originaria, posteriormente, normalizações nacionais e internacionais, conforme destacado por Assumpção (2013, p. 28):

O formato legível por máquina desenvolvido na LC, na década de 1960, visava à transmissão de registros em fitas magnéticas, o que justifica - caráter sequencial da codificação utilizada originalmente na transmissão de registros MARC. Essa codificação foi reconhecida nacionalmente nos Estados Unidos pelo American National Standards Institute (ANSI) (Instituto Nacional Americano de Padrões) em 1971 como a norma Z39.2, e internacionalmente em 1981 pela International Organization for Standardization (ISO) (Organização Internacional para Padronização) como a 2709, Documentation - Format for bibliographic information interchange on magnetic tape (Documentação - Formato para intercâmbio de informação bibliográfica em fita magnética).

Assim, observa-se que a norma internacional ISO 2709, que ainda é utilizada nos dias atuais, teve a sua origem na década de 1970, a partir da codificação do MARC (MARCONDES; SAYÃO, 1991; MEY; SILVEIRA, 2009, ASSUMPÇÃO; SANTOS, 2015). Esta norma indica as regras para a organização do layout físico dos registros para serem intercambiados em meio magnético, e passou a ser universalmente aceita e adotada pela grande maioria dos formatos de intercâmbio que surgiram em todo mundo (MARCONDES; SAYÃO, 1991). Acerca da Norma ISO 2709, Côrte et al (2002, p. 36) explicam:

Esta norma especifica os requisitos para o formato de intercâmbio de registros bibliográficos que descrevam todas as formas de documentos sujeitos à descrição bibliográfica. Não define a extensão do conteúdo de documentos individuais nem designa significado algum para os parágrafos, indicadores ou identificadores, sendo essas especificações as funções dos formatos de implementação.

Portanto, entende-se que a Norma ISO 2709 não é um código de catalogação, tal como o AACR2 e nem tampouco um formato de descrição bibliográfica propriamente dito, tal como o MARC. Esta norma, por sua vez, traça as diretrizes para a criação do layout físico que os formatos de intercâmbio precisam adotar, de modo a fazer com que os registros bibliográficos se tornem legíveis por máquina. Na Figura 1, disposta a seguir, é possível observar a estrutura de um registro 
bibliográfico em formato MARC, codificado com a Norma ISO 2709, tornando-o legível por computador:

Figura 1 - Registro bibliográfico codificado com a Norma ISO 2709

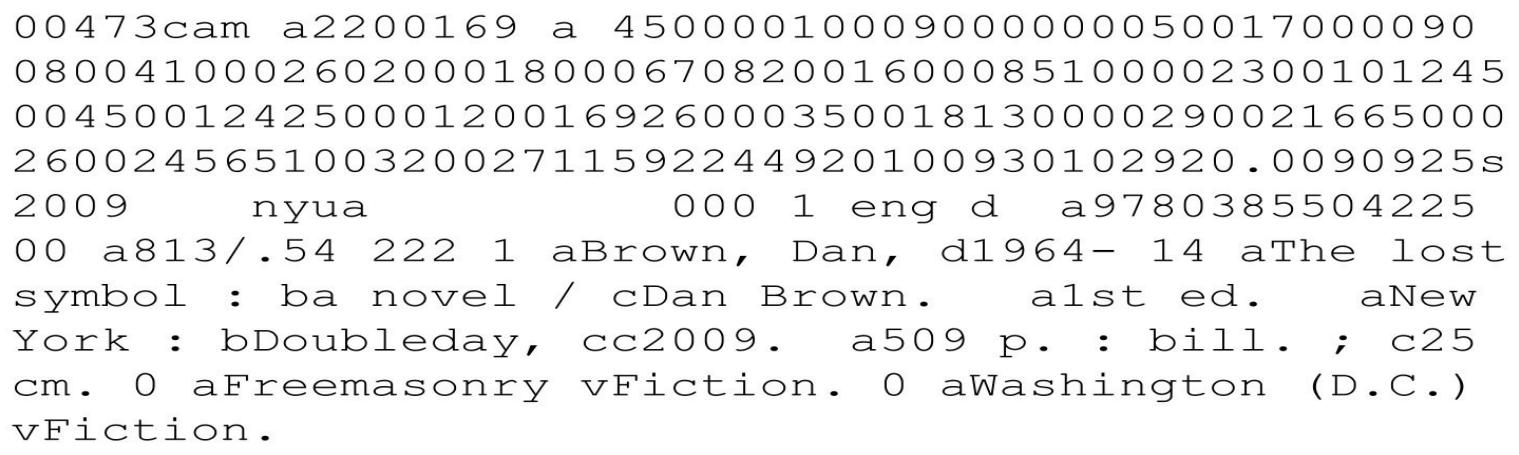

Fonte: Assumpção e Santos (2015, p. 60, adaptado de: http://lccn.loc.gov/2009464840).

Conforme demonstrado na Figura 1, os dados descritivos de um material bibliográfico impresso, que no caso é um livro do autor Dan Brown, aparecem de forma sequencial, tornando o registro intercambiável entre sistemas. Porém, para se chegar a este layout do registro em questão, primeiro foi necessário o preenchimento adequado dos dados do material na estrutura do formato MARC.

Assim, a observação da Norma ISO 2709 passou a ser parte importante na etapa de construção de formatos de intercâmbio e criação de softwares para bibliotecas. De acordo com Marcondes e Sayão (1991), tecnicamente, um formato de intercâmbio constitui-se de três níveis de padronização, sendo:

1. o padrão do layout físico dos registros, legível por computador, possibilitando o intercâmbio (por exemplo, a norma ISO 2709);

2. a semântica dos campos de informação dentro do registro, ou seja, convenciona-se, por exemplo, que o parágrafo ou campo 100 conterá o autor principal de uma referência;

3. a convenção para a representação da informação, ou seja, as Regras de Catalogação, tal como o AACR2 no qual se define, por exemplo, que no campo do autor deve-se entrar primeiro com o sobrenome, seguido dos prenomes. (MARCONDES; SAYÃO, 1991). 
Diante do exposto, observa-se que a Norma ISO 2709, a qual inclusive passou por atualização no ano de 2008, não é um instrumento que o bibliotecário precisa ter à mão para consultas ou para auxílio no esclarecimentos de dúvidas durante o trabalho de representação descritiva de materiais do acervo, visto que a mesma deve estar embutida no próprio funcionamento interno do sistema. Porém, é de fundamental importância que o profissional da informação tenha conhecimento acerca desses mecanismos para que possa tomar decisões acertadas no momento da escolha dos softwares gerenciadores de bibliotecas (STORTI; ZAFALON; LANDGRAF, 2013).

Assim, voltando a destacar as muitas variações de Formatos de Intercâmbio que surgiram, ressaltam-se aqueles desenvolvidos com base no próprio padrão MARC dos Estados Unidos, dentre os quais, pode-se citar: o CAN/MARC (no Canadá), o MONOCLE (na França), o MARCAL (na América Latina), o CALCO (no Brasil), UNIMARC (criado pela IFLA) e muitos outros, conforme apontam Vetter e Araújo (2012, p. 4):

[...] o MARC II passou a ser considerado como uma linguagem padrão para o intercâmbio de informações bibliográficas, e, diversos países começaram a desenvolver seus próprios formatos, baseados nele, a exemplo do ANNMARC (Itália); AUSMARC (Austrália); CANMARC (Canadá); CATMARC (Espanha/Barcelona, Catalunha); FINMARC (Finlândia); HUNMARC (Hungria); IBERMARC (Espanha); INDIMARC (Índia); INTERMARC (França); JPNMARC (Japão); LibrisMARC (Suécia); MAB (Alemanha); RUSMARC (Rússia); UKMARC (Reino Unido), entre outros que possibilitaram agilidade e otimização no processo de descrição bibliográfica.

Depois disso, na década de 1980, o formato MARC II passou por uma nova atualização e, nessa época, a LC passou a chamá-lo de United States MARC (USMARC), ou seja, o MARC dos Estados Unidos (VOSGRAU, 2003; LIBRARY OF CONGRESS, 2006a; ASSUMPÇÃO; SANTOS, 2015). De acordo com Robredo e Cunha (1994, p. 136), o formato MARC II foi originalmente projetado para o processamento de livros, ao passo que o seu sucessor USMARC passou a abranger também outros tipos de materiais como séries, filmes, mapas, manuscritos, músicas e registros sonoros.

Às portas do Século XXI, no final da década de 1990, os formatos de intercâmbio então vigentes nos Estados Unidos (USMARC) e no Canadá (CAN/MARC), por serem bastante semelhantes, passaram por uma harmonização. $A$ 
partir da junção desses dois formatos foi lançado, no ano de 1998, o formato MARC 21, nome pelo qual o padrão MARC é conhecido em sua versão atual (LIBRARY OF CONGRESS, 2006a; VETTER; ARAÚJO, 2012). O nome MARC 21 "aponta para o futuro à medida que avançamos no Século XXI e sugere o caráter internacional do formato [...]" (LIBRARY OF CONGRESS, 1998, tradução nossa). De acordo com Ferreira (2013), os formatos MARC 21 se constituem hoje numa família de cinco formatos coordenados, sendo:

- MARC 21 para Dados Bibliográficos;

- MARC 21 para Dados de Autoridade;

- MARC 21 para Dados de Coleção;

- MARC 21 para Dados de Classificação; e

- MARC 21 para Informação Comunitária.

Dentre estes cinco formatos da família MARC 21 mencionados anteriormente, a presente pesquisa pauta-se unicamente no MARC 21 para Dados Bibliográficos cujas características serão explicitadas nos parágrafos subsequentes.

\subsection{O MARC 21 PARA DADOS BIBLIOGRÁFICOS}

O formato MARC 21 para Dados Bibliográficos é muito divulgado e utilizado, atualmente, por bibliotecas na realização da representação descritiva dos recursos informacionais. Conforme ressaltado por Ferreira (2013, p. 18), "o Formato MARC 21 para Dados Bibliográficos é destinado a ser o veículo para informação bibliográfica, referente a livros, materiais de arquivo e manuscritos, arquivos de computador, mapas, músicas materiais visuais e periódicos”.

Ainda de acordo com Ferreira (2013), um registro bibliográfico em formato MARC 21 possui três componentes principais estabelecidos em consonância com a norma ISO 2709: o líder, o diretório e os campos variáveis.

- Líder: possui números ou códigos com informações para o processamento do registro. Neste componente é definido, por exemplo, entre outros elementos, o tipo de registro que está sendo catalogado (material textual, gravação sonora, 
etc.) e a convenção ou código de catalogação que está sendo utilizado, tal como o AACR2.

- Diretório: é um índice gerado por computador, compreende uma série de entradas, que contém a localização e o tamanho de cada campo dentro do registro.

- Campos variáveis: são indicados por uma etiqueta de três caracteres numéricos. Cada campo possui tamanho variável e é designado para uma categoria específica de dados. Existem dois tipos: a) campos de controle variável, que são os campos 00X, por exemplo, o campo 005-Data e hora da última atualização do registro; e b) campos de dados variáveis, que são agrupados em bloco de acordo com o primeiro caractere da etiqueta, por exemplo, o campo $2 X X$-Título, edição, imprenta. Os campos de dados variáveis possuem ainda posição para indicadores e subcampos (FERREIRA, 2013).

O padrão MARC 21 é consolidado e alicerçado com base em normalizações reconhecidas internacionalmente. Além da norma ISO 2709, o formato MARC 21 observa muitas outras normas (LIBRARY OF CONGRESS, 2006b), dentre as quais se destacam, por exemplo:

- ANSI/NISO Z39.2 (Bibliographic Information Interchange - Padrão para Intercâmbio de Informações Bibliográficas);

- ISO 3166-2 (Code for the Representation of Names of Countries and their Subdivisions: Part 2, Country subdivision code - Código para a Representação de Nomes de Países e suas Subdivisões: Parte 2, Código de subdivisão do país);

- ISO 8601 (Representations of Dates and Times - Representações de datas e horas)

O Quadro 1 mostra a divisão geral básica dos campos MARC 21 para Dados Bibliográficos. Esta divisão básica abarca os conjuntos de campos para a descrição bibliográfica de diferentes tipos de recursos informacionais, tais como: livro 
impresso, gravação de vídeo ou som, publicações periódicas, recurso eletrônico e outros.

Quadro 1 - Blocos de Campos do MARC 21 para Dados Bibliográficos

\begin{tabular}{|c|l|}
\hline $\begin{array}{c}\text { Bloco de } \\
\text { Campos }\end{array}$ & \multicolumn{1}{|c|}{ Conteúdo dos campos } \\
\hline $\mathbf{0 X X}$ & Informação de controle, números e códigos \\
\hline $\mathbf{1 X X}$ & Entradas principais \\
\hline $\mathbf{2 X X}$ & Títulos, edição, imprenta \\
\hline $\mathbf{3 X X}$ & Descrição física \\
\hline $\mathbf{4 X X}$ & Série \\
\hline $\mathbf{5 X X}$ & Notas \\
\hline $\mathbf{6 X X}$ & Entradas de assunto \\
\hline $\mathbf{7 X X}$ & Entradas secundárias de nomes de autores \\
\hline $\mathbf{8 X X}$ & Entradas secundárias de série \\
\hline $\mathbf{9 X X}$ & Reservado para decisões locais \\
\hline
\end{tabular}

Fonte: adaptado de Moura e Costa (2016).

No Quadro 1, os campos aparecem em blocos que contêm um número inicial em comum. Cada bloco representa um conjunto de campos, sendo cada campo identificado por três caracteres numéricos. O bloco 1XX, por exemplo, engloba o grupo das Entradas Principais e abrange os seguintes campos: 100 para Nome Pessoal, 110 para Nome Corporativo, 111 para Nome de Evento e 130 para entrada de Título Uniforme.

Ao fazer a representação descritiva de um material, o catalogador deverá selecionar o campo correspondente para as entradas, de acordo com os atributos do item que está registrando. No Quadro 2 é possível observar os campos do MARC 21 utilizados com frequência na representação descritiva de Livros impressos. 
Quadro 2 - Divisão básica dos Campos do MARC 21 para Livros Impressos

\begin{tabular}{|l|l|}
\hline Campos & \multicolumn{1}{|c|}{ Conteúdo dos campos } \\
\hline 008 & Campos fixos \\
\hline 020 & ISBN \\
\hline 040 & Instituição catalogadora \\
\hline $\mathbf{0 8 0}$ & Número da CDU (Classificação Decimal Universal) \\
\hline $\mathbf{0 9 0}$ & Número de chamada \\
\hline $\mathbf{1 0 0}$ & Autor principal - nome pessoal \\
\hline $\mathbf{2 4 5}$ & Título principal e indicação de responsabilidade \\
\hline $\mathbf{2 5 0}$ & Indicação da edição \\
\hline $\mathbf{2 6 0}$ & Local, editora e ano de publicação \\
\hline $\mathbf{3 0 0}$ & Descrição física, detalhes físicos e dimensões do documento \\
\hline $\mathbf{4 9 0}$ & Indicação da série \\
\hline $\mathbf{5 0 0}$ & Notas gerais \\
\hline $\mathbf{6 0 5 0}$ & Assuntos controlados \\
\hline $\mathbf{8 0 0}$ & Entrada Secundária - nome pessoal \\
\hline
\end{tabular}

Fonte: adaptado de Silva e Baptista (2013).

De acordo com o apresentado no Quadro 2, o campo 080 é indicado para a informação do número da Classificação Decimal Universal (CDU), porém, caso a instituição catalogadora adote a Classificação Decimal de Dewey (CDD), a informação de classificação entrará no campo 082 - Classificação Decimal de Dewey. Isto reforça a ideia de que os campos variam de acordo com as características dos dados que precisarão ser inseridos.

Dentro de cada campo existem os indicadores e também um conjunto de subcampos para a descrição dos conteúdos (FERREIRA, 2013). 
- indicadores são as duas primeiras posições no início de cada campo, podem ser letras ou números, que complementam os dados contidos no campo. Os indicadores também poderão conter o símbolo \#, informando que se trata de um indicador indefinido.

- subcampos são posicionados depois dos indicadores. Os subcampos são designados por letras minúsculas ou números, precedidos por um delimitador de subcampo o qual pode ser uma barra vertical (|) ou um cifrão (\$), dependendo do sistema. Cada subcampo contém uma informação específica dentro do campo.

No quadro 3 é possível observar o preenchimento do campo 245, no MARC 21, para uma edição ilustrada do livro $A$ pena e a $L e i$, do autor Ariano Suassuna. Esse campo destina-se às informações de título e indicação de responsabilidade do material que está sendo catalogado.

Quadro 3 - Exemplo de preenchimento do campo 245 no MARC 21

\begin{tabular}{|l|c|c|l|l|}
\hline Campo & $\begin{array}{l}\text { Primeiro } \\
\text { Indicador }\end{array}$ & $\begin{array}{l}\text { Segundo } \\
\text { indicador }\end{array}$ & Subcampo \$a & Subcampo \$c \\
\hline 245 & 1 & 2 & \$a A pena e a lei / & $\begin{array}{l}\text { \$c Ariano Suassuna ; ilustrações } \\
\text { Romero de Andrade Lima. - }\end{array}$ \\
\hline
\end{tabular}

Fonte: elaboração própria, a partir de Ferreira (2013).

Nota-se, no quadro 3, que o campo 245 requer o preenchimento de indicadores e subcampos. No primeiro indicador deste campo, o catalogador informará se o sistema deve ou não gerar uma entrada secundária para o título, e poderá ser preenchido com as seguintes opções:

0 - não gerar entrada secundária de título, ou

1 - gerar entrada secundária de título

Já o segundo indicador, no campo 245, serve para informar ao sistema a quantidade de caracteres a desprezar na alfabetação. No exemplo acima, observa-se 
que o segundo indicador foi preenchido com o número 2, indicando que serão desprezados dois caracteres, sendo referentes ao artigo 'A' seguido do 'espaço' no início do título $\underline{A}$ pena e a lei. Quando não há quantidades de caracteres a desprezar, o segundo indicador no campo 245 deverá ser preenchido com 0 (zero).

Ainda considerando o exemplo do quadro 3, nota-se que, além dos indicadores, foram preenchidos também os subcampos \$a e \$c conforme as informações contidas no material.

O campo 245 possui diversos subcampos, cada um com uma função específica. No caso dos registros de livros impressos, os subcampos mais utilizados no campo 245 são: \$a para o título, \$b para complemento do título (incluindo o subtítulo, quando houver), e \$c para Indicação de responsabilidade.

O registro de uma edição do livro $A$ pena e a lei pode ser observado na figura 2, apresentada a seguir, que mostra a representação descritiva do título mencionado, segundo as regras do AACR2 e em formato MARC 21, feita pela Fundação Biblioteca Nacional do Brasil (BN).

Figura 2 - Representação Descritiva do livro A pena e a Lei em formato MARC 21

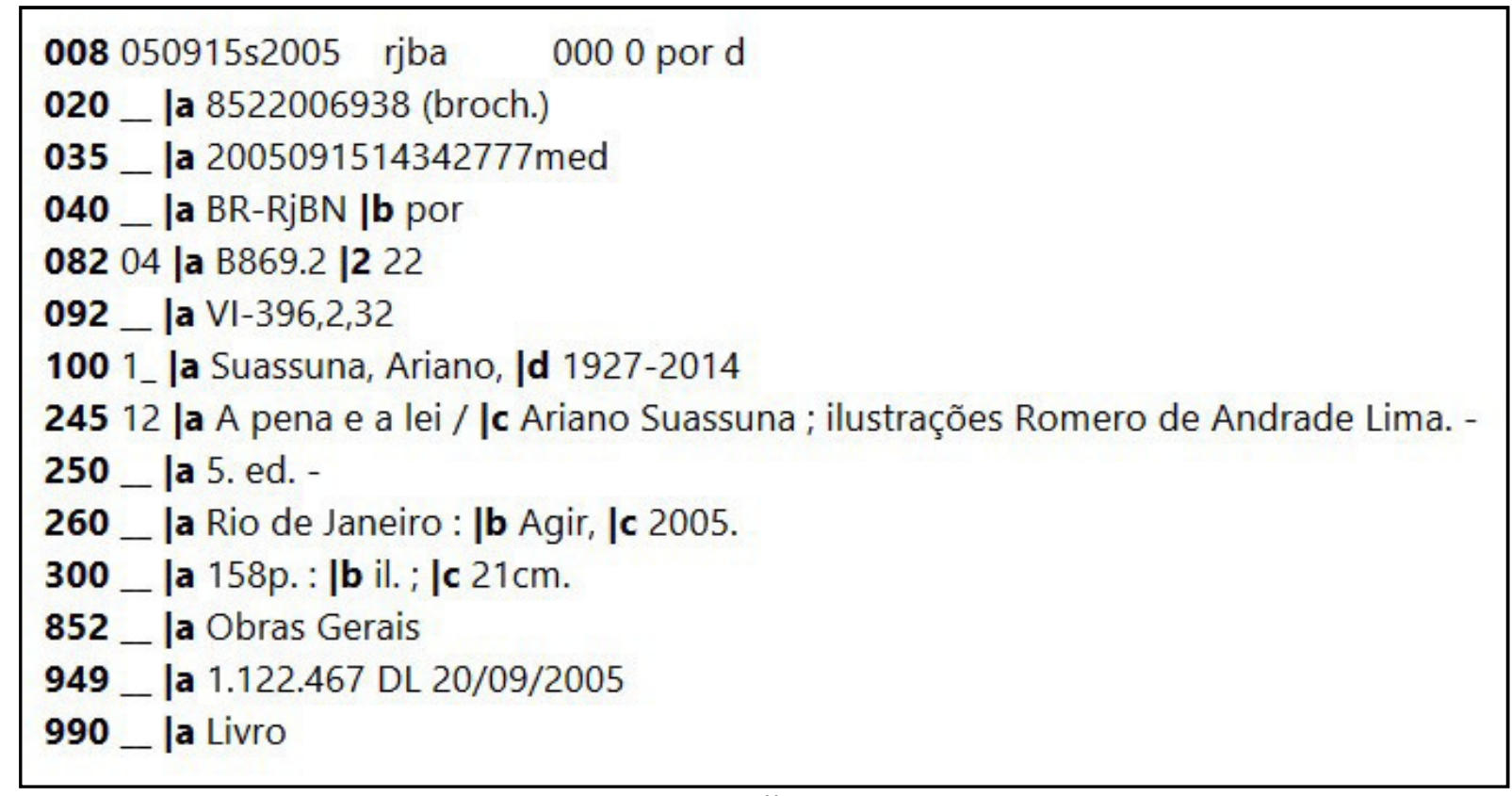

Fonte: catálogo on-line da BN. Disponível em: http://acervo.bn.br. Acesso em: 23 mar. 2018.

$\mathrm{Na}$ Figura 2 nota-se que o campo 082, por exemplo, contém exclusivamente informações acerca da Classificação Decimal Dewey, e observa-se que em suas primeiras posições, aparecem os dois indicadores contendo, respectivamente, os números 0 e 4. 
O primeiro indicador, neste campo 082, tem a função de informar o tipo de edição da CDD que está sendo usada, podendo ser preenchido com os seguintes caracteres:

0 para edição completa,

1 para edição abreviada ou

7 para outra edição.

Já o segundo indicador no campo 082, tem a função de informar se a fonte do número de classificação pertence à LC ou outra instituição, podendo ser preenchido com os seguintes caracteres:

\# para nenhuma informação fornecida,

0 para atribuído pela $L C$, ou

4 para atribuído por outra instituição diferente da $L C$.

Depois desses dois indicadores, o campo 082 trouxe os subcampos |a, cuja função é informar o número de classificação do livro, seguido do subcampo |2, cuja função é apontar a edição da CDD da qual a classificação foi retirada. Sendo assim, observa-se que o campo 082 (Figura 2) aparece com os seguintes dados: 08204 |a B869.2 |2 22. Com isto, este campo pode ser interpretado da seguinte forma: campo da Classificação Decimal Dewey cuja edição é a completa, atribuído por Instituição diferente da LC, onde a notação escolhida para classificar o assunto foi B869.2 e essa notação foi retirada da $22^{a}$ edição da CDD.

Ainda analisando a Figura 2, é possível observar que o campo 100, designado para a descrição da Entrada Principal de nome pessoal contém, em suas primeiras posições, apenas o primeiro indicador preenchido com o número 1. Preencher este indicador com ' 1 ' significa apontar que a entrada principal ali descrita será feita primeiro pelo sobrenome do autor, seguido do prenome. Neste campo 100 o segundo indicador fica em branco (em alguns sistemas pode conter \#) por tratar-se de indicador indefinido.

Depois dos indicadores, o campo 100, no exemplo da Figura 2, foi cadastrado com os seguintes subcampos: |a para o nome do autor, e |d para datas associadas ao nome, ou seja, as datas que compreendem os anos de nascimentomorte do referido autor. 
Para a descrição do conteúdo e da ordem de cada campo e subcampo dos registros no formato MARC 21, são observados os padrões como a International Standard Bibliographic Description (ISBD ou Descrição Bibliográfica Internacional Normalizada), o Anglo-American Cataloguing Rules - (AACR2 ou Código de Catalogação Anglo-Americano) ou outras, sendo que é a biblioteca catalogadora ou a organização responsável pelos registros quem define o código de catalogação a ser adotado (FERREIRA, 2013; MOURA; COSTA, 2016).

Esses exemplos demonstram que, no formato MARC 21, cada campo, subcampo ou indicador possui uma função específica na confecção dos registros bibliográficos. É possível realizar uma representação descritiva bastante detalhada, tendo em vista a diversidade dos campos e subcampos disponíveis. Isso não significa que o catalogador precisará decorar toda a estrutura do MARC ou mesmo utilizar todos os campos disponíveis para fazer um registro. Com o intuito de facilitar a inserção dos dados, os softwares gerenciadores de bibliotecas que adotam o padrão MARC 21 costumam disponibilizar planilhas para cadastro de materiais onde o bibliotecário, ao fazer a representação descritiva de um item, pode visualizar o número dos campos com a respectiva informação do conteúdo de cada campo, incluindo explicações sobre os indicadores e os subcampos. Dessa forma, o catalogador preencherá apenas os campos e subcampos necessários de acordo com o material informacional que está registrando no momento.

Uma outra facilidade que os sistemas que utilizam o padrão MARC 21 costumam disponibilizar, é a opção de importação e exportação de registros entre instituições. Isto é possível tendo em vista que muitas vezes a mesma edição de um material bibliográfico pode encontrar-se disponível em bibliotecas distintas. De forma mais simples, significa dizer que é possível o catalogador consultar catálogos de outras bibliotecas e copiar para a sua base de dados os registros bibliográficos prontos, com os campos e subcampos já preenchidos. Após a importação de um registro, o catalogador ficaria encarregado apenas de revisar os dados da importação e finalizar o cadastro conforme as necessidades de sua instituição. Essa possibilidade de intercambiar informações bibliográficas facilita e agiliza o processo diminuindo os custos com o trabalho de representação descritiva da informação. Com isso, enfatizase a importância da adoção de sistemas que permitam a observação das normas e dos padrões de descrição bibliográfica internacionalmente conhecidos e utilizados. 


\section{A REPRESENTAÇÃO DA INFORMAÇÃO EM BIBLIOTECAS}

De acordo com Ribeiro (2005, p. 95), "representar informação significa criar "imagens", não exactas e integrais [...], mas suficientemente rigorosas para tornar possível uma identificação inequívoca dos objectos representados". No âmbito das bibliotecas, ao longo dos tempos, a representação da informação esteve vinculada à produção de catálogos e instrumentos de consulta onde é feita a representação dos dados dos materiais e dos conteúdos informacionais que compõem o acervo, visando a recuperação da informação por parte dos usuários.

$\mathrm{Na}$ era digital, surge um desafio para os profissionais que lidam com a representação da informação, visto que as bibliotecas necessitam organizar e disponibilizar grandes quantidades de documentos e em diferentes tipos de suportes, fazendo a representação adequada desses materiais em ambientes automatizados. Com isso, os profissionais da informação devem estar atentos para a adoção de "[...] princípios e métodos capazes de representar com exatidão o acervo disponível, como também permitir que o acesso/recuperação da informação seja efetivado por meio de instrumentos de classificação bem estruturados" (FERREIRA; ALBUQUERQUE, 2013, p. 15).

A representação da informação no âmbito das bibliotecas se divide em dois tipos, conforme salientado por Maimone, Silveira e Tálamo (2011, p. 28, grifo nosso):

[...] a representação da informação pode ser subdividida em representação descritiva e representação temática. A primeira representa as características específicas do documento, denominada descrição bibliográfica, que permite a individualização do documento. Ela também define e padroniza os pontos de acesso, responsáveis pela busca e recuperação da informação, assim como pela reunião de documentos semelhantes, por exemplo, todas as obras de um determinado autor ou de uma série específica. A segunda detém-se na representação dos assuntos dos documentos a fim de aproximá-los, tornando mais fácil a recuperação de materiais relevantes que dizem respeito a temas semelhantes. Neste contexto, são elaboradas as linguagens documentárias, instrumentos de controle vocabular a fim de tornar possível a "conversação" entre documentos e usuários.

Estando assim, portanto, o processo de representação da informação subdividido em dois tipos: representação descritiva e representação temática. Considera-se que isso resultará para os usuários em diversas possibilidades de busca e recuperação nos sistemas, conforme mencionado por Gomes e Santos (2013): 
1) a partir da representação descritiva, que se atém à descrição dos dados físicos do material, é possibilitada a realização de buscas por autor, por título, por tipo de material, etc.; e

2) a partir da representação temática, caracterizada pela descrição do conteúdo, ou seja, dos assuntos contidos no material, será permitido ao usuário realizar buscas por assuntos de interesse.

No que diz respeito à etapa de representação descritiva (dados físicos) dos materiais, os bibliotecários, ao longo dos anos, vêm consolidando instrumentos e padrões que auxiliam na sua realização, destacando-se o AACR2, o RDA, o Formato MARC 21 para Dados Bibliográficos, bem como diversos formatos de intercâmbio bibliográfico, os quais serão mencionados nos capítulos adiante. Esses instrumentos e regras muitas vezes são considerados complexos, no entanto, são fundamentais para a descrição bibliográfica de materiais dos acervos com vistas à organização da informação. Conforme ressaltam Okada e Ortega (2009, p. 32),

O profissional deve saber utilizar os instrumentos de organização da
informação [...] e discernir sobre a forma como os mesmos são
institucionalizados. Não deve abordar estes instrumentos como a
causa de todos os problemas, mas saber interpretá-los e empregá-los,
propondo soluções que decorram em processos satisfatórios de
recuperação da informação.

Quanto à representação temática (de assuntos), os bibliotecários realizam, nessa etapa, as atividades de classificação e indexação, quando são identificados e extraídos os assuntos contidos nos materiais, com vistas a padronizar os termos que representarão esses conteúdos no sistema para o usuário. Essa atividade envolve aspectos cognitivos, de análise e de uso de linguagens por parte dos profissionais da informação, que, para isso, lançam mão de instrumentos que auxiliam neste trabalho, tais como: os esquemas de classificação hierárquicos de assuntos, os vocabulários controlados e os tesauros.

Desse modo, quando se pensa em organização, acesso e uso da informação bibliográfica, percebe-se que, tanto a representação descritiva quanto a representação temática são indispensáveis e se complementam mutuamente nos "bastidores" dos sistemas, viabilizando a recuperação satisfatória da informação pelos 
usuários nas interfaces de busca. Mas, para tornar todo esse processo possível no ambiente digital contemporâneo, um fator importante é a escolha adequada de softwares para o gerenciamento de bibliotecas e unidades de informação, nesse sentido, Vetter e Araújo (2012, p. 12) destacam que,

[...] a participação do bibliotecário na escolha do software para a instituição deve se dar de forma efetiva, tendo em vista a melhoria na qualidade dos serviços oferecidos, e o compartilhamento de recursos, que viabilize parcerias com outras instituições, com o objetivo de racionalizar as operações e aumentar o acesso à informação aos usuários.

Assim, diante das grandes quantidades de informação a serem disponibilizadas diariamente nos catálogos, o profissional da informação precisa estar familiarizado com os recursos e os aparatos tecnológicos que possam facilitar tarefas. Importa conhecer e saber lidar com as ferramentas disponíveis de modo que se possa estabelecer políticas institucionais em prol da padronização da representação temática e descritiva da informação. Essa preocupação com a padronização deve ser constante, principalmente nas instituições que atuam em rede, onde bibliotecários realizam a representação da informação em unidades ou bibliotecas distintas para serem exibidas no mesmo catálogo coletivo on-line.

Frente ao exposto, considera-se que o foco da presente pesquisa está concentrado na etapa de representação descritiva da informação, visto que busca elucidar aspectos dos principais instrumentos e padrões de descrição bibliográfica que precisam estar à mão do bibliotecário para a organização, a descrição e o intercâmbio de registros entre bibliotecas.

\subsection{O LUGAR DA REPRESENTAÇÃO DESCRITIVA}

No processo de representação da informação o bibliotecário realiza a descrição dos materiais disponíveis no acervo cadastrando os seus elementos no sistema da biblioteca, para a posterior recuperação por meio da busca. Portanto, a qualidade da representação descritiva terá impacto direto nos resultados de buscas on-line feitas pelos usuários nos sistemas de recuperação da informação. Com a descrição bibliográfica, serão delimitados os pontos pelos quais o material 
bibliográfico poderá ser acessado pelos usuários, tais como os nomes dos autores responsáveis e o título.

Nessa perspectiva, Joudrey, Taylor e Wisser (2018) mencionam que, no âmbito das bibliotecas, o conjunto de atributos utilizados na descrição de um item/material é também denominado hoje de metadados.

Apesar das várias formas em que a informação pode ser registrada, todos os recursos de informação possuem alguns atributos básicos ou propriedades em comum, como o título (do que chamamos um recurso), criador (quem é responsável por ele) e assunto (sobre o que se trata). Esses atributos (e outros) são gravados para ajudar a organizar informações; coletivamente, esses atributos podem ser referidos como metadados. Metadados em sua definição mais informal, mais predominante, são "dados sobre dados". Isso significa que os atributos usados para descrever um recurso de informação são metadados sobre esse recurso [...] (JOUDREY; TAYLOR; WISSER, 2018, p. 6, tradução nossa).

Os metadados são definidos por Gracio (2002, p. 23) como um "[...] conjunto de elementos que descrevem as informações contidas em um recurso, com o objetivo de possibilitar sua busca e recuperação". Lopes e Ferneda (2016, p. 151) explicam que esse conjunto de metadados, ou elementos de metadados codificados em estruturas padronizadas, compõem os "padrões de metadados". Dessa forma, pode-se considerar que o MARC foi o primeiro padrão de metadados, criado na década de 1960 e que persiste até os dias atuais, sendo hoje conhecido como MARC 21 (GRACIO, 2002; FUSCO, 2011).

Conforme ressaltado por Caplan (2003) o termo metadados origina-se do campo da Ciência da Computação e entrou no vocabulário da Biblioteconomia somente por volta do ano de 1995, a partir da criação e da promoção do padrão de metadados Dublin Core. O Dublin Core e outros padrões de metadados, surgidos a partir da era da web, serão abordados adiante, na sexta seção.

Além da criação de metadados por meio da descrição dos atributos básicos dos materiais, o texto de Joudrey, Taylor e Wisser (2018) aponta também a importância do controle de autoridades no contexto da representação descritiva. $\mathrm{Na}$ atividade de controle de autoridades, o profissional da informação é o responsável por criar e gerenciar dados sobre autoridades, dando todo o suporte para a recuperação adequada desses dados por parte do usuário final. Nesse sentido, os autores explicam que, 
A recuperação mais satisfatória vem da busca por nomes, títulos e assuntos específicos que foram escolhidos e construídos sob o controle de autoridade para reunir formas variantes e termos relacionados. Se uma pessoa foi identificada por nomes diferentes e ou formas de nomes [...], e se o nome dessa pessoa foi submetido ao controle de autoridade então um nome ou forma de nome é escolhido como o preferido e os outros são documentados como referências cruzadas a ele (JOUDREY; TAYLOR; WISSER, 2018, p. 10, tradução nossa).

Observa-se, portanto, que o processo de representação descritiva de recursos informacionais em bibliotecas envolve três atividades principais, conforme mostra o quadro a seguir:

Quadro 4 - Atividades do processo de Representação Descritiva em catálogos de bibliotecas.

\begin{tabular}{|c|c|c|}
\hline Atividades & Objetivos & Tipos de Atributos \\
\hline $\begin{array}{l}\text { Criação da } \\
\text { descrição }\end{array}$ & $\begin{array}{l}\text { Registrar os atributos mais } \\
\text { importantes de um recurso } \\
\text { para permitir aos usuários } \\
\text { encontrar, identificar, } \\
\text { selecionar, obter e explorá-lo. }\end{array}$ & $\begin{array}{l}\text { Título do recurso; declarações } \\
\text { de responsabilidade; } \\
\text { informações de versão ou } \\
\text { edição; informação de } \\
\text { disseminação; o tipo de recurso; } \\
\text { sua extensão, dimensões e } \\
\text { tamanho; e números padrão } \\
\text { associados ao recurso. }\end{array}$ \\
\hline $\begin{array}{c}\text { Escolha dos Pontos } \\
\text { de Acesso }\end{array}$ & $\begin{array}{l}\text { Garantir que os nomes das } \\
\text { partes responsáveis, bem } \\
\text { como os vários títulos } \\
\text { associados ao recurso sejam } \\
\text { enumerados nos metadados } \\
\text { e que esses pontos possam } \\
\text { ser usados para encontrar o } \\
\text { recurso no catálogo. }\end{array}$ & $\begin{array}{l}\text { Nomes de criadores (por } \\
\text { exemplo, autores, artistas, } \\
\text { órgãos governamentais, } \\
\text { compiladores, compositores, } \\
\text { famílias e outros); nomes de } \\
\text { contribuidores (editores, } \\
\text { tradutores, ilustradores e } \\
\text { outros); títulos atribuídos ao } \\
\text { recurso; títulos de recursos } \\
\text { relacionados (adaptações, } \\
\text { títulos de série e outros) }\end{array}$ \\
\hline
\end{tabular}




\begin{tabular}{|c|c|c|}
\hline $\begin{array}{l}\text { Controle de } \\
\text { autoridades }\end{array}$ & $\begin{array}{l}\text { Fornecer consistência em } \\
\text { como nomes e alguns títulos } \\
\text { aparecem como pontos de } \\
\text { acesso autorizados (ou seja, } \\
\text { cadeias de caracteres } \\
\text { padronizados escolhidas } \\
\text { para representar nomes ou } \\
\text { títulos). }\end{array}$ & $\begin{array}{l}\text { Nomes e Títulos padronizados. } \\
\text { (Por exemplo, quando os } \\
\text { catalogadores usam o nome } \\
\text { autorizado Onassis, Jacqueline } \\
\text { Kennedy, 1929-1994 nos } \\
\text { metadados para recursos por } \\
\text { ou sobre Jackie Kennedy). }\end{array}$ \\
\hline
\end{tabular}

Fonte: adaptado de Joudrey, Taylor e Wisser (2018, p. 15-16, tradução nossa).

Observa-se no quadro acima que o processo de representação descritiva não é uma tarefa tão simples quanto parece. Os diferentes materiais de um acervo podem conter diversas variáveis descritivas em seus atributos. Por exemplo, a responsabilidade pela autoria dos diferentes recursos bibliográficos, ora pode ser de apenas uma ou de várias pessoas físicas, ora pode ser de uma entidade governamental ou de uma empresa privada, ora pode ser resultado de um evento, entre outros. Com isso, muitas questões e dúvidas podem surgir durante a descrição dos materiais de um acervo, principalmente quando o catalogador é iniciante. Portanto, para que se possa alcançar a qualidade na representação da informação e, consequentemente, a satisfação dos usuários pesquisadores, torna-se necessário o uso adequado dos instrumentos que norteiam, padronizam e auxiliam no esclarecimento das dúvidas.

Além disso, os materiais de uma biblioteca muitas vezes não são exclusivos de um único acervo, ou seja, o mesmo título de livro, por exemplo, pode fazer parte dos acervos de bibliotecas distintas, fortalecendo-se ainda mais a necessidade de padronização da descrição bibliográfica. Tal padronização contribui para evitar a criação de registros duplicados e para facilitar o intercâmbio de informações, principalmente entre bibliotecas que atuam em rede, cujos catálogos ficam disponíveis para consultas on-line. Contudo, os esforços dos profissionais da informação no sentido de padronizar a descrição bibliográfica dos recursos informacionais não é uma novidade no cenário mundial. 


\section{REPRESENTAÇÃO DESCRITIVA: REGRAS E CONTEXTOS}

Muito antes da chegada da internet, diversos países passaram a desenvolver suas regras para a descrição bibliográfica dos recursos informacionais de bibliotecas, gerando os códigos de catalogação nacionais. Segundo Mey e Silveira (2009), foi ainda no Século XVIII, durante a Revolução Francesa, que começaram a surgir os primeiros Códigos de Catalogação, determinando regras para a representação descritiva de materiais para as bibliotecas francesas. Entretanto, foi na Grã-Bretanha, em meados do século XIX, que o bibliotecário Antonio Panizzi, da Biblioteca Britânica, publicou as "91 regras de catalogação" as quais abrangiam a catalogação de livros, mapas e música e cujas características técnicas serviram de base para a criação dos códigos mais modernos (RIBEIRO, 2005, p. 86).

Assim, Segundo Mey e Silveira (2009, p.71), o Século XIX foi marcado como uma "época de proliferação de códigos de catalogação" e já no Século XX iniciaram-se os trabalhos no sentido da normalização visando a padronização internacional.

O primeiro evento no sentido da normalização internacional foi a Conferência Internacional sobre Princípios de Catalogação, ou Conferência de Paris, realizada em 1961. Reuniu representantes de 53 países e de 12 organizações internacionais, com diferentes filosofias e códigos de catalogação, dispostos a um acordo (MEY; SILVEIRA, 2009, p. 78).

Em consonância com os Princípios de Catalogação, discutidos em 1961, na Conferência de Paris, foi publicada, no ano de 1967, a primeira edição das AngloAmerican Cataloging Rules (AACR), em duas versões, sendo uma inglesa e outra norte-americana, cuja tradução para o português foi editada no Brasil em 1969, intitulada: Código de Catalogação Anglo-Americano. Uma segunda edição do código foi publicada em 1978, quando passou a se chamar AACR2 (MEY; SILVEIRA, 2009).

O AACR2 passou por várias revisões e alterações, tornando-se o AACR2r. Conforme destacado por Silva et al (2017, p. 9), "em 2002, além de cobrir pequenas alterações, uma mudança substancial foi introduzida ao código: a entrada de instruções para descrição de recursos eletrônicos". Segundo Mey e Silveira (2009), no ano de 2004, foi publicada no Brasil uma tradução com base nesta revisão de 2002, a qual permanece em uso em muitas bibliotecas brasileiras. 
No Brasil, após várias discussões, o AACR2 foi recomendado e adotado como código de catalogação nacional, com tradução e distribuição realizada pela Federação Brasileira de Associações de Bibliotecários, Cientistas da Informação e Instituições (FEBAB) (OKADA; ORTEGA, 2009, p. 21).

Convém destacar que o Código de Catalogação Anglo-Americano, em sua segunda edição (AACR2), além de basear-se nos Princípios de Catalogação discutidos em Paris, foi estruturado também com base na norma International Standard Bibliographic Description (ISBD ou Descrição Bibliográfica Internacional Normalizada), publicada pela Federação Internacional das Associações e Instituições Bibliotecárias (IFLA) na década de 1970. Segundo Fusco (2011, p. 29), a ISBD é um documento que "[...] organiza e sistematiza a ordem das informações bibliográficas, identifica elementos e utiliza uma sequência de pontuações padronizadas". Essas regras foram publicadas separadamente, de acordo com o tipo de material, por exemplo, publicou-se: $\operatorname{ISBD}(G)$ com regras gerais referentes a todos os tipos de documentos; ISBD(M) com regras para monografias; ISBD(S) com regras para publicações periódicas; ISBD $(\mathrm{CM})$ com regras para material cartográfico, dentre outras.

Desse modo, vários elementos existentes nas ISBDs foram transportados para o AACR2. Nesse sentido, destacam-se, principalmente, a identificação das áreas de descrição bibliográfica de cada uma das diferentes formas de materiais. Essas áreas de descrição advindas da ISBD são apresentadas na Parte I do AACR2, separadas da seguinte forma, conforme o CÓDIGO... (2004):

- Área do título e da indicação de responsabilidade;

- Área da edição;

- Área de detalhes específicos do material;

- Área da publicação, distribuição, etc.;

- Área da descrição física;

- Área de série;

- Área de notas;

- Área de número normalizado e das modalidades de aquisição. 
Além dessa organização da descrição dividida em áreas, o AACR2 também segue a ISBD para a definição da pontuação dos elementos de cada área. Para exemplificar isso, a Figura 3 mostra um recorte do padrão para a pontuação da Área do Título e da Indicação de Responsabilidade, conforme estabelecido na ISBD.

Figura 3 - Pontuação para Área de Título e Indicação de Responsabilidade na ISBD $(G)$.

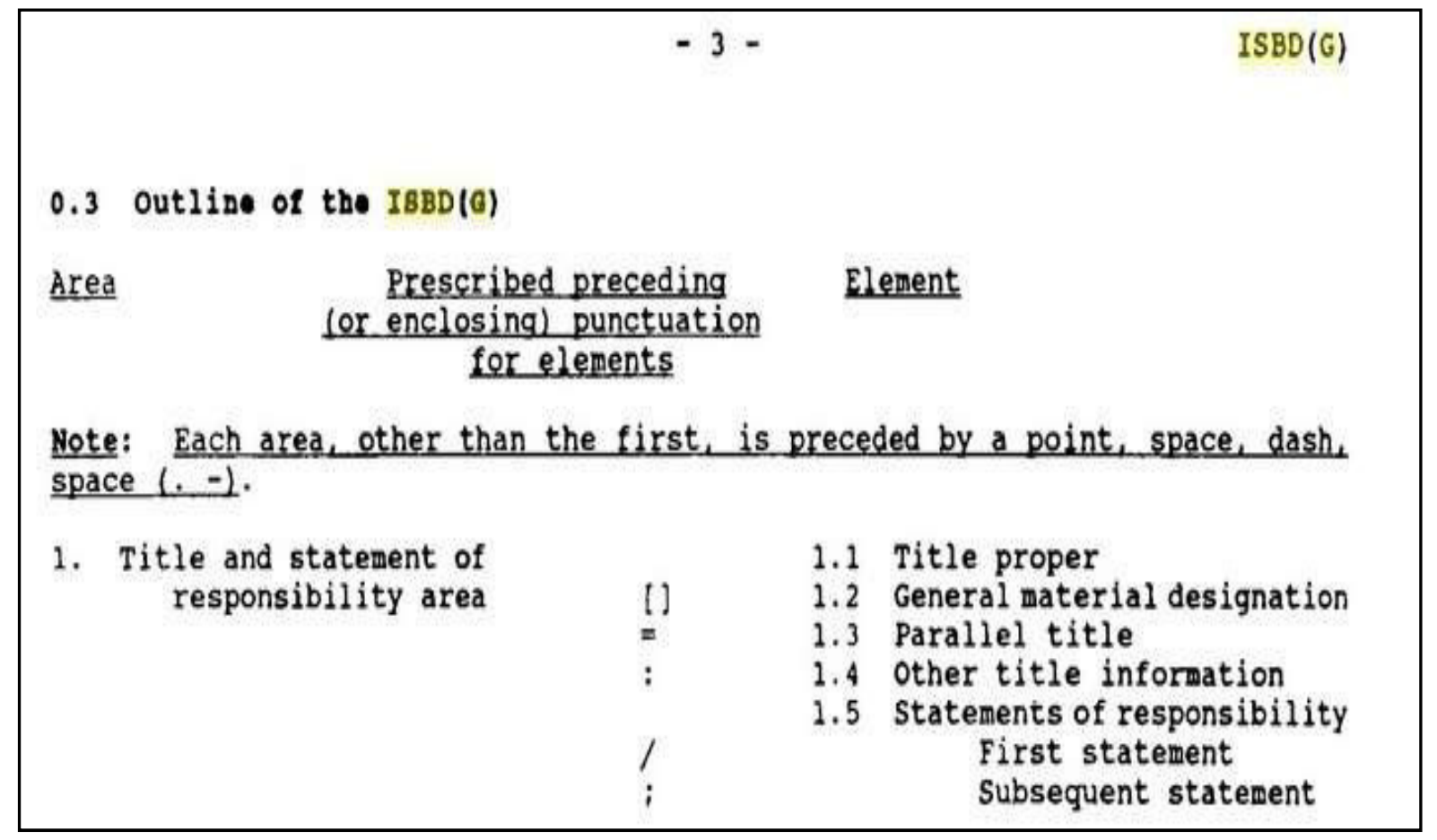

Fonte: ISBD Review Commitee Working Group (1992).

Na figura acima é possível verificar que se origina da ISBD a prescrição para as pontuações que se encontram no AACR2, indicando, por exemplo, que a Designação Geral do Material (DGM) deve estar entre colchetes [ ], ou que um título paralelo deve ser precedido do sinal de igualdade $=$, e assim por diante.

Essas orientações sobre pontuações, constantes na ISBD, foram incorporadas ao AACR2 e aparecem no seu primeiro capítulo, onde são definidas Regras Gerais de Descrição, conforme exemplificado na Figura 4. 
Figura 4 - Pontuação para Área do Título e Indicação de Responsabilidade no AACR2 - Regra 1.1A1.

\subsection{A1. Pontuação}

Para instruçōes sobre o uso de espaços antes e depois da pontuação prescrita, veja $1.0 \mathrm{C}$. Anteponha um ponto ao título de um suplemento ou seção (veja 1.1B9).

Coloque entre colchetes a designação geral do material.

Anteponha um sinal de igualdade a cada título equivalente.

Anteponha dois pontos a cada unidade de outras informações sobre o titulo.

Anteponha uma barra obliqua à primeira indicação de responsabilidade.

Anteponha um ponto e virgula a cada indicação subsequente de responsabilidade.

Para pontuaçảo desta área no que se refere a itens sem título coletivo, veja I.1G3.

Para o uso de sinais de igualdade antes de indicações equivalentes, veja as regras apropriadas a seguir.

Fonte: CÓDIGO... (2004).

Conforme apresentado por Fusco (2011), o AACR2 divide-se em duas partes:

- Parte I - Descrição, que é onde são apresentadas as regras para a descrição de diferentes formas de materiais. Esta primeira parte é composta por 13 (treze) capítulos: 1. Regras Gerais de Descrição; 2. Livros, Folhetos e Folhas Impressas; 3. Materiais Cartográficos; 4. Manuscritos (incluindo Coleções Manuscritas); 5. Música; 6. Gravação de Som; 7. Filmes Cinematográficos; 8. Materiais Gráficos; 9. Recursos Eletrônicos; 10. Artefatos Tridimensionais e Realia; 11. Microformas; 12. Recursos Contínuos; e 13. Análise.

- Parte II - Pontos de Acesso, Títulos Uniformes e Remissivas, que é onde se estabelece as regras que definem a forma de apresentação dos pontos de acesso aos usuários do Catálogo. Esta segunda parte é composta por 6 (seis) capítulos: 21. Escolha dos Pontos de Acesso; 22. Cabeçalhos para Pessoas; 23. Nomes Geográficos; 24. Cabeçalhos para entidades; 25. Títulos Uniformes; e 26. Remissivas. Na parte II do AACR2 constam também os apêndices, o glossário e o índice.

Dessa forma, o AACR2 consolidou-se como um importante instrumento construído com base em decisões internacionais oriundas de acordos e documentos 
firmados nos anos de 1960 e 1970, onde são estabelecidas as diretrizes para a representação descritiva de materiais bibliográficos, as quais possibilitaram o intercâmbio de dados entre bibliotecas.

\subsection{REGRAS DE DESCRIÇÃO: DO CONTEXTO IMPRESSO AO ELETRÔNICO}

Antes da chegada da web e dos catálogos on-line, o registro dos materiais dos acervos de bibliotecas era realizado por meio da confecção de fichas ou cartões impressos, nos quais a descrição bibliográfica era feita com base nas regras dos códigos de catalogação. O armazenamento dessas fichas padronizadas possibilitava buscas por meio de catálogos e arquivos manuais. Segundo Mey e Silveira (2009), os catálogos manuais se dividiram em duas categorias:

- Catálogos externos: aqueles destinados ao público, organizado de modo a permitir a busca pelos pontos de acesso dos materiais.

- Catálogos internos: aqueles destinados aos serviços bibliotecários. Abrangem os catálogos de autoridade de nomes, autoridades de assuntos, catálogos de títulos (por exemplo, títulos de série), catálogo topográfico entre outros.

Ainda com a utilização das fichas e dos catálogos impressos, as bibliotecas começaram a realizar o intercâmbio, ou seja, a troca de informações bibliográficas entre si, dando início às redes de catalogação cooperativa. A LC foi a pioneira na comercialização de fichas catalográficas impressas, tendo iniciado esse serviço, desde 1901.

Já no Brasil a catalogação cooperativa teve início em 1942 com a implantação do serviço de Intercambio de Catalogação (SIC), na biblioteca do DASP. Sendo que qualquer biblioteca poderia enviar suas fichas catalográficas para participar deste serviço. Em 1947 a Fundação Getulio Vargas começou a participar do SIC, dando curso e distribuindo as fichas. E em 1954 o Instituto Brasileiro de Documentação (IBBD) também começou a utilizar este serviço. [...] (SILVA; SOUZA, 2011, p. 2).

Todavia, mais adiante, a década de 1960 trouxe o desenvolvimento dos recursos computacionais e com isso a necessidade de se acompanhar e usufruir de 
seus benefícios. No campo da Biblioteconomia não foi diferente (MEY; SILVEIRA, 2009; SILVA; BAPTISTA, 2013). Com o avanço tecnológico e a partir do Projeto MARC as fichas e os catálogos manuais impressos começaram a ser registrados em sistemas computadorizados de recuperação da informação tendo seus dados estruturados de forma legível por máquina. No princípio, a automatização dos catálogos não parecia ser tão profícua, no entanto, a partir daquele momento, um novo horizonte se abria para a representação descritiva da informação, conforme argumentam Mey e Silveira (2009, p. 207),

Logo em seu início, os catálogos ditos automatizados nada mais eram do que a mecanização dos catálogos em fichas, sem nenhuma vantagem aparente aos usuários e com muito mais trabalho para os bibliotecários [...]. Na era da internet e dos bancos de dados relacionais, a história se torna muito diferente.

A transição do ambiente de base impressa para os sistemas automatizados impulsionou a criação das redes de catalogação cooperativas e o intercâmbio de registros bibliográficos entre bibliotecas.

\begin{abstract}
Motivadas pela necessidade do compartilhamento de recursos, algumas bibliotecas começaram a organizar-se em consórcios ou redes, visando a dividir as despesas com a aquisição de equipamentos e desenvolvimento de sistemas e iniciando a construção de bancos de dados compartilhados, que viriam dar uma nova dimensão ao princípio de reaproveitamento dos registros bibliográficos (VASCONCELLOS, 1996, p. 1).
\end{abstract}

Diante desse cenário, a padronização dos dados na representação da informação tornou-se cada vez mais importante. Para possibilitar esse intercâmbio de registros entre as bibliotecas participantes dos catálogos coletivos automatizados, além dos Códigos de Catalogação, tornou-se necessária a criação de formatos para a descrição padronizada dos registros bibliográficos nos sistemas, com o objetivo de manter a qualidade tanto na representação descritiva de materiais como também na recuperação dos mesmos nos sistemas computadorizados. Conforme salientam Okada e Ortega (2009, p. 22, grifo nosso),

$\mathrm{Na}$ catalogação cooperativa, a catalogação de um documento é feita apenas uma vez e o registro resultante é disponibilizado a outras bibliotecas por meio de um catálogo coletivo, ou seja, existe um registro original que é compartilhado por um grupo de unidades de 
informação, agilizando o serviço. Para que um registro seja mais bem reaproveitado no meio eletrônico, é necessário que se adote formato e código de catalogação que permita a importação sem grandes custos de conversão de dados e/ou de revisão posterior dos mesmos.

Destarte, em meados do Século XX as comunidades bibliotecárias ao redor do mundo se viram diante da necessidade de pensar e a adotar sistemas de automação que contemplassem a junção destes dois elementos fundamentais para a organização e representação da informação em catálogos automatizados, que são:

a) o uso das regras (por exemplo, o Código de Catalogação Anglo-Americano) estabelecidas para a descrição de cada material ou recurso informacional; e

b) os formatos de descrição e intercâmbio de dados, os quais fornecem uma estrutura adequada para o registro/inserção dos atributos de cada material informacional no sistema.

No Quadro 5, foram posicionados os campos do formato MARC 21 mais usados para a descrição de livros impressos, o que transportou, para o meio eletrônico, as áreas de descrição definidas no AACR2, na parte I.

Quadro 5 - Exemplo de Campos MARC 21 para áreas de descrição de livros impressos.

\begin{tabular}{|c|c|}
\hline $\begin{array}{c}\text { ÁREAS DE DESCRIÇÃO SEGUNDO } \\
\text { O AACR2 - PARTE I }\end{array}$ & $\begin{array}{l}\text { CAMPOS CORRESPONDENTES } \\
\text { PARA LIVROS, NO MARC } \mathbf{2 1}\end{array}$ \\
\hline $\begin{array}{l}\text { Área do título e da indicação de } \\
\text { responsabilidade }\end{array}$ & $\begin{array}{l}240 \text { - Título uniforme } \\
245 \text { - Indicação de título } \\
246 \text { - Forma variante do título }\end{array}$ \\
\hline Área da edição & 250 - Indicação de edição \\
\hline Área da publicação, distribuição, etc. & 260 - Publicação, distribuição, etc. (Imprenta) \\
\hline Área da descrição física & 300 - Descrição física \\
\hline Área de série & $\begin{array}{l}490 \text { - Indicação de série } \\
800 \text { - Entrada secundária de série - Nome pessoal } \\
810 \text { - Entrada sec. de série - Nome Corporativo }\end{array}$ \\
\hline
\end{tabular}




\begin{tabular}{|c|l|}
\hline & 811 - Entrada sec. de série - Nome de evento \\
& 830 - Entrada secundária de série - Título uniforme \\
\hline \multirow{3}{*}{ Área de notas } & $\mathbf{5 0 0}$ - Nota geral \\
& 504 - Nota de bibliografia \\
& $\mathbf{5 0 5}$ - Nota de conteúdo formatada \\
& $\mathbf{5 3 4}$ - Nota de versão original \\
& $\mathbf{5 4 6}$ - Nota de idioma \\
& $\mathbf{5 9 X}$ - Notas locais \\
\hline Área de número normalizado e das & 020 - ISBN \\
\hline modalidades de aquisição & \\
\hline
\end{tabular}

Fonte: elaboração própria, a partir de Ferreira (2013) e CÓDIGO...(2004).

Além dos campos para as áreas de descrição, nos registros bibliográficos existem também os campos MARC 21 para a inclusão dos pontos de acesso, os quais abrangem as entradas primárias (campos do bloco $1 \mathrm{XX}$ ) e entradas secundárias (campos do bloco 7XX) ligadas ao material.

Os pontos de acesso e as suas remissivas, conforme previstos na Parte II do AACR2, podem ser cadastrados previamente utilizando-se o formato MARC 21 para Dados de Autoridade, gerando um banco de dados controlado para nomes de autores, entidades coletivas, eventos, nomes geográficos e títulos uniformes. Esse formato específico para cadastro de autoridades não será explicado em detalhes no presente estudo por não fazer parte do foco principal da pesquisa. Porém, convém destacar a sua importância porque é nele que um nome autorizado é ligado às suas remissivas e aos seus atributos.

Assim, ao cadastrar os materiais bibliográficos no MARC 21 para Dados Bibliográficos, o catalogador sempre consultará o seu banco de dados de autoridades ao preencher os campos de pontos de acesso dos materiais, fazendo uma ligação/relacionamento dos dados de autoridades controladas com os dados dos materiais bibliográficos. Esses relacionamentos serão de fundamental importância para um resultado satisfatório nas buscas realizadas pelos usuários dos catálogos online. O Quadro 6, a seguir, aponta os campos do MARC 21 para Dados Bibliográficos destinados para a inserção dos pontos de acesso dos materiais. 
Quadro 6 - Campos para descrição dos Pontos de Acesso no MARC 21 para Dados Bibliográficos

\begin{tabular}{|c|c|}
\hline $\begin{array}{c}\text { PONTOS DE ACESSO SEGUNDO O } \\
\text { AACR2 - PARTE II }\end{array}$ & $\begin{array}{c}\text { CAMPOS CORRESPONDENTES } \\
\text { NO MARC 21 Para Dados Bibliográficos }\end{array}$ \\
\hline Cabeçalhos para Pessoas & $\begin{array}{c}100 \text { - Entrada principal - Nome Pessoal } \\
600 \text { - Assunto - Nome Pessoal } \\
700 \text { - Entrada Secundária - Nome Pessoal }\end{array}$ \\
\hline Nomes Geográficos & 651 - Assunto - Nome Geográfico \\
751 - Entrada Secundária - Nome Geográfico \\
\hline Cabeçalhos para entidades & 110 - Entrada principal - Nome Corporativo \\
& 610 - Assunto - Nome Corporativo \\
& 111 - Entrada Secundária - Nome Corporativo \\
& 611 - Assunto - Nome de Evento \\
& 711 - Entrada Secundária - Nome de Evento \\
\hline Títulos Uniformes & 130 - Entrada principal - Título Uniforme \\
& 630 - Assunto - Título Uniforme \\
& 730 - Entrada Secundária - Título Uniforme \\
\hline
\end{tabular}

Fonte: elaboração própria, a partir de Ferreira (2013) e CÓDIGO...(2004).

Há casos em que os pontos de acesso para pessoas, nomes geográficos, entidades e títulos uniformes podem ser utilizados também como o assunto do material, tendo cada um o seu respectivo campo no MARC 21 para Dados Bibliográficos, conforme demonstrado no quadro acima. A Parte II do AACR2 prevê também as regras para o cadastro de remissivas, no entanto, conforme já mencionado, as remissivas dos pontos de acesso são registradas no formato MARC 21 para Dados de Autoridades.

Assim, as regras do AACR2, embora construídas com base em princípios e estruturas pensadas para a organização da informação em ambientes analógicos (por exemplo em fichas), foram transportadas para os sistemas automatizados, junto com os formatos de Intercâmbio e de descrição bibliográfica e seguiram cumprindo o seu papel para a padronização bibliográfica ao longo dos anos (ASSUMPÇÃO, 2013). 
Entretanto, com a chegada da web e da era digital, muitas mudanças vêm ocorrendo no cenário das bibliotecas,

As mudanças que se verificaram no ambiente da catalogação nas décadas de 1960 e 2000 foram enormes, não somente por causa da rápida proliferação de novos tipos de publicações, novas formas de conteúdo e novos suportes de conteúdo, mas também porque a passagem para um ambiente de rede em linha alterou qualitativamente a maneira como a biblioteca e seus usuários realizam suas atividades (OLIVER, 2011, p. 2).

Frente a essas mudanças e ao avanço tecnológico, impulsionou-se a necessidade de renovação e de criação de novas diretrizes e regras para a representação descritiva da informação, uma vez que o Código de Catalogação AngloAmericano foi originalmente construído para a descrição de materiais impressos.

\subsection{REGRAS DE DESCRIÇÃO: AATUALIZAÇÃO PARA O CONTEXTO DIGITAL}

A partir da década de 1990, com a chegada da web, ocorreu a popularização do uso do computador pessoal e da internet. Assim, as empresas e instituições passaram a adotar ambientes em rede como principal meio para a divulgação de informações e produtos com o uso dos websites. As bibliotecas acompanharam o avanço tecnológico e foram inseridas nesse novo contexto que se apresentava, em que a representação da informação ganhou um novo status frente à facilidade do acesso aos grandes conteúdos informacionais, proporcionados pelo ambiente digital. De acordo com Aquino e Silva (2011, p. 59), as tecnologias da informação estão diretamente relacionadas com os processos de recuperação da informação, pois "[...] facilitaram a expansão da mente e a ruptura das distâncias que se constituíam em barreiras para a comunicação humana".

Porém, convém destacar que as TICs não descartaram a análise e a interpretação humanas nos processos de organização e representação da informação para recuperação em sistemas, conforme salientado por Ribeiro (2012, p. 14):

Os procedimentos de organização e representação foram sempre uma necessidade natural, uma vez que são indispensáveis para recuperar e usar a informação. Tais procedimentos sofreram uma evolução em consonância com a complexidade dos contextos em que a informação foi sendo produzida ao longo dos tempos e, por isso, parece ser 
inquestionável que eles continuam (e continuarão) a ser necessários na Era Digital, apesar da existência de sofisticadas tecnologias, pois estas não dispensam a análise e a interpretação humanas, condições sine qua non para se conseguir o rigor próprio do conhecimento científico.

Com isso, cada vez mais o bibliotecário precisa conhecer as necessidades de informação de seus usuários para a realização de uma representação descritiva que possa atendê-los de forma satisfatória nas suas buscas. Isso está de acordo com o pensamento de Lêdo e Silveira (2017, p. 196), quando mencionam que "a Representação Descritiva não é uma atividade absolutamente técnica, pois o bibliotecário precisa refletir para catalogar, devendo sempre levar em conta o grupo de usuários para quem está catalogando". Nesse sentido, Almeida Júnior (2009) esclarece que todos os serviços dos profissionais da informação estão relacionados com a "mediação da informação" seja de forma implícita ou explícita,

O armazenamento de informações é alimentado a partir de interesses e demandas dos usuários. A política de seleção, amplamente discutida no desenvolvimento de coleções, tem o usuário final como base de sustentação. O mesmo se dá com os trabalhos de processamento das informações: têm suas ações voltadas para a recuperação de informações que atendam e satisfaçam necessidades dos usuários [...] (ALMEIDA JÚNIOR, 2009, p. 92).

Além disso, as próprias necessidades informacionais dos usuários das bibliotecas estão passando por transformações com o uso da tecnologia, de modo que, para suprir essas necessidades as bibliotecas precisam constantemente readaptar e atualizar seus instrumentos e padrões.

Após vários estudos nesse sentido, a IFLA publicou, no ano de 1998, os Functional Requirements for Bibliographic Records (FRBR ou Requisitos Funcionais para Registros Bibliográficos). Os FRBR não são códigos de catalogação, mas são modelos teóricos e conceituais criados com base no modelo entidade-relacionamento (E-R) aplicados no desenvolvimento de bases de dados relacionais e onde se identificam: as entidades dos registros bibliográficos, os atributos de cada entidade e as relações entre as entidades (MEY; SILVEIRA, 2009). No que se refere às entidades mencionadas, elas se dividem em 3 (três) grupos, sendo 1- os produtos da criação intelectual ou artística; 2- as pessoas físicas ou jurídicas que tenham ligação com a criação intelectual ou artística; e 3 - os assuntos dos produtos. Já os atributos 
se referem aos dados descritivos de cada entidade, ou seja, as características que cada entidade possui. O relacionamento é a ligação/relação entre essas entidades (OLIVER, 2011).

\begin{abstract}
Esse modelo apresenta um conjunto de entidades de interesse do universo bibliográfico, os atributos que caracterizam cada uma dessas entidades e os relacionamentos existentes entre elas, assim como ações, denominadas tarefas dos usuários, que demandam tais atributos e relacionamentos (ASSUMPÇÃO; SANTOS; ZAFALON, 2017 p. 26).
\end{abstract}

Acerca disso, Fusco (2011, p. 155) acrescenta que esses modelos conceituais possuem "[...] a pretensão de atingir todo tipo de informação, em qualquer suporte, atendendo assim, de maneira mais abrangente, as necessidades dos usuários". Os FRBR serviram de base para a criação de outros modelos conceituais, tais como os Functional Requirements for Authority Data (FRAD ou Requisitos Funcionais para Dados de Autoridades), publicados pela IFLA em 2009 como uma extensão dos FRBR (KINCY; LAYNE, 2014). Conforme explicado por Oliver (2011, p. 19) esses modelos conceituais "[...] mapeiam a relação entre o dado que é registrado, tanto em registros bibliográficos quanto de autoridades, e as necessidades daqueles que utilizarão esses dados".

De acordo com Mey e Silveira (2009, p. 87), a publicação dos FRBR provocou, entre outras coisas, a necessidade de "[...] revisões das ISBDs e dos Códigos de Catalogação, tanto por sua base teórica quanto pela adoção de uma nova terminologia na área”. De acordo com Ribeiro (2005), as normas precisariam ser repensadas e reelaboradas com base em uma nova fundamentação, e afirma:

A questão essencial está em saber se as normas internacionais aplicáveis à representação descritiva, concebidas num paradigma estático, tecnicista e documental, se ajustam e adequam ao novo paradigma dinâmico, científico e informacional (RIBEIRO, 2005, p. 95).

Com relação à terminologia, dentre outras coisas, a autora pondera que termos como cabeçalhos, entrada principal e entrada secundária, conforme aparecem nos códigos de catalogação tradicionais, associam-se aos catálogos manuais em fichas e não fazem mais sentido no contexto digital (RIBEIRO, 2005). Além disso, representar a informação na época das fichas catalográficas impressas exigia 
pontuações e abreviações extremamente rigorosas devido ao espaço limitado para a descrição, isso se torna muito diferente no ambiente digital.

Foi, portanto, com a publicação do modelo conceitual FRBR e com essa necessidade de se fazer revisões nos códigos de catalogação que se iniciaram os trabalhos em prol da atualização do AACR2. A princípio, a intenção era lançar o AACR3, porém os trabalhos de revisão do AACR2 culminaram na elaboração de um novo código de catalogação o qual foi denominado Resource Description and Access (RDA), conforme explicado por Machado e Pereira (2015, p. 299):

O AACR2 tornou-se obsoleto no que se refere a alguns requisitos para descrever documentos, especialmente no ambiente digital. Em vista disso, elaborou-se o Resource Description and Access, ou RDA, que na tradução para a língua portuguesa, significa Descrição e Acesso de Recursos, com o intuito de que o mesmo torne-se o novo código de catalogação e substitua o AACR2 a fim de melhorar a recuperação do conhecimento registrado nas bibliotecas.

Isso foi corroborado por Silva et al (2017, p.11), ao afirmarem que:

O RDA surgiu após várias propostas de reorganização e atualização do AACR2r em eventos ocorridos entre 1997 e 2004, procurando atender às exigências atuais referentes aos impactos das novas tecnologias. Porém, para que essas novas necessidades surgidas fossem atendidas, seriam necessárias profundas mudanças estruturais no código.

Percebe-se que o RDA foi criado sob a mesma estrutura de governança do AACR2, ou seja, também foi "[...] concebido pelo Joint Steering Committee (JSC) e contou com a participação de diversas instituições representantes de países, como a Austrália, Canadá, Estados Unidos e Inglaterra, entre outros" (MACHADO; PEREIRA, 2015, p. 299). A publicação oficial do RDA se deu no ano de 2010, trazendo significativas diferenças em relação ao AACR2, porém construído a partir dos pontos positivos do AACR2 (OLIVER, 2011; FUSCO, 2011).

Segundo Silva et al (2017), o RDA propõe regras mais simplificadas em relação ao AACR2, e projetadas para o ambiente digital. Dentre as diferenças básicas encontradas destacam-se: a própria estrutura do RDA; a não utilização de pontuações e abreviações, suprimindo o uso das expressões latinas como [et. al], [s.n]; [s.l]; 
mudanças na terminologia, por exemplo em lugar de cabeçalhos utiliza-se ponto de acesso, dentre outras (OLIVER, 2011).

Construída com base nos elementos dos modelos conceituais como os FRBR e FRAD, a estrutura do RDA se torna flexível e extensível podendo ser utilizada para descrição tanto de recursos tradicionais quanto não-tradicionais, analógicos e digitais. Desse modo, seu escopo é ampliado, podendo ser usada não só por bibliotecas, mas também por outras comunidades ligadas ao patrimônio cultural como arquivos, museus e repositórios digitais (OLIVER, 2011). Isso é muito importante uma vez que "as fronteiras entre comunidades de metadados não têm significado algum para o usuário que faz buscas num ambiente de rede em linha" (OLIVER, 2011, p. 4).

Diferentemente do AACR2, onde cada capítulo se dedica a um tipo de material, o RDA divide-se em duas grandes partes com instruções que podem ser aplicadas a qualquer tipo de material informacional, sendo que a primeira parte trata dos Atributos e a segunda parte descreve os Relacionamentos, além de possuir 12 apêndices. As duas partes do RDA são divididas em dez seções (JSC-RDA, 2009; FUSCO, 2011), da seguinte forma:

- Atributos $\rightarrow$ abrange as Seções de 1 a 4: 1. Registro de atributos de manifestação e item; 2. Registro de atributos de obra e expressão; 3 : Registro de atributos de pessoa, família e entidade coletiva; 4. Registro de atributos de conceito, objeto, evento e lugar.

- Relacionamentos $\rightarrow$ abrange as Seções de 5 a 10: 5. Registro de relações primárias; 6. Registro de relações para pessoas, famílias e entidades coletivas associadas a um recurso; 7. Registro de relações de assuntos; 8. Registro de relações entre obras, expressões, manifestações e itens; 9. Registro de relações entre pessoas, famílias e entidades coletivas; e 10. Registro de relações entre conceitos, objetos, eventos e lugares.

Segundo Silva et al (2017, p. 14), "o RDA surge em um novo contexto de descrição, cujas regras foram projetadas para a descrição de documentos digitais e de acesso online”. Portanto, o RDA foi "[...] designado para ser o sucessor do AACR2, que foi pensado e desenvolvido para descrever documentos analógicos" (SILVA et al., 
2017, p. 22). Para apoiar a utilização do RDA, a LC vem atualizando e alterando o formato MARC 21. Essas atualizações envolvem a inclusão e a modificação de alguns campos e subcampos de modo a torná-los compatíveis com as regras do novo código de catalogação e facilitando a descrição de materiais nos diversos tipos de suporte. Dentre essas atualizações do MARC 21, visando sua adequação ao RDA, destaca-se a criação dos seguintes novos campos: campo 336 para a descrição do Tipo de conteúdo; Campo 337 para Tipo de mídia; e 338 para Tipo de suporte (ASSUMPÇÃO, 2013; LIBRARY OF CONGRESS, 2014).

No Brasil, ainda há grande utilização do AACR2 como código de catalogação, porque, conforme explicado por Machado e Pereira (2015, p. 309), "o novo código é um instrumento com padrões catalográficos diferenciados e que ainda está em fase de análise entre os profissionais da área". Nesse sentido, Aganette e Teixeira (2017, p. 182) argumentam:

[...] O RDA não é um código em vigor uma vez que está em fase de "alinhamento" pois precisa de testes para resolver alguns problemas. Sendo assim, a LC - Library of Congress (Biblioteca do Congresso) iniciou sua implantação apenas em janeiro de 2013, a Biblioteca Nacional do México iniciou os testes para implantação do RDA no catálogo de autoridades e no Brasil os estudos e testes com o RDA fazem parte de algumas iniciativas isoladas.

Atualmente, registros bibliográficos feitos com base no RDA podem ser encontrados no catálogo on-line da LC dos EUA. Na figura a seguir, apresenta-se um exemplo do registro bibliográfico de um livro feito pela LC, segundo o novo código RDA, permitindo-nos ter uma noção das adaptações feitas no MARC, para atendimento ao novo código. 
Figura 5 - Registro de um livro nos campos MARC conforme o RDA.

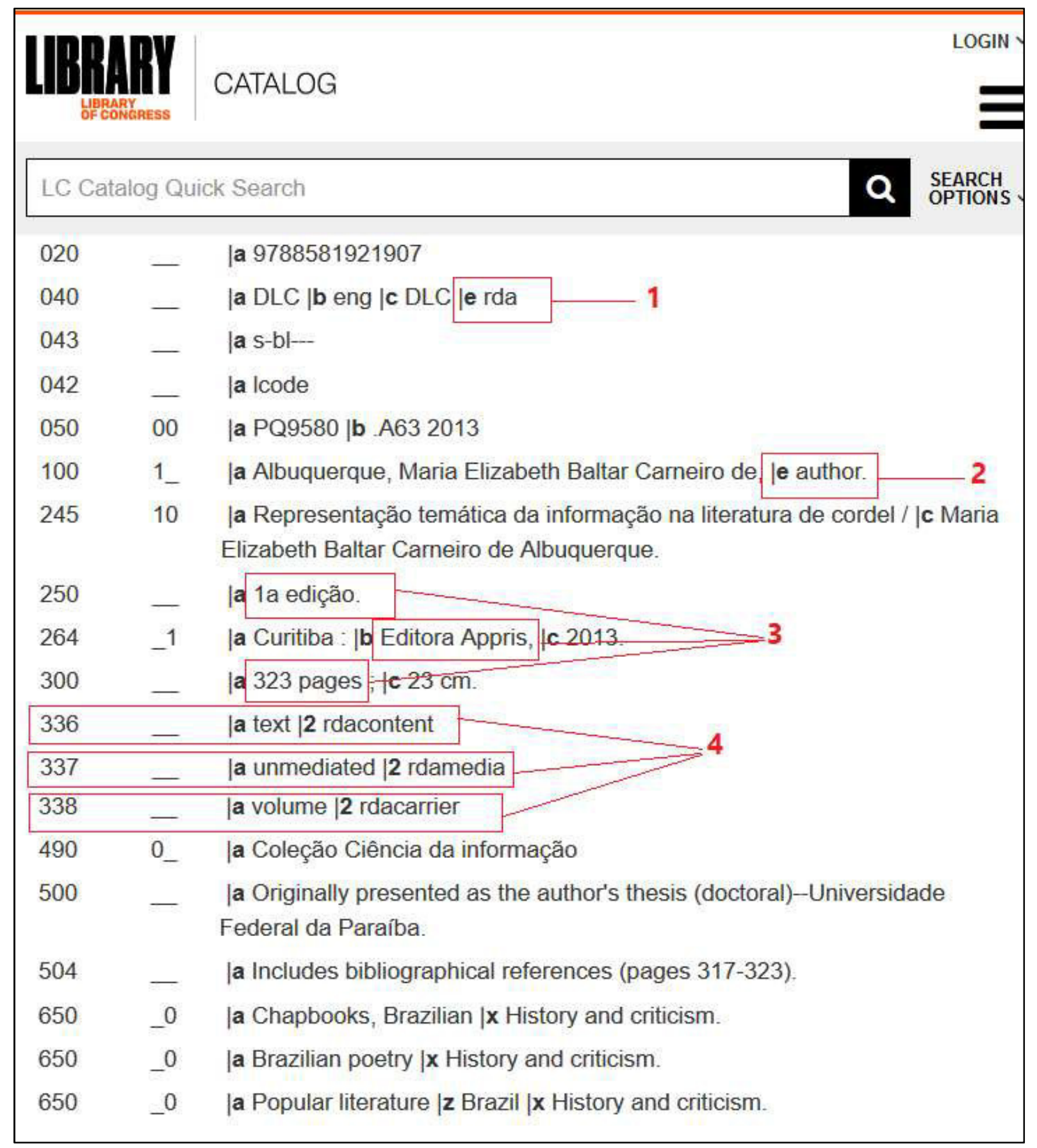

Fonte: adaptado de LC Catalog. Disponível em: https://catalog.loc.gov. Acesso em 10 jan. 2019.

Na figura acima, foram marcados quatro pontos que demonstram algumas diferenças na descrição do livro, para atender às normas do RDA, que são:

1) no campo 040, designado para Fonte da Catalogação, foi incluído o subcampo le onde é informada a regra de descrição usada na criação do registro, ficando, portanto: 040 |a DLC |b eng |c DLC |e rda 
2) no campo 100, designado para o autor principal, foi incluído o subcampo \$e, destinado à função que descreve a relação entre o nome da pessoa e a obra, portanto, 100 1_ |a Albuquerque, Maria Elizabeth Baltar Carneiro de, |e Autor.

3) nos campos 250, 264 e 300, designados respectivamente para: edição, dados de publicação e descrição física, observa-se que não são mais utilizadas abreviações (por exemplo 1. ed., 232 p., Ed. Apris), agora, em RDA, as informações aparecem escritas por extenso. É interessante destacar também que, conforme explicado por Ferreira (2013), o campo 264 foi criado em 2011 e é semelhante ao campo 260 (imprenta), a diferença é que, caso a instituição catalogadora necessite, o campo 264 possui indicador que permite fazer distinção entre funções: produtor, publicador, distribuidor, manufatureiro ou informação de copyright.

4) foram incluídos, no registro acima, os novos campos: 336 para Tipo de conteúdo, 337 para Tipo de mídia e 338 para Tipo de suporte, sendo que cada um destes campos foi preenchido com os seguintes subcampos: |a Termo do tipo de conteúdo, mídia ou suporte, e $\mid 2$ fonte de onde foi consultado o tipo de conteúdo, mídia ou suporte.

Entre as iniciativas brasileiras, o Sistema de Bibliotecas da Universidade Caxias do Sul (UCS) vem utilizando o RDA nos seus registros de controle de autoridades (TEIXEIRA, 2013). Além disso, a Biblioteca Central Irmão José Otão, da Pontifícia Universidade Católica do Rio Grande do Sul (PUCRS) divulgou oficialmente a implantação do RDA como código de catalogação a partir de 2016, e segue realizando aprimoramentos no seu sistema (TEIXEIRA, 2017; AMORIM; PEREIRA, 2017).

Ao consultar o catálogo on-line da LC percebe-se que os registros antigos permanecem em AACR2 e os mais recentes em RDA e assim revelam a necessidade, que as bibliotecas poderão ter, de adotar sistemas que permitam a "aderência" aos dois códigos, conforme ressaltado por Serra (2013). Nota-se, portanto, que a mudança para o novo código é uma evolução necessária, porém vem ocorrendo de modo gradativo. De acordo com Serra (2013, p.15), 
Estas mudanças não serão realizadas em curto prazo, porém cabe aos catalogadores iniciarem estudos e capacitação nas regras do RDA planejando sua aplicação cientes dos limites inerentes ao formato MARC, evidenciando quais os ajustes são necessários e quais características um novo formato que suporte estas demandas deve apresentar.

Além disso, conforme destacado por Oliver (2011, p. 6) "a implantação da RDA terá impacto imediato nos catalogadores e também nos projetistas de sistemas para bibliotecas" (OLIVER, 2011, p. 6). Com isto, é possível afirmar que ainda há um caminho a ser percorrido para que o RDA alcance a predominância como o código de catalogação vigente no Brasil. Sendo assim, percebe-se que o AACR2 deverá estar presente nas mãos dos bibliotecários brasileiros, ainda por algum tempo. 


\section{CONHECENDO OUTROS FORMATOS DE INTERCÂMBIO}

Conforme já mencionado, no campo da Biblioteconomia, muitos formatos de intercâmbio surgiram para a representação de dados bibliográficos, em diversos países. A maioria desses formatos manifestou-se como uma variação do original formato MARC, desenvolvido na década de 1960 pela LC. Com o passar dos anos, algumas dessas variações continuaram em vigor, porém outras foram abandonadas para dar lugar ao próprio MARC, principalmente com o lançamento do MARC 21, em 1998, o qual vem passando por novas atualizações desde então. Entretanto, apesar de ter sido a pioneira na criação de um padrão de descrição legível por máquina, a LC não foi a única instituição, na época, preocupada em desenvolver e compartilhar meios para a padronização dos registros bibliográficos.

A década de 1970 foi marcada pelo esforço de organizações internacionais no desenvolvimento de programas com o fito de promover um controle da produção bibliográfica dos países. Dentre as iniciativas, destacam-se, por exemplo, a criação do Controle Bibliográfico Universal (CBU) e também do United Nations International System for Information in Science and Technology (UNISIST ou Sistema de Informação das Nações Unidas em Ciência e Tecnologia).

O Controle Bibliográfico Universal (CBU) foi desenvolvido pela Organização das Nações Unidas para a Educação, Ciência e Cultura (UNESCO), em parceria com a Federação Internacional das Associações e Instituições Bibliotecárias (IFLA), e teve por objetivo "[...] reunir e tornar disponíveis os registros da produção bibliográfica de todos os países, concretizando assim o ideal do acesso de todos os cidadãos ao conjunto do conhecimento universal" (CAMPELLO, 2006, p. 12). Com o intuito de efetivar esse controle, a biblioteca nacional de cada país passou a exercer o papel de Agência Bibliográfica Nacional, com duas funções primárias: 1) preparar os registros oficiais e completos de cada nova publicação editada, de acordo com normas catalográficas internacionais; e 2) divulgar esses registros, com a maior rapidez possível, na bibliografia nacional (CAMPELLO, 2006).

\subsection{O MANUAL DE REFERÊNCIA UNISIST}

Foi também na tentativa de coordenação das atividades de documentação e informação, em nível mundial, que surgiu o UNISIST, na década de 1970, fruto de 
um projeto que vinha sendo desenvolvido pela UNESCO. Conforme ressaltado por Campello (2006, p. 12), o UNISIST surgiu em 1972, com a finalidade de

[...] promover a coordenação de ações de cooperação no campo da informação científica e tecnológica, o que levaria a uma rede flexível de sistemas e serviços de informação, baseada em cooperação voluntária, cuja meta seria a livre circulação da informação em ciência e tecnologia.

Com a criação desse sistema, a UNESCO desenvolveu e lançou o Manual de Referência UNISIST, publicado a primeira vez nos anos 70 e tendo sua segunda edição publicada em 1981 (UNESCO, 1981). A segunda edição pode ser consultada, atualmente, via internet ${ }^{1}$. O objetivo desse manual foi salientado por Marcondes e Sayão (1991, p. 248):

[...] o Programa Geral de Informação PGI/UNESCO e a UNISIST desenvolveram e ampliaram o "Reference Manual for Machine Readable Bibliografic Description". Este manual de referência tem como objetivo fundamental servir de formato padrão de intercâmbio de informações bibliográficas entre bases de dados bibliográficas e qualquer outro serviço de Informações bibliográficas; se apóia fundamentalmente na Norma ISO-2709, assim como em outras normas ISO.

O Manual UNISIST ressalta que há uma distinção entre o formato de entrada dos dados, com o qual o bibliotecário catalogador tem contato para o preenchimento dos campos e subcampos, e o formato de intercâmbio, o qual segue o layout da Norma ISO 2709 e é gerado automaticamente, permitindo a transmissão do registro entre computadores. O IBICT (1987) também explicou essa diferença ao mencionar que,

O formato de entrada, que é visto pelo usuário através de formulário de captação de dados ou tela de terminal de vídeo, tem relação com o formato de intercâmbio, mas não necessariamente se iguala a ele. Entretanto, embora possam utilizar conceitos e estruturas diferentes, é imprescindível que o formato de entrada seja transformável, automaticamente, no formato de intercâmbio. Ou seja, sua estrutura e conteúdo devem ser mapeáveis, através de programa de computador, na estrutura e conteúdo do formato de intercâmbio. Para tanto, as

${ }^{1} \mathrm{O}$ documento completo do Manual de Referência UNISIST encontra-se disponível no endereço https://unesdoc.unesco.org/ark:/48223/pf0000047859 onde pode ser acessado nos idiomas inglês, francês ou espanhol. 
regras de tratamento de seu conteúdo de informação devem necessariamente ser compatíveis ou transformáveis nas regras de tratamento especificadas pelo formato de intercâmbio (IBICT, 1987, p. 11)

Apesar de ser um modelo de aplicação da Norma ISO 2709, visando principalmente essa codificação/transformação dos dados de entrada para o intercâmbio maquina a máquina, o Manual de Referência UNISIST define também a representação dos elementos obrigatórios e complementares da própria descrição bibliográfica de entrada, demonstrando, de forma detalhada, como os campos devem aparecer em um registro para torná-lo legível por máquina e intercambiável (UNESCO 1981). O manual contém, inclusive, exemplos práticos do preenchimento dos campos, indicadores e subcampos, facilitando assim o trabalho dos produtores de bases de dados na época, conforme foi salientado por Dierickx (1985, p. 8, tradução nossa):

[...] todo formato de intercâmbio a ser usado com eficiência requer o desenvolvimento de um formato de entrada ou implementação local compatível. O fato de o Manual de Referência já conter os elementos necessários para a descrição bibliográfica facilita essa tarefa e promove a padronização dos formatos de entrada locais.

Além disso, o Manual de Referência UNISIST define diferentes níveis bibliográficos nos quais os documentos devem ser tratados, sendo:

a) Nível Analítico (A): quando o documento é parte de um trabalho maior e não pode ser descrito sozinho. Por exemplo: o capítulo de um livro, o artigo de uma revista, etc.;

b) Nível Monográfico $(M)$ : quando o documento constitui uma entidade bibliográfica independente, mesmo que faça parte de uma coleção ou série. Por exemplo: um livro, uma monografia etc.;

c) Nível Coleção (C): quando o documento é composto por dois ou mais trabalhos. Por exemplo: todos os trabalhos de um autor, reeditados em um ou mais volumes; enciclopédias sistemáticas etc;

d) Nível de Publicação Seriada (S): quando o documento é publicado em partes sucessivas, contendo informação numérica/cronológica, e pretende continuar indefinidamente. Por exemplo: revistas, publicações periódicas etc. (UNESCO, 1981). 
Observa-se, portanto, que a descrição de um livro pode envolver mais de um nível de descrição quando este fizer parte de uma série ou coleção. Para exemplificar isso, na Figura 6 apresenta-se o preenchimento de um registro bibliográfico, conforme as convenções do manual, para o seguinte material monográfico que é parte de uma série:

WELLISCH, Hans H. The conversion of Scripts - its Nature, History and Utilization. New York, Wiley, 1978. xviii, 509 p. (Hayes, Robert, M.; Becker, Joseph (editores). Infomation Science Séries). Bibliografia pp. $441-461$. ISBN 0-471-01620-9.

Figura 6 - Exemplo do registro bibliográfico de entrada, conforme as convenções do Manual UNISIST

\begin{tabular}{|c|c|}
\hline Campos & \\
\hline 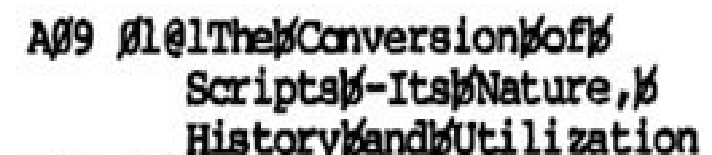 & Titulo - monografla \\
\hline Aø3 g1elinformationbscience & Título - publicación \\
\hline 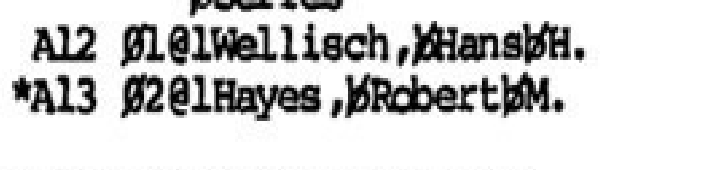 & $\begin{array}{l}\text { Autor - monografla } \\
\text { Editor - publicación } \\
\text { seriada }\end{array}$ \\
\hline ॠA13 W2@1Becker, KJoseph & $\begin{array}{l}\text { Editor - publicación } \\
\text { seriada }\end{array}$ \\
\hline *A15 Ø1elUniversi tybof Maryland & Afiliación - monografia \\
\hline 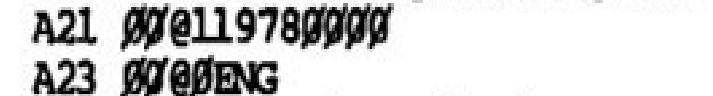 & $\begin{array}{l}\text { Fecha de publicación } \\
\text { Idioma del documento }\end{array}$ \\
\hline A25 ope1wileye2NewbYork & Editor \\
\hline A26 $\phi 2 \phi-471-\phi 162 \phi-9$ & ISBN \\
\hline $\begin{array}{l}\text { A29 oxelxviii, } 65 \% 9 \\
\text { A51 oxeous }\end{array}$ & $\begin{array}{l}\text { Clación - monografla } \\
\text { osdigo del pals de } \\
\text { publicación }\end{array}$ \\
\hline 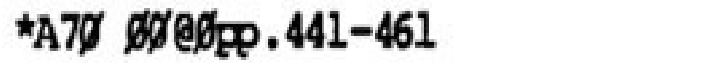 & Nota de bibliografia \\
\hline
\end{tabular}

Fonte: UNESCO (1981).

Em linhas gerais, percebe-se que o registro ora ilustrado foi composto de campos, indicadores e subcampos nos quais são usadas letras, números e delimitadores diferenciados do padrão MARC, porém com uma estrutura parecida. Além disso, percebe-se que as diretrizes do Manual UNISIST já previam a ligação de diferentes segmentos em um único registro, permitindo a catalogação do material no 
todo e em partes, ligando, por exemplo, o registro de um artigo ao seu periódico de origem, ou um capítulo de livro ao livro como um todo. O MARC, no princípio, foi projetado para os materiais monográficos no todo, porém com sua evolução, passou a abranger também os itens que são parte de outros materiais fazendo também a ligação entre eles dentro de um único registro.

O mesmo registro bibliográfico demonstrado na Figura 6 aparece na Figura 7, porém já codificado/transformado no layout para o intercâmbio em meio magnético, notando-se a existência do líder, do diretório e dos campos variáveis, em forma sequencial.

Figura 7 - Codificação do registro para o intercâmbio em meio magnético, conforme as convenções do Manual UNISIST

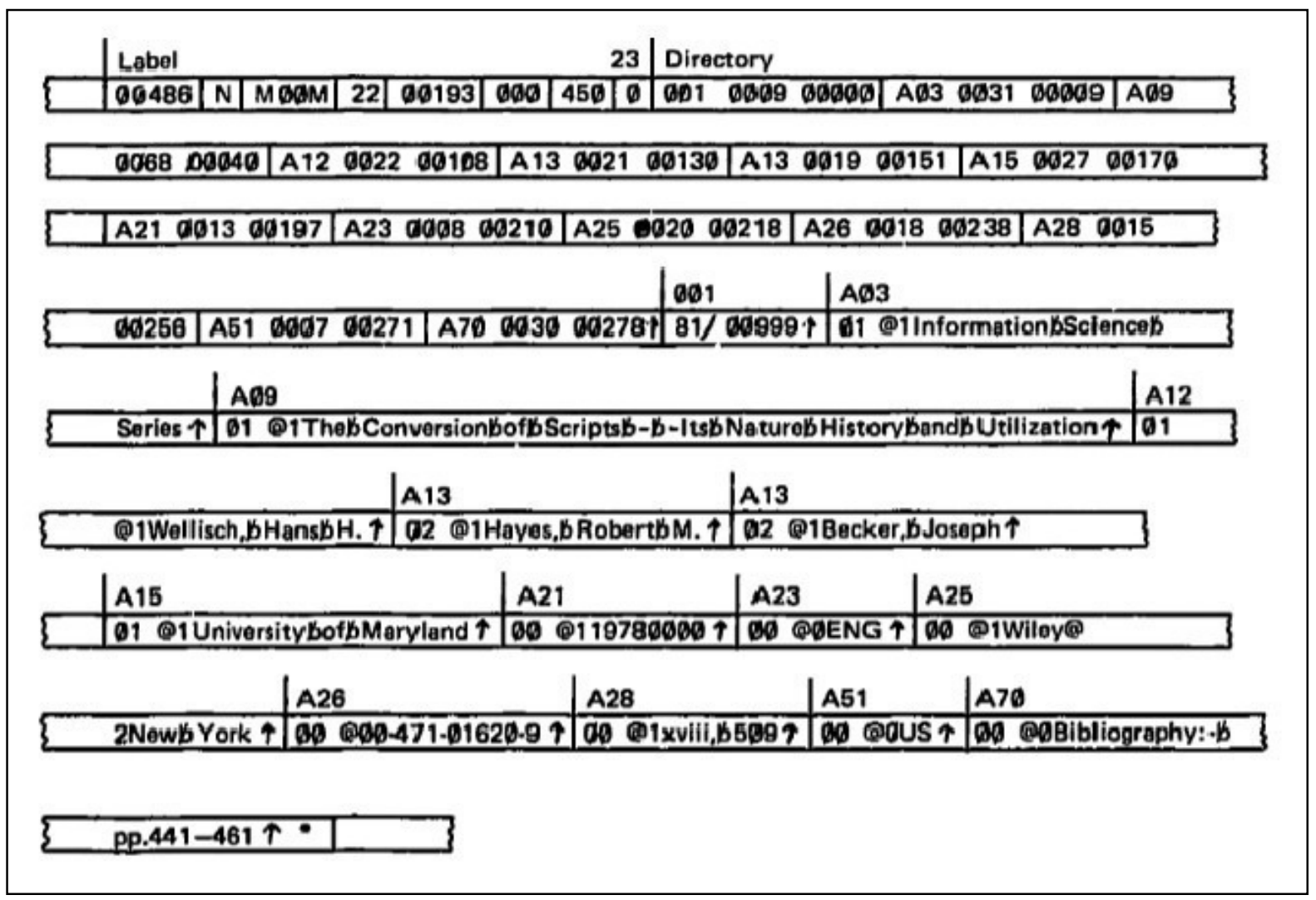

Fonte: UNESCO (1981).

Dessa forma, assim como o MARC, a partir de 1970, o Manual de Referência UNISIST também passou a servir como fonte de instruções para o desenvolvimento de formatos de descrição bibliográfica, possibilitando a atuação do intercâmbio de registros bibliográficos, principalmente entre bases de dados de periódicos científicos. Foi, por exemplo, a partir do Manual UNISIST, que a Comissão 
Econômica para a América Latina e o Caribe (CEPAL) criou, na década de 1980, o formato CEPAL. Foi também de acordo com as convenções desse manual que o Centro Latino-Americano e do Caribe de Informação em Ciências da Saúde (mais conhecido pela sigla BIREME) criou um formato para a base de dados em Literatura Latino-Americana e do Caribe em Ciências da Saúde (LILACS), denominado de formato LILACS. Esses dois formatos serão abordados com mais detalhes adiante.

Na época, o Manual de Referência UNISIST foi considerado flexível por não se prender ao uso das regras de catalogação específicas, permitindo maior liberdade na catalogação. De acordo com Dierickx (1985), essa flexibilidade em relação às regras foi considerada positiva, porém, ocasionou limitações na compatibilidade com os sistemas que utilizam o padrão MARC.

\subsection{O FORMATO CALCO: IMPLEMENTAÇÃO DO MARC NO BRASIL}

No Brasil, no início da década de 1970, o formato MARC II foi adaptado por meio do projeto de CAtalogação Legível por COmputador (CALCO), tendo sido implementado pela bibliotecária Alice Príncipe Barbosa, na Fundação Getulio Vargas do Rio de Janeiro (OKADA; ORTEGA, 2009; MOURA; COSTA, 2016). O projeto deu origem ao formato CALCO e "[...] serviu como base para o desenvolvimento de sistemas de catalogação automatizados na Fundação Getulio Vargas (FGV) e na Universidade Federal do Rio Grande do Sul (UFRGS)" (IBICT, 1987, p. 7). Nesse sentido, Silva e Souza (2011, p. 5) argumentam que,

[...] o Projeto CALCO foi desenvolvido tendo em vista a possibilidade de cooperação entre as bibliotecas, fazendo com que uma obra já catalogada não precisasse sê-la feita novamente por uma outra biblioteca, e com isso estabelecer significativa economia de escala, bem como dinamizar a relação entre as bibliotecas.

No entanto, é interessante destacar que, na década de 1970, ainda não se almejavam os serviços on-line, assim, esses trabalhos de automação bibliográfica "[...] estavam voltados principalmente para racionalizar a geração de produtos, tais como fichas catalográficas, etiquetas de lombada e bibliografias, entre outros" (BETTENCOURT, 2014, p. 127). Nesse cenário, o objetivo principal do CALCO era promover o intercâmbio de registros bibliográficos entre as bibliotecas brasileiras. "Foi com esse formato que a Fundação Getulio Vargas, no Rio de Janeiro, criou a então 
rede Bibliodata/CALCO de catalogação cooperativa [...]" (OKADA; ORTEGA, 2009, p. 26).

Além disso, "[...] foi desenvolvido, também, pela Fundação, um software específico para registro do acervo de suas próprias bibliotecas em computador" (MONTE-MÓR; CYSNEIROS, 1982, p. 138). Assim, em 1976 a Rede Bibliodata/CALCO foi pioneira no Brasil na criação de uma rede de catalogação cooperativa, segundo Silva e Souza (2011, p. 5).

Nos anos de 1980, o trabalho cooperativo da Rede Bibliodata/CALCO promovia uma catalogação descentralizada, realizada em cada biblioteca participante. Os registros eram feitos em formulários preenchidos à mão, em fitas magnéticas ou em disquetes gravados a partir do software fornecido pela FGV. Já o processamento desses dados em computador ocorria de forma centralizada na própria Fundação Getulio Vargas (MONTE-MÓR; BOTELHO, 1987).

A Biblioteca Nacional (BN) aderiu ao sistema Bibliodata/CALCO, oficialmente, em abril de 1982, e, nessa época, fazia a descrição bibliográfica dos materiais em formulários/folhas de catalogação em formato CALCO (BETTENCOURT, 2014). As bibliotecas participantes da rede preenchiam e remetiam esses formulários à FGV para o processamento dos dados no catálogo coletivo da Rede Bibliodata/CALCO e geração dos produtos e serviços.

A Figura 8, a seguir, mostra um modelo desse formulário utilizado pela rede de bibliotecas do Sistema Bibliodata/Calco, na década de 1980. 
Figura 8 - Formulário usado para catalogação no Formato CALCO (continua...)

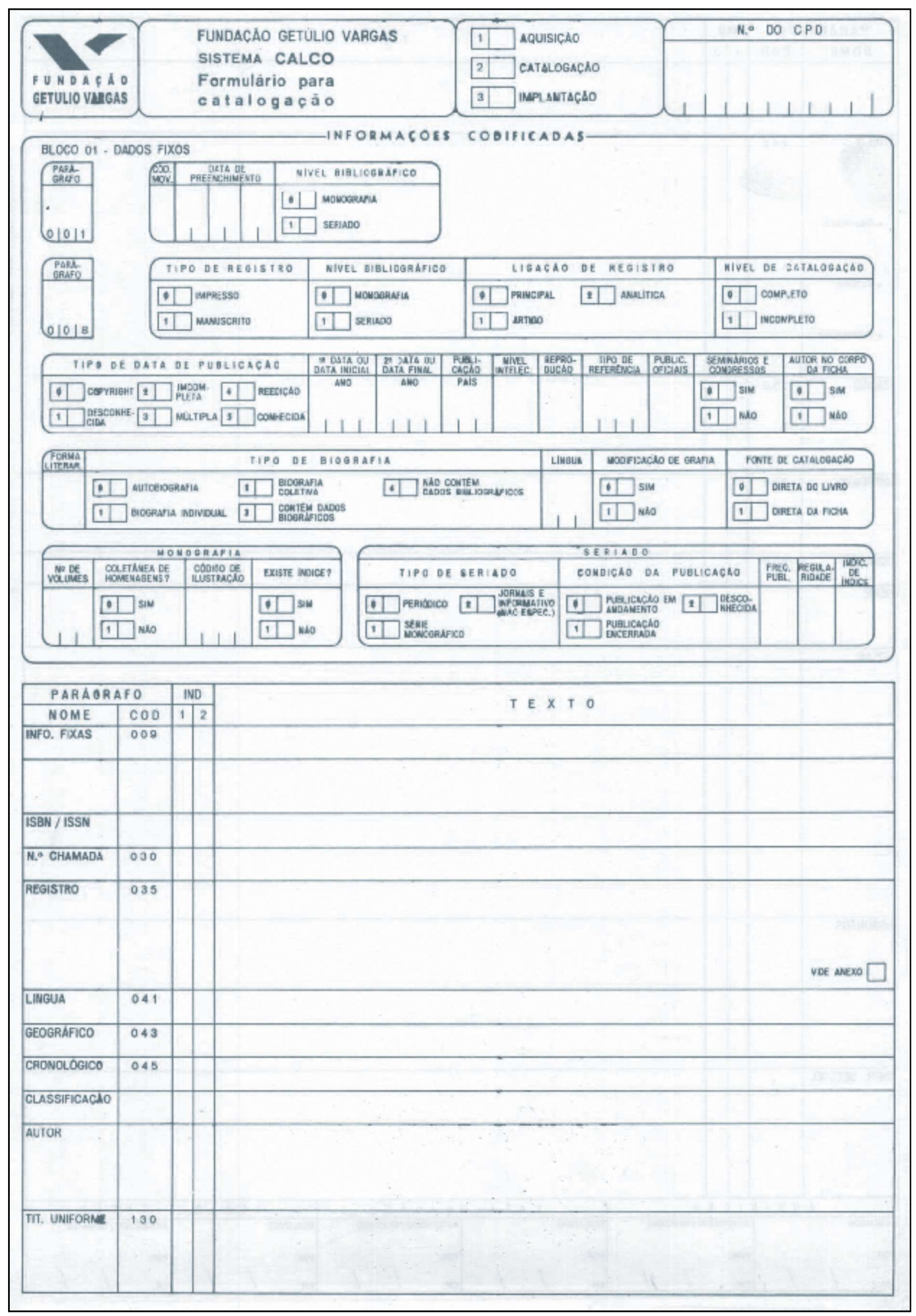




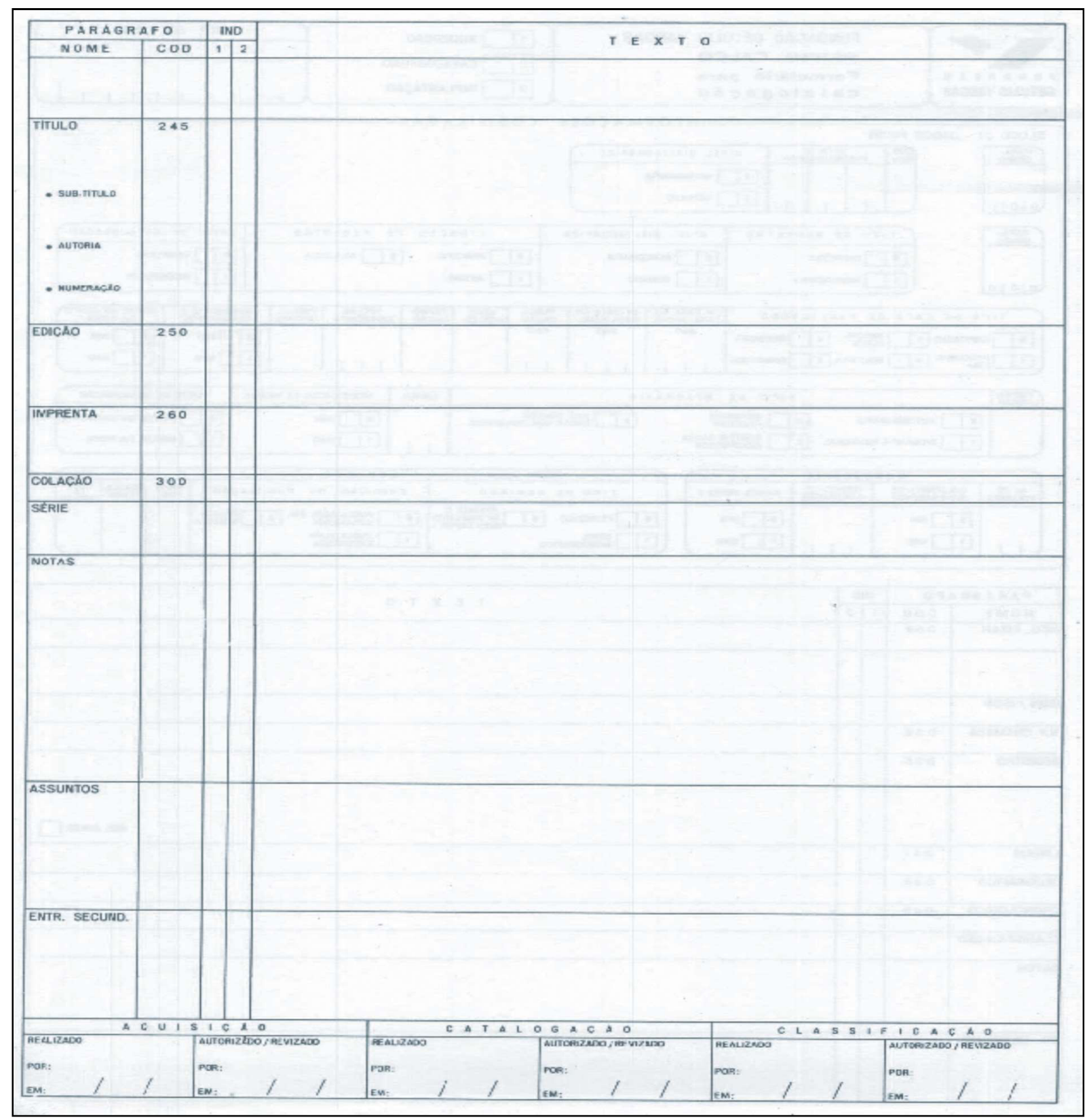

Fonte: Bettencourt (2014, p. 187).

Já na década de 1990, o formato CALCO deixou de ser utilizado e, com isso, a rede cooperativa passou a se chamar apenas Rede Bibliodata (MOURA; COSTA, 2016; SILVA; SOUZA, 2011). Acerca disso, Vasconcellos (1996, p. 3) relata:

Infelizmente, o sistema Calco ficou estagnado por mais tempo do que o desejável. O principal motivo desta estagnação é que a Rede não conseguia gerar os recursos financeiros necessários para ampliação do equipamento que havia sido inicialmente disponibilizado pela FGV para instalação do catálogo coletivo. A contribuição pecuniária das bibliotecas cooperantes cobria apenas os custos operacionais da Rede e, eventualmente, nem isso, necessitando constantemente do suporte financeiro provido pela FGV. 
Assim, a Rede Bibliodata deixou de desenvolver um formato de intercâmbio próprio e passou a adotar diretamente os padrões de descrição atualizados LC. Em 1996, em consequência de um plano de modernização tecnológica, houve uma mudança de software e os registros da Rede Bibliodata foram convertidos do formato CALCO para o então formato USMARC da LC (VASCONCELLOS, 1996, p. 4). Acompanhando o avanço tecnológico, a Rede Bibliodata passou a disponibilizar serviços on-line, sendo que, atualmente, as bibliotecas cooperadas utilizam o formato MARC 21 na descrição bibliográfica (MOURA; COSTA, 2016).

\begin{abstract}
A biblioteca ao encontrar o registro pertinente ao livro que deseja catalogar faz uma cópia de registro, podendo acrescentar ou modificar informações com características locais. Não encontrando o registro do livro a ser catalogado a biblioteca efetuará a catalogação desse novo registro. Este registro será incorporado ao Catálogo Coletivo da Rede Bibliodata e ficará à disposição para as outras bibliotecas participantes da Rede. Facilitando assim este processo de catalogação (SILVA; SOUZA, 2011, p. 6).
\end{abstract}

A partir de 2015, a Rede passou a funcionar sob a responsabilidade do IBICT. O acesso ao seu catálogo on-line passou a ser restrito às instituições que assinaram o Termo de Adesão com o IBICT (FGV, 2016).

\title{
5.3 O FORMATO UNIMARC: NA ROTA DO CONTROLE BIBLIOGRÁFICO UNIVERSAL
}

Diante da grande quantidade de variações de formatos criados a partir do MARC em diferentes países, começaram a surgir preocupações concernentes à incompatibilidade no intercâmbio entre sistemas. Com isso, no ano de 1977, a IFLA lançou o UNIMARC com o propósito de ser um padrão MARC universal tornando os dados compatíveis entre os sistemas. Assim, esse formato foi concebido como um "denominador comum" para o intercâmbio de informações, e com esta função foi oficialmente adotado pelas bibliotecas nacionais europeias, facilitando assim a compatibilidade no intercâmbio internacional de dados bibliográficos entre agências responsáveis pelas bibliografias nacionais (MARTíNEZ; RAMON, 1999). 
O formato UNIMARC foi criado em 1977 pela IFLA, voltado à descrição de monografias e publicações seriadas, como um formato de intercâmbio entre agências nacionais de catalogação; Apesar de ter sido criado como formato de intercâmbio, o formato UNIMARC é mais utilizado como formato de registro do que em sua função de intercâmbio, constituindo-se, junto com o MARC 21, como as maiores fontes de definição para uso deste formato (CORDEIRO, 2008 apud OKADA; ORTEGA, 2009, p. 26).

Em 1991, a IFLA formou o Comitê Permanente do UNIMARC com o objetivo de administrar o desenvolvimento deste formato de acordo com os princípios do Controle Bibliográfico Universal (CBU). Em 2003 foi criado o Programa Estratégico UNIMARC com a responsabilidade de realizar a sua manutenção e o seu desenvolvimento (IFLA, 2018). Com isso, o formato UNIMARC vem passando por atualizações constantes e é bastante utilizado por bibliotecas principalmente na Europa. Um exemplo de sua utilização é a rede de bibliotecas portuguesas PORBASE,

A PORBASE é o catálogo colectivo em linha das bibliotecas portuguesas. Estabelecida em 1986, a PORBASE é coordenada pela Biblioteca Nacional de Portugal (BNP) e está disponível ao público desde Maio de 1988, sendo actualmente a maior base de dados bibliográficos do país, que reflecte não só as colecções da BNP como também de mais 180 outras bibliotecas portuguesas de variados tipos e dimensões, tanto públicas como privadas (BNP, 2018, on-line).

O formato legível por computador definido na PORBASE é o UNIMARC, tanto para registos bibliográficos como de autoridade. A descrição bibliográfica segue as Regras Portuguesas de Catalogação (RPC, reimp. 1996), que por sua vez seguem a ISBD - International Standard Bibliographic Description e se baseiam nas AACR2 - AngloAmerican Cataloguing Rules (BNP, 2018, on-line).

O catálogo PORBASE está disponível para consultas na internet ${ }^{2}$, onde inclusive é possível visualizar a representação descritiva dos materiais nos campos do formato UNIMARC. A título de exemplo, a Figura 9 mostra a representação descritiva de um livro feita nos campos do formato UNIMARC, em um registro do catálogo on-line da Biblioteca Nacional de Portugal.

${ }^{2}$ O catálogo PORBASE está disponível para consultas em http://porbase.bnportugal.pt/. 
Figura 9 - Registro de livro no Formato UNIMARC no Catálogo da Biblioteca Nacional de Portugal

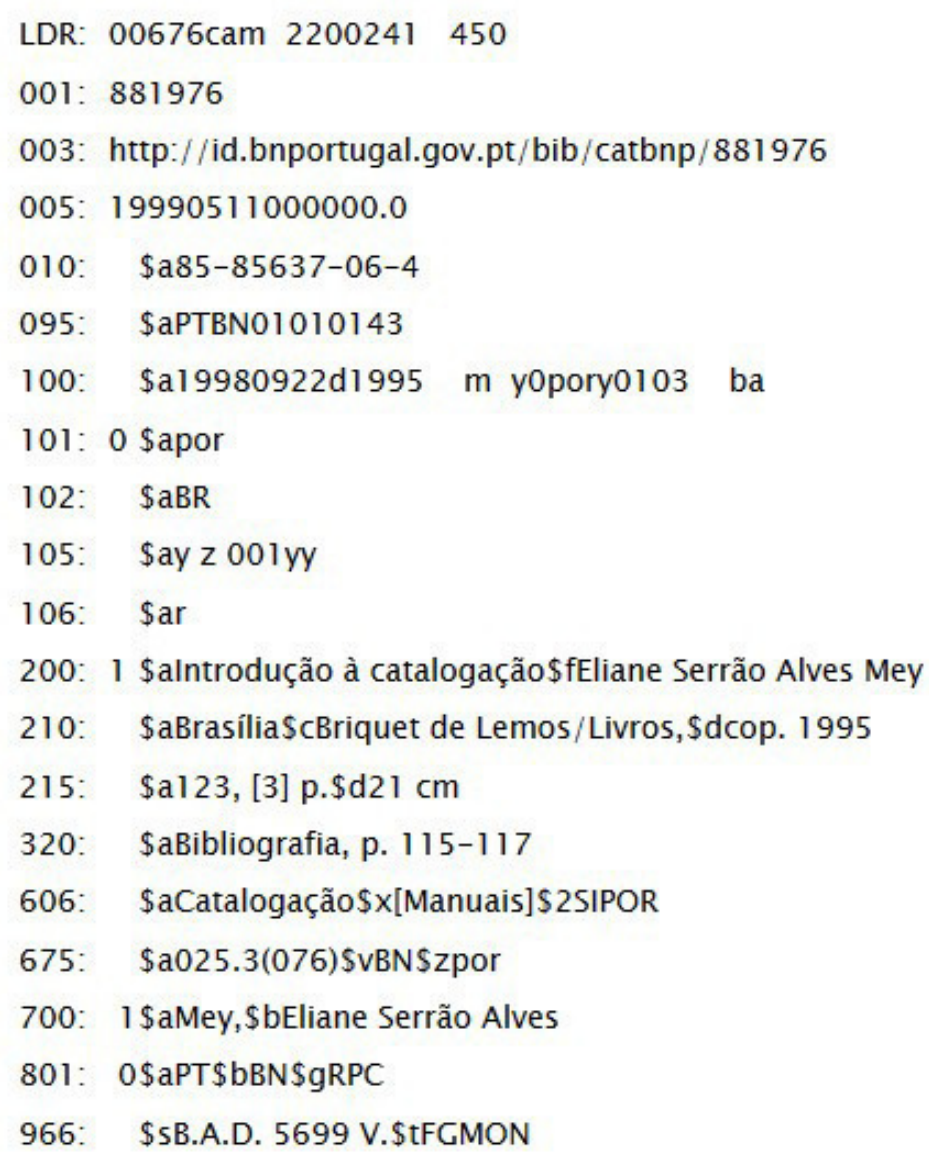

Ver Detalhe Bibliográfico | Exportar registo em ISO2709

Fonte: Biblioteca Nacional de Portugal. Disponível em: http://catalogo.bnportugal.pt. Acesso em 12 jan. 2019.

$\mathrm{Na}$ Figura acima nota-se a descrição bibliográfica do livro impresso Introdução à catalogação, da autora Eliane Serrão Alves Mey, nos campos e subcampos do formato UNIMARC.

\subsection{O FORMATO CCF: UMA “PONTE” ENTRE O MARC E O MANUAL UNISIST}

Além dos formatos que se desenvolveram a partir do MARC ou do Manual UNISIST, destaca-se ainda, no final da década de 1970, o Common Comunication Format (CCF ou Formato Comum de Comunicação), criado pela UNESCO. "O CCF, com características mais modernas e mais amplas, foi desenvolvido repensando os formatos existentes permitindo maior liberdade na entrada de dados" (LIMA et al,1992, p. 204). De acordo com Martínez e Ramon (1999, p. 29), o formato CCF foi criado com 
o objetivo de compatibilizar o formato UNIMARC (que universaliza os padrões MARC) com o Manual de Referência UNISIST.

Na Figura 10, é possível ter uma noção de como se apresentava a descrição de um livro nos campos e subcampos do formato CCF.

Figura 10 - Registro de material informacional em formato CCF.

\begin{tabular}{|c|c|c|c|}
\hline Tag & $\begin{array}{l}\text { Seg } \\
\text { Iden }\end{array}$ & $\begin{array}{l}\text { Occur } \\
\text { Iden }\end{array}$ & Data Fields \\
\hline 001 & 0 & 0 & $92-10167$ \\
\hline 020 & 0 & 0 & 00@ATate Gallery \\
\hline 021 & 0 & 0 & $11 @ A A$ \\
\hline 022 & 0 & 0 & $100 \mathrm{~A} 19920318$ \\
\hline 030 & 0 & 0 & $00 \oplus \mathrm{B} 2$ \\
\hline 031 & 0 & 0 & 00@Aeng \\
\hline 040 & 0 & 0 & 00@Aeng \\
\hline 050 & 0 & 0 & $00 @ A 10$ \\
\hline 060 & 0 & 0 & $00 \otimes A 100$ \\
\hline 100 & 0 & 0 & $00 @ A 0-9518717-0-6$ \\
\hline 200 & 0 & 0 & $\begin{array}{l}01 @ \text { AVisual arts and crafts guide to the new law } \\
\text { of copyright and moral rights@BHenry Lydiate }\end{array}$ \\
\hline 300 & 0 & 0 & $00 \oplus$ ALydiate@BHenry \\
\hline 400 & 0 & 0 & $00 \otimes A$ [London] BBBritannia Publications \\
\hline 440 & 0 & 0 & $00 @ A 19910000$ \\
\hline 460 & 0 & 0 & $000 \mathrm{~A} 34 \mathrm{p} . \mathrm{C}_{2} 1 \mathrm{~cm}$. \\
\hline 480 & 0 & 0 & 00@AArtlaw \\
\hline 540 & 0 & 0 & 00 AThe Copyright Act, 1956 \\
\hline 610 & 0 & 0 & $00 @ \mathrm{~A} 7: 347.78 @ \mathrm{CU}$ \\
\hline 620 & 0 & 0 & 00@ACopyright@AArt - Law@9 \\
\hline
\end{tabular}

Fonte: UNESCO (1994, p. 76).

A figura acima mostra a descrição de um livro cujo título é Visual arts and crafts guide to the new law of copyright and moral rights, do autor Henry Lydiat. Notase, por exemplo, que o título está registrado no campo 200 e o autor no campo 300, sendo que, cada campo possui seus indicadores e subcampos. Para Marcondes e Sayão (1991), o formato CCF surgiu, de certa forma, da comparação entre os elementos de dados dos principais formatos de intercâmbio existentes na época. Os autores explicam que,

Em fins da década de 1970, a própria UNESCO, alertada para os prejuízos da disseminação de formatos nacionais calcados no MARC mas nem sempre compatíveis entre si, desenvolveu e propôs o CCF (Common Comunication Format). Isto se deu a partir do Simpósio 
Internacional sobre Formatos Bibliográficos para Intercâmbio, promovido pelo PGI/UNESCO em cooperação com o UNISIST, ICSUAB, IFLA, ISO. Este evento resultou na criação do CCF - Common Comunication Format, Formato Comum de Comunicação. O objetivo mais importante do CCF era servir de formato "ponte" entre os formatos da família MARC e os baseados no Manual de Referência do UNISIST [...] (MARCONDES; SAYÃO, 1991, p. 249).

De acordo com Hopkinson (1985), no momento de sua criação, o formato CCF era destinado particularmente àquelas instituições que possuíam registros de monografias e seriados, registros de artigos de periódicos, de anais de congressos e outras partes de documentos físicos, que constituem unidades intelectualmente independentes, comumente criados pelos serviços de indexação e resumos. O CCF foi fundamentado na norma ISO 2709 e não adotou um código de catalogação em particular (HOPKINSON, 1985). Não foi possível encontrar exemplos de redes de bibliotecas com catálogo on-line que ainda estejam usando este formato.

\title{
5.5 O FORMATO LILACS: UNINDO INFORMAÇÕES BIBLIOGRÁFICAS DA SAÚDE
}

A metodologia LILACS ou Literatura Latino-Americana e do Caribe em Ciências da Saúde "[...] foi desenvolvida a partir de 1982, e surgiu diante da necessidade de uma metodologia comum para o tratamento descentralizado da literatura científica-técnica em saúde produzida na América Latina e Caribe" (BIREME, 2008, p. 3).

A base de dados LILACS abrange, atualmente, 26 (vinte e seis) países e é um produto coordenado pelo Centro Latino-Americano e do Caribe de Informação em Ciências da Saúde (BIREME). O seu catálogo pode ser acessado via internet. ${ }^{3}$

\begin{abstract}
Estabelecida no Brasil em 1967, com o nome de Biblioteca Regional de Medicina (que originou a sigla BIREME), atendeu desde o princípio à demanda crescente de literatura científica atualizada por parte dos sistemas nacionais de saúde e das comunidades de pesquisadores, profissionais e estudantes. Posteriormente, em 1982, passou a chamar-se Centro Latino-Americano e do Caribe de Informação em Ciências da Saúde para melhor expressar as suas funções orientadas ao fortalecimento e ampliação do fluxo de informação científica e técnica em saúde em toda a região, mas conservou sua sigla (BIREME, 2008, p. 1).
\end{abstract}

\footnotetext{
${ }^{3}$ A base LILACS pode ser acessada pelo endereço eletrônico http://lilacs.bvsalud.org/.
} 
O formato LILACS de descrição bibliográfica, desenvolvido pela BIREME, foi criado segundo as diretrizes do Manual de Referência UNISIST, porém, a partir de 2006, começou a ter adaptações baseadas no formato MARC 21 (BIREME, 2008).

Dada a capilaridade do formato MARC em todo o mundo, a qual se ampliou nos últimos anos, observamos mostras de influência deste formato sobre os outros. O formato LILACS, por exemplo, já incorporou vários elementos do formato MARC (como lista de conteúdos de tipo de material do campo 008, listas para forma do item, tipo de periódico, inclusão de campos específicos de Notas, e outros) (ORTEGA, 2009, p. 186).

A Figura a seguir, mostra como se apresenta a descrição de um material monográfico em formato LILACS.

Figura 11 - Registro de material informacional em Formato LILACS

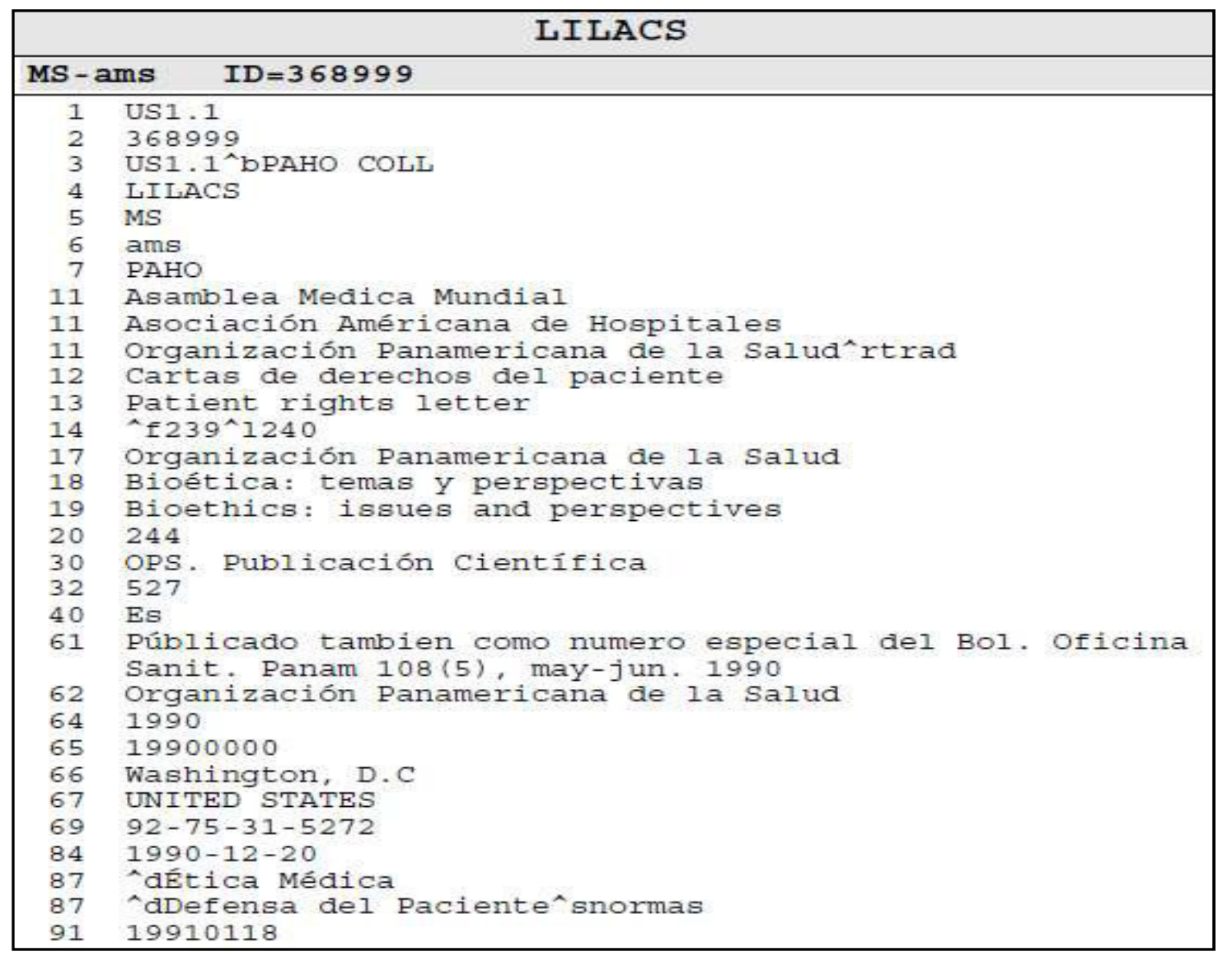

Fonte: Adaptado de BIREME (2008, p. 128).

Na Figura 11, nota-se, por exemplo, que os atributos do material estão distribuídos em campos nos quais se faz uso de sinais diacríticos, tal como $\circ^{\wedge}$. 
Percebe-se, por exemplo, que o título do item está descrito no campo 12, o ISBN da publicação está no campo 69 e os assuntos estão lançados no campo 87.

De acordo com a BIREME (2008), a padronização dos elementos de dados no formato LILACS segue as normas do AACR2, os padrões da International Standard Organization (ISO) e outros.

\subsection{O FORMATO CEPAL: GERANDO BASES BIBLIOGRÁFICAS NA AMÉRICA} LATINA

Na década de 1980, a Comissão Econômica para a América Latina e o Caribe (CEPAL), com sede em Santiago no Chile, desenvolveu o formato CEPAL com base nas orientações do Manual de Referência UNISIST e pautado também no AACR2 e em normas ISO. Segundo Martínez e Ramon (1999), a princípio, este formato foi criado para atender comunidades bibliográficas da área de Ciências Sociais, porém se expandiu também para outras áreas.

O formato CEPAL contou com três edições $(1984,1989,1993)$ e foi distribuído para bibliotecas em conjunto com o software livre desenvolvido pela UNESCO, sendo inicialmente o MicroISIS e depois o WinISIS. O software MicroISIS foi a primeira versão para microcomputadores do Computerized Documentation System / Integrated Scientific Information System (CDS/ISIS). Esse sistema CDS/ISIS surgiu em 1975, sendo fruto de uma parceria da UNESCO com a Organização Internacional do Trabalho (OIT), e começou a ser distribuído de forma gratuita, a partir da década de 1980, com o objetivo de facilitar a organização da informação bibliográfica, principalmente nos países em desenvolvimento. Na década de 1990, o MicrolSIS evoluiu para sua versão Windows, passando a se chamar WinISIS (ORTEGA, 1998; MARTÍNEZ; RAMÓN, 1999).

Já no ano de 2008, o WinISIS evoluiu para sua versão web, chamada de Automação de Bibliotecas e Centros de Documentação (ABCD). O software ABCD continua sendo livre e de acesso aberto e, além do formato CEPAL, comporta, atualmente, também o formato MARC 21 (SMET; SPINAK, 2009; CASTRO; BARBOZA, 2011).

Na Figura 12, é possível verificar a lista geral de definição dos campos do formato CEPAL. 
Figura 12 - Definição dos Campos do Formato CEPAL

\begin{tabular}{|c|c|c|c|}
\hline Número & Nombre & Número & Nombre \\
\hline 01 & Nombre del archivo & 42 & Información descriptiva \\
\hline 03 & Ubicación & 43 & Fecha de publicación \\
\hline 04 & Tipo de literatura & 44 & Fecha normalizada (ISO) \\
\hline 06 & Nivel de registro & $\begin{array}{l}44 \\
45\end{array}$ & Símbolo (Naciones Unidas) \\
\hline 10 & Autor personal - nivel analítico & $\begin{array}{l}45 \\
47\end{array}$ & $\begin{array}{l}\text { IImbolo (Naciones Unidas) } \\
\text { ISBN }\end{array}$ \\
\hline 11 & Autor institucional - nivel analítico & 47 & ISBN \\
\hline 12 & Título - nivel analítico & 48 & \\
\hline 14 & Páginas - nivel analítico & 52 & Conferencia: institución \\
\hline 16 & Autor personal - nivel monográfico & 53 & Conferencia: nombre \\
\hline 17 & Autor institucional - nivel monográfico & 58 & Proyecto: institución \\
\hline 18 & Título - nivel monográfico & 59 & Proyecto: nombre \\
\hline 20 & Páginas - nivel monográfico & 63 & Formato \\
\hline 23 & Autor personal - nivel colección & 64 & Idioma del texto \\
\hline 24 & Autor institucional - nivel colección & 68 & Notas \\
\hline 25 & Título - nivel colección & 72 & Resumen \\
\hline 27 & $\begin{array}{l}\text { litulo - nivel coleccion } \\
\text { Número de volúmenes }\end{array}$ & 73 & Referencias bibliográficas \\
\hline 29 & & 76 & Descriptores: contenido temático \\
\hline $\begin{array}{l}29 \\
30\end{array}$ & $\begin{array}{l}\text { Editor institucional de publicación seriada } \\
\text { Título de publicación seriada }\end{array}$ & 77 & Descriptores: contenido estadístico \\
\hline 31 & $\begin{array}{l}\text { Título de publicación seriada } \\
\text { Volumen de publicación seriada }\end{array}$ & 80 & Categoría temática primaria \\
\hline $\begin{array}{l}31 \\
32\end{array}$ & $\begin{array}{l}\text { Volumen de publicación seriada } \\
\text { Número de publicación seriada }\end{array}$ & 81 & Categoría temática secundaria \\
\hline 33 & $\begin{array}{l}\text { Número de publicación seriada } \\
\text { Periodicidad de publicación seriada }\end{array}$ & 83 & Países primarios \\
\hline 34 & Existencias de publicación seriada & 84 & Países secundarios \\
\hline 35 & ISSN & 95 & Indicador de publicación \\
\hline 38 & Editorial & 98 & Indicador de procedencia \\
\hline 39 & Ciudad de la editorial & 100 & Enlace a recursos electrónicos \\
\hline 41 & Edición & & \\
\hline
\end{tabular}

Fonte: adaptado de Arendt (2003, p. 15).

Atualmente, a Comissão Econômica para a América Latina e o Caribe não está atualizando mais o formato CEPAL para descrição e o intercâmbio de registros bibliográficos. No catálogo on-line da Biblioteca da CEPAL é possível verificar que a representação descritiva dos materiais já está sendo feita em formato MARC 21. Assim, a tendência é que as bases de dados bibliográficas que usam o formato CEPAL sejam convertidas para o formato MARC 21.

\subsection{O FORMATO IBICT: UMA EVOLUÇÃO DO CALCO NO BRASIL}

O IBICT, com o apoio da UNESCO, desenvolveu no ano de 1986, o Formato de Intercâmbio BIbliográfico e CaTalográfico (Formato IBICT) com o intuito de tornálo o padrão de intercâmbio oficial no Brasil. Com esta iniciativa, o IBICT almejava regulamentar a forma, o conteúdo e o meio pelo qual as instituições, no Brasil, fariam o intercâmbio de informações bibliográficas e catalográficas para processamento em computador (MELGAÇO, 1989, p. 351). 
Assim, em 1987, foi publicado no Brasil o manual de utilização deste novo formato, como sendo uma evolução do formato CALCO (IBICT, 1987), numa tentativa de estabelecer um formato de intercâmbio nacional. Construído a partir do formato CALCO, que foi seu antecessor no Brasil, o formato IBICT seguiu os pilares do código de catalogação AACR2 e da Norma ISO 2709, sendo composto por: Líder, Diretório e Campos de dados (IBICT, 1987). Além de possuir semelhanças com o padrão MARC, advindas do próprio CALCO, conforme explicado por Melgaço (1989, p. 355), o formato IBICT foi ainda enriquecido com características do formato CCF e do UNIMARC. Na Figura 13, é possível observar a descrição de um livro nos campos do formato IBICT.

Figura 13 - Registro de um livro nos Campos do Formato IBICT

\begin{tabular}{|c|c|c|}
\hline \multicolumn{3}{|c|}{ Monografia no todo } \\
\hline Líder & & N1M2 \\
\hline 001 & & $000456-8$ \\
\hline 008 & & 180886LM119811981 BSPbьbbb6RAbZNSX4PORN2NAbbbNNbbbbbb \\
\hline 010 & $0 \mathrm{Ob}$ & $\$ a 000087-7$ \\
\hline 010 & 16 & $\$ a 000226-7$ \\
\hline 041 & 16 & $\begin{array}{l}\text { \$aPOR } \\
\text { \$cFRE }\end{array}$ \\
\hline 082 & бе & $\begin{array}{l}\text { \$a303.33 } \\
\text { \$b19.ed. }\end{array}$ \\
\hline 100 & 10 & $\begin{array}{l}\text { \$aLebrun, Gerard } \\
\text { \$d1930- }\end{array}$ \\
\hline 245 & 12 & $\begin{array}{l}\text { \$aO que é poder } \\
\text { \$eGerard Lebrun } \\
\text { \$eTradução de Renato Janine Ribeiro e Silvia Lara Ribeiro } \\
\text { \$eCaricaturas de Emilio Damiani }\end{array}$ \\
\hline 250 & bы & \$a3.ed. \\
\hline 260 & $\mathbf{O b}$ & $\begin{array}{l}\text { SaSão Paulo } \\
\text { SbBrasiliense }\end{array}$ \\
\hline 261 & вь & \$a1981 \\
\hline 300 & bb & $\begin{array}{l}\$ a 122 \mathrm{p} \\
\text { \$bil. } \\
\text { \$c16 cm. }\end{array}$ \\
\hline 440 & 10 & $\begin{array}{l}\text { \$c16 cm. } \\
\text { \$aColeçấo primeiros passos } \\
\text { \$vn. } 24\end{array}$ \\
\hline 500 & b6 & \$aContém dados biográficos \\
\hline 504 & bb & \$aBibliografia: p. 120-22 \\
\hline 650 & bb & $\begin{array}{l}\text { \$aPoder } \\
\text { \$xCiências Sociais }\end{array}$ \\
\hline 700 & 11 & \$aRibeiro, Renato Janine \\
\hline 700 & 11 & SaRibeiro, Silvia Lara \\
\hline
\end{tabular}

Fonte: adaptado de IBICT (1987, p. 382).

Conforme já mencionado, a intenção do Instituto Brasileiro de Informação em Ciência e Tecnologia era que o formato IBICT se tornasse o padrão de Intercâmbio oficial do Brasil. No entanto, alguns entraves dificultaram a implantação do formato IBICT, conforme salientado por Marcondes e Sayão (1991), o Instituto lançou o 
formato, porém, não dispunha, na época, de um software adequado para a implementação e distribuição dele nas instituições.

De acordo com Ortega (1998), o IBICT chegou a ser o distribuidor oficial, no Brasil, do software MicroISIS, desenvolvido pela UNESCO, entretanto, o formato IBICT não era completamente compatível com esse software, o qual era mais indicado para receber outros formatos construídos com base no Manual UNISIST, tal como o já mencionado formato CEPAL e o LILACS. Com isso, o uso do formato IBICT com o software MicrolSIS não chegou a se expandir muito no Brasil (MARCONDES; SAYÃO, 1992; ORTEGA, 1998). 


\section{A ERA DA WEB E OS PADRÕES DE METADADOS}

A partir da década de 1990, com a chegada da web, um grande avanço ocorreu no modo de compartilhar informações nos catálogos de bibliotecas, entretanto, houve a permanência do uso dos Códigos de Catalogação e das normas anteriormente estabelecidas para a representação descritiva, conforme explicado por Assumpção, Santos e Zafalon (2017, p. 31):

Os catálogos digitais, com seus dados bibliográficos e de autoridade, passaram a ser disponibilizados na Web e, apesar do novo ambiente tecnológico, os instrumentos de descrição, regras de catalogação e formatos para o intercâmbio de dados, principalmente, mantiveram-se em certa medida imutáveis, contribuindo, assim, para uma reprodução na $W e b$ do mesmo modelo de dados utilizado nos catálogos digitais anteriores a ela.

Assim, no ambiente da web, o formato MARC manteve o destaque como um rico padrão de metadados estruturados, muito utilizado para a representação da informação no campo da Biblioteconomia. No entanto, na era digital, a representação da informação ganhou força e importância de tal forma que ultrapassou os limites da biblioteca. A partir dos anos de 1990, com a proliferação do uso dos computadores e a popularização da internet, diferentes instituições e empresas começaram a usar essas ferramentas para a divulgação e comercialização dos mais diversificados produtos e serviços, necessitando, para isso, representá-los no ambiente digital para posterior busca e acesso do usuário. Para atender a essa demanda, muitos padrões de metadados começaram a ser desenvolvidos com estruturas mais simplificadas em relação ao MARC 21 das bibliotecas. Conforme já mencionado em capítulos anteriores, embora o termo metadados tenha se popularizado, recentemente (a partir da década de 1990), cerca de 30 (trinta) anos antes, na década de 1960, surgia o formato MARC, que pode ser considerado, portanto, o primeiro padrão de metadados.

É importante acrescentar que não apenas a padronização dos metadados, mas também outros recursos advindos da Biblioteconomia tradicional começaram a ser aplicados também na construção dos websites, tais como: o uso de vocabulários controlados, os tesauros e as classificações hierárquicas e facetadas. A aplicação dessas "estruturas de representação da informação" ocorre hoje, não somente no 
âmbito das bibliotecas, mas em diferentes contextos na web (ROSENFELD; MORVILLE; ARANGO, 2015).

Dentre as instituições que têm se sobressaído no desenvolvimento dos padrões de metadados, Lourenço (2005) destaca a Dublin Core Metadata Initiative (DCMI) que vem trabalhando em um padrão com base no próprio MARC: o Dublin Core, que pode ser codificado com a linguagem de marcação HTML ${ }^{4}$. A autora aponta também a Wold Wide Web Consortium (W3C), instituição desenvolvedora do padrão Resource Description Framework (RDF), um padrão baseado na linguagem $\mathrm{XML}^{5}$. O XML é "[...] também um produto da W3C que tem como principal foco de pesquisa o estudo e aperfeiçoamento da semântica na web" (LOURENÇO, 2005, p. 59). Essas iniciativas também foram mencionadas por Gracio (2002, p. 31):

\begin{abstract}
Iniciativas importantes para ajudar a resolver o problema da descrição de recursos na Web têm surgido, como a "Dublin Core Metadata Iniciative" (DCMI), que envolve profissionais de diversas áreas e países trabalhando juntos nas discussões sobre como metadados podem ajudar a resolver esse problema, e o "Resource Description Framework" (RDF), uma aplicação de metadados em XML com o objetivo de facilitar a utilização de pacotes de metadados diversos.
\end{abstract}

Além dessas instituições, a própria LC tem desenvolvido esquemas de metadados para contextos específicos, como, por exemplo, o Metadata Object Description Schema (MODS) que é um esquema de metadados para a descrição de objetos; e também o Metadata Authority Description Schema (MADS), um esquema de metadados para a descrição de registros de autoridades (ASSUMPÇÃO, SANTOS 2015).

Os estudos de Caplan (2003) e Serra et al (2017) trazem à atenção o formato Online Information eXchange (ONIX), um padrão de metadados criado pelo EDItEUR, um grupo internacional que desenvolve a infraestrutura de padrões para o comércio eletrônico nos setores relacionados ao mercado editorial de livros e publicações seriadas. Esse padrão de metadados tem sido utilizado por varejistas,

\footnotetext{
${ }^{4}$ HyperText Markup Language (HTML) é uma linguagem de marcação utilizada para visualizar e editar páginas da internet. As linguagens de marcação, como a HTML e a eXtended Markup Language (XML) são utilizadas para que os metadados sejam armazenados e codificados em meio legível por programas de computador (BETTENCOURT, 2014).

5 Extensible Markup Language (XML) é um padrão desenvolvido em 1996 “[...] para representação e transporte de informações na web [...]. A portabilidade, que significa não depender de plataformas de hardware ou de software, torna a XML fundamental para a interoperabilidade entre sistemas” (BETTENCOURT, 2014, p. 67).
} 
atacadistas, distribuidores e outras partes da cadeia de fornecedores de livros, ebooks e periódicos.

No Brasil, a Biblioteca Digital de Teses e Dissertações (BDTD), do IBICT, criou o Padrão Brasileiro de Metadados para Teses e Dissertações (MTD-BR), para a representação descritiva e disponibilização de arquivos relativos a teses e dissertações em formato eletrônico em bibliotecas digitais (LOURENÇO, 2005).

Além desses exemplos de padrões de metadados mencionados, muitos outros vem sendo criados para o uso em diferentes contextos da web. Assim, de acordo com Gracio (2002, p. 21), "o termo metadados possui um significado ou um conceito de acordo com o profissional e a área em que é utilizado, mas tem sempre como objetivo principal a descrição da informação para sua busca e recuperação".

Conforme ressaltado por Formenton (2015), existe uma distinção entre padrão de metadados de domínio bibliográfico, como é o caso do MARC 21 , e os padrões de metadados de domínio Web, tal como o Dublin Core. O autor acrescenta:

A concepção de metadados está fundamentada na tradicional atividade de catalogação em bibliotecas, cuja principal função é descrever um recurso informacional de forma única, multidimensionando suas formas de acesso, garantindo sua recuperação pelo usuário final. No domínio bibliográfico temos como exemplo, o padrão ou formato de metadados MARC 21 , que está baseado em regras de codificação definidas pela segunda edição do Anglo-American Cataloguing Rules (AACR2). Já no domínio Web temos o Dublin Core (DC), cuja finalidade é a de localizar recursos na Web. O termo domínio Web deve ser entendido como o domínio relacionado aos diferentes tipos de ambientes informacionais digitais na $W e b$, bem como os variados tipos de recursos disponibilizados nela por diferentes domínios do conhecimento (FORMENTON, 2015, p. 54, grifo nosso).

Conforme salienta Gracio (2002, p. 26), diferentemente do MARC 21, os padrões de metadados criados para descrever recurso em geral na internet, tal como o Dublin Core, tendem a ser mais simples.

Os padrões criados para descrever informações bibliográficas e catalográficas, como o MARC, possuem um conjunto de elementos complexos e rígidos, necessitando de especialistas para a descrição desses elementos. Diferente desses padrões, os padrões criados para a descrição de recursos disponíveis na Internet têm a característica de possuir um conjunto de elementos mais simples, em menor quantidade e flexíveis, o que facilita a descrição desses elementos pelo próprio autor do recurso ou por administradores de sites. Essa 
simplicidade é o segredo para sua rápida utilização na Web (GRACIO, 2002, p. 26)

No entanto, isto não significa que os padrões de metadados simplificados, como o Dublin Core, substituirão os mais complexos, como o MARC 21, ou ainda que um seja melhor em relação ao outro. Para Alves (2010, p. 61), "é necessário saber que cada tipo de padrão apresenta uma funcionalidade e valor em ambientes informacionais digitais". A autora argumenta que o grau de complexidade dos padrões de metadados aumenta de acordo com a especificidade do domínio em que se aplicam.

Os padrões de metadados ricos ou altamente estruturados caracterizam-se por serem específicos de um domínio. Por mais que se busque uma maior funcionalidade e flexibilidade dos padrões de metadados por meio de estruturas simples de descrição, não é possível evitar a complexidade de descrição, criada pela necessidade de especificidade em um domínio. Por esse motivo, os padrões de metadados ricos apresentam uma estrutura de descrição formal, baseada em normas e códigos especializados, e um nível de descrição detalhado, ou seja, descrevem o recurso informacional com especificidade. $O$ formato MARC 21 se constitui como um exemplo de formato ou padrão de metadados desta tipologia no domínio bibliográfico. O formato MARC reflete o grau de desenvolvimento e especificidade da área de Biblioteconomia em relação à descrição de diversos tipos de recursos informacionais em uma unidade de informação (ALVES, 2010, p. 61).

Dessa forma, cada domínio ou ambiente digital específico define o padrão de metadados que melhor atende às suas necessidades, entretanto, é possível ter a utilização de padrões diferentes dentro de um mesmo domínio (GRACIO, 2002). Por exemplo, no estudo realizado por Yamane e Castro (2018) são mapeados os padrões de metadados utilizados especificamente para a representação de imagens digitais na web. Os autores apontam 8 (oito) padrões de metadados que podem ser adotados no domínio específico das imagens digitais: o Dublin Core, o próprio MARC 21, o Metadata Object Description Schema (MODS), o Metadata for Digital Still Images Standarts Committee (MIX), o International Press Communications Council (IPTC), o Core VRA, o Extensible Metadata Platform (XMP), e o Picture Licensing Universal System (PLUS).

No campo da Biblioteconomia tem-se observado o emprego do MARC 21 associado ao padrão Dublin Core. Nessa perspectiva, Caplan (2003) ressalta que o 
Dublin Core é um padrão de metadados criado para o contexto da web em geral, porém tem sido usado com frequência no âmbito das bibliotecas. Assumpção e Santos (2015) também apontam que o padrão Dublin Core é muito utilizado no domínio bibliográfico, embora não tenha sido projetado para atender às necessidades de tal domínio. Sendo assim, optou-se por incluir, no presente estudo, o cotejamento dos elementos do padrão Dublin Core com o formato MARC 21 para Dados Bibliográficos. Para tal, as características do Dublin Core são melhor detalhadas a seguir.

\subsection{O DUBLIN CORE: UM PADRÃO SIMPLIFICADO}

No ano de 1995, em Dublin, Ohio (EUA), um grupo de 50 profissionais se reuniu em um workshop intitulado "OCLC/NCSA Metadata Workshop". Nesse evento, organizado pelo Online Computer Library Center (OCLC) e o National Center for Supercomputing Applications (NCSA), foi definido um conjunto semântico de elementos básicos para representar e organizar recursos em ambiente web. Esse conjunto de elementos foi chamado de "Metadados Dublin Core" com base na localização do evento (DCMI, 2017).

Conforme explicado por Gracio (2002, p. 41), foi também como resultado desse evento que surgiu a Dublin Core Metadata Iniciative (DCMI), uma "[...] organização dedicada a promover a difusão da adoção de padrões de metadados". A DCMI é composta por profissionais representando instituições de diversas áreas (Museus, Bibliotecas Digitais, Instituições Educacionais, Informática e outras), os quais "[...] estão distribuídos pelo mundo, destacando-se EUA, Reino Unido, Suécia, Dinamarca, Alemanha, Portugal, Austrália, Nova Zelândia, Japão, China etc." (GRACIO, 2002, p. 42).

O Padrão Dublin Core define um conjunto simplificado de 15 (quinze) elementos de metadados para descrição de recursos na web, conforme demonstrado no quadro a seguir. 
Quadro 7 - Elementos do Padrão de Metadados Dublin Core.

\begin{tabular}{|c|c|c|}
\hline Elemento & Identificador & Conteúdo \\
\hline 1- Título & Title & $\begin{array}{l}\text { Nome pelo qual o recurso é formalmente } \\
\text { conhecido, podendo ser o próprio título, o } \\
\text { nome ou uma descrição curta. }\end{array}$ \\
\hline 2- Autor & Creator & $\begin{array}{l}\text { Entidade primeiramente responsável pelo } \\
\text { conteúdo do recurso. Pode ser uma pessoa, } \\
\text { uma organização ou um serviço. }\end{array}$ \\
\hline 3- Assunto & Subject & $\begin{array}{l}\text { Tema do conteúdo do recurso. Pode ser } \\
\text { expresso com palavras-chave, frases-chave, } \\
\text { descritores ou códigos de classificação que } \\
\text { descrevem o tema do recurso. }\end{array}$ \\
\hline 4- Descrição & Description & $\begin{array}{l}\text { Um relato do conteúdo do recurso. Pode incluir } \\
\text { um abstract, um texto livre, etc. }\end{array}$ \\
\hline 5- Editor & Publisher & $\begin{array}{l}\text { Entidade responsável por tornar o recurso } \\
\text { disponível. }\end{array}$ \\
\hline 6- Colaborador & Contributor & $\begin{array}{l}\text { Pessoa ou organização responsável por fazer } \\
\text { contribuições para o conteúdo do recurso. }\end{array}$ \\
\hline 7- Data & Date & $\begin{array}{l}\text { Data associada com a criação ou a } \\
\text { disponibilização do recurso. }\end{array}$ \\
\hline 8- Tipo & Type & $\begin{array}{l}\text { A natureza ou a espécie do conteúdo do } \\
\text { recurso. Inclui termos descrevendo categorias } \\
\text { gerais, funções, etc. Exemplos: Interactive } \\
\text { Resource; Text; Image. }\end{array}$ \\
\hline 9- Formato & Format & $\begin{array}{l}\text { Manifestação física ou digital do recurso. Pode } \\
\text { incluir o tipo da mídia ou as dimensões do } \\
\text { recurso. }\end{array}$ \\
\hline 10- Identificador & Identifier & $\begin{array}{l}\text { Uma referência inequívoca para o recurso } \\
\text { dentro de um contexto. Por exemplo: o } \\
\text { Localizador de Recursos Uniforme (URL), o } \\
\text { Identificador de Objetos Digitais (DOI), o } \\
\text { Número Internacional Normalizado para Livros } \\
\text { (ISBN), dentre outros. }\end{array}$ \\
\hline 11- Fonte & Source & $\begin{array}{l}\text { Uma referência para o recurso/fonte do qual o } \\
\text { presente recurso é derivado. }\end{array}$ \\
\hline 12- Língua & Language & Língua do conteúdo intelectual do recurso. \\
\hline 13- Relação & Relation & $\begin{array}{l}\text { Uma referência para um recurso relacionado, } \\
\text { por exemplo: uma versão, tradução ou parte } \\
\text { de um trabalho. }\end{array}$ \\
\hline 14- Cobertura & Coverage & $\begin{array}{l}\text { O âmbito do conteúdo do recurso. Inclui } \\
\text { localização de espaço, período de tempo ou } \\
\text { jurisdição. }\end{array}$ \\
\hline 15- Direitos & Rights & $\begin{array}{l}\text { Informações sobre direitos do recurso. } \\
\text { Abrange Direitos de Propriedade Intelectual, } \\
\text { Copyright, e várias propriedades de direitos. }\end{array}$ \\
\hline
\end{tabular}

Fonte: elaboração própria, a partir de Gracio (2002). 
Atualmente, o padrão Dublin Core tem sido muito utilizado por repositórios e bibliotecas digitais, conforme mencionado por Bettencourt (2014, p. 65),

O objetivo original do Dublin Core é a definição de um conjunto de elementos, simples e autoexplicativos, que possibilitem ao próprio autor do documento descrevê-lo, ao publicá-lo eletronicamente na web [...]; por sua popularidade, é o [padrão] mais utilizado para fins de interoperabilidade entre sistemas de bibliotecas e de repositórios digitais.

Ainda acerca do objetivo da criação do padrão Dublin Core, Souza e Alves (2009, p. 193) destacam que

O conjunto de elementos de metadados [Dublin Core] foi estabelecido com o objetivo de facilitar a descrição de recursos de informação em formato eletrônico, tornando-os mais visíveis aos motores de busca e sistemas de recuperação. Esses quinze elementos visam fornecer um conjunto mínimo de descrição da informação eletrônica, apropriado ao ambiente web, sem qualquer intenção de substituir modelos mais completos, como a AACR2 e o MARC 21, por exemplo.

Acontece que, no cenário atual, muitas vezes, uma mesma biblioteca ou rede de bibliotecas, necessita lidar com o tratamento de informações registradas nos dois suportes - o físico e o digital. É comum que um mesmo catálogo on-line direcione os usuários a documentos que podem ser encontrados no suporte físico, tal como um livro impresso que é armazenado na estante, como também documentos no suporte digital, tal como um livro eletrônico em PDF, imagens digitais, etc. Desse modo, percebe-se que algumas instituições que lidam com a informação bibliográfica começaram a adotar sistemas que compatibilizam os dois formatos: o MARC 21 e o Dublin Core.

A título de exemplo, pode-se mencionar a Biblioteca Nacional Digital (BNDigital). Lançada oficialmente no ano de 2006, a BNDigital ${ }^{6}$ vem trabalhando com os dois padrões de metadados: o MARC 21 e o Dublin Core (BETTENCOURT, 2014). Na figura a seguir, observa-se o resultado de uma busca feita no acervo da BNDigital, onde o pesquisador tem a opção de ver o registro do material nos campos do MARC e/ou no padrão de metadados Dublin Core.

\footnotetext{
${ }^{6}$ O acervo da BNDigital está disponível em http://bndigital.bn.gov.br onde a representação descritiva
} dos recursos informacionais pode ser visualizada nos dois formatos. 
Figura 14 - Resultado de busca na página on-line da BNDigital.

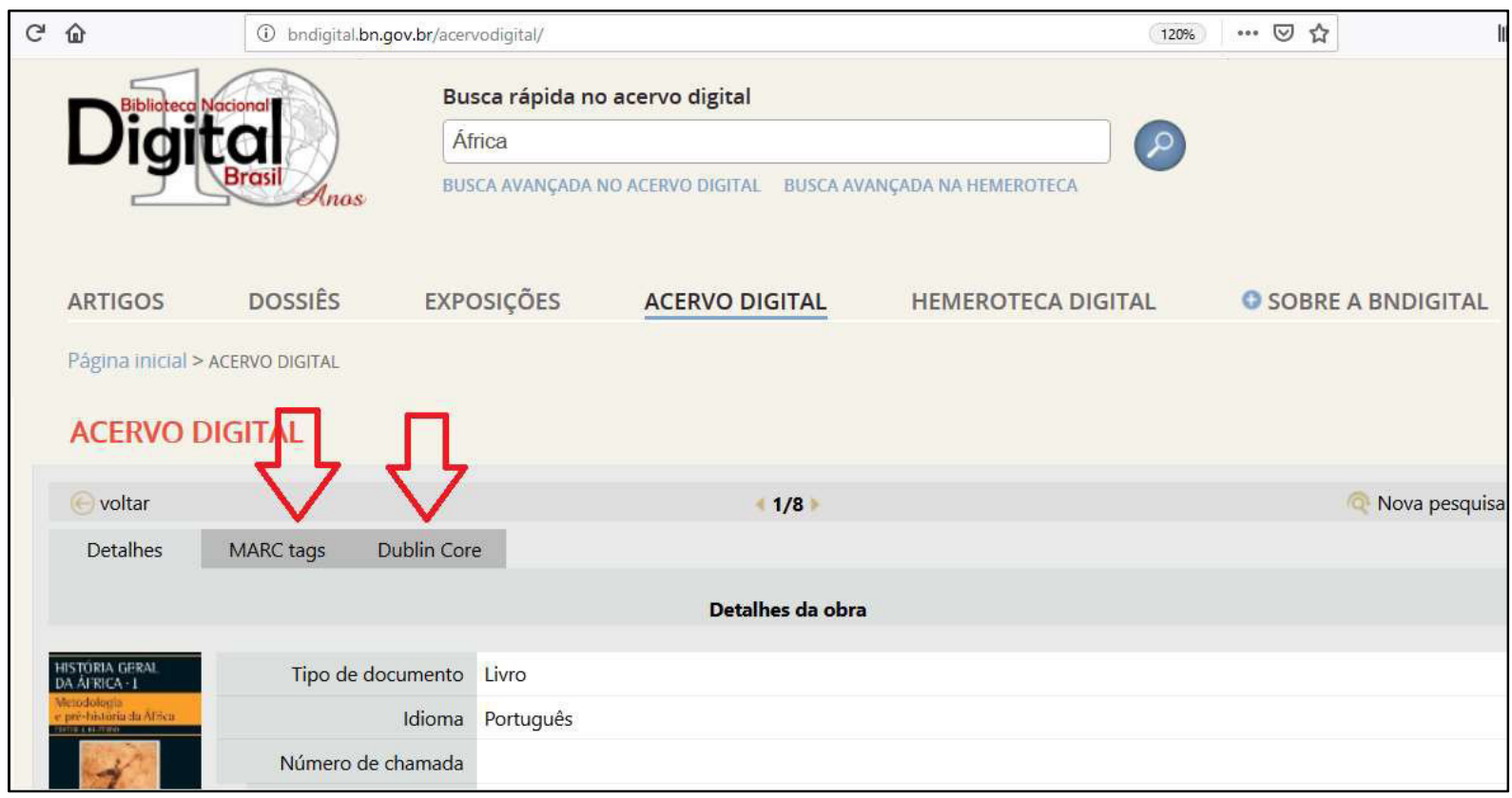

Fonte: adaptado de BNDigital. Disponível em: http://bndigital.bn.gov.brl. Acesso em: 08 jan. 2019.

Na figura 15, observa-se a descrição de um livro eletrônico no padrão de metadados Dublin Core, pesquisado no acervo da BNDigital.

Figura 15 - Registro de um livro eletrônico no padrão de metadados Dublin Core.

\begin{tabular}{|ll|}
\hline & \\
title & Coleção História geral da África : v. 1: Metodologia e pré-história da África \\
title & General history of Africa \\
contributor & Unesco \\
contributor & Brasil. Ministério da Educação \\
contributor & Universidade Federal de São Carlos \\
coverage & África \\
coverage & Africa \\
subject & África - História \\
subject & Africa - History \\
publisher & Brasilia, DF, Unesco \\
date & 2011 \\
language & por \\
rights & Biblioteca Nacional (Brasil) \\
type & Livro \\
description & il. (algumas col.) \\
identifier & http://objdigital.bn.br/objdigital2/acervo_digital/div_obrasgerais/drg1481796/drg1481796_01.pdf \\
format & PDF \\
relation & http://acervo.bndigital.bn.br/sophia/index.asp?codigo_sophia=83291 \\
\hline
\end{tabular}

Fonte: BNDigital. Disponível em: http://bndigital.bn.gov.brl. Acesso em: 08 jan. 2019. 
É evidente que essa visualização do registro dos materiais nos campos do formato MARC ou do Dublin Core não importa para o usuário que apenas deseja encontrar o documento de forma fácil e rápida, sendo assim, geralmente, esses dados estruturados - que podem ser considerados de "bastidores" - não aparecem na interface inicial de apresentação do resultado de busca. No entanto, dar a opção de visualizá-los, conforme faz a BNDigital, pode ser de grande ajuda para bibliotecários e outros profissionais que precisam conhecer a dinâmica da informação bibliográfica no ambiente digital.

\subsection{O MARC 21 E SEUS AVANÇOS NA ERA DA WEB}

Ao discorrer sobre sua percepção em relação à representação descritiva de documentos em suporte digital, Bettencourt (2014, p. 161, grifo nosso) argumenta:

Com relação ao tratamento do digital, foi possível perceber que diversos padrões e instrumentos relacionados à representação da informação tradicional, sobretudo os relacionados ao controle dos pontos de acesso de autoria e de assuntos, foram transportados para a representação do digital. No entanto, pôde-se também constatar a forte tendência à simplificação da representação descritiva, isto porque a possibilidade de acesso ao documento, na sua integralidade, elimina a necessidade da exaustividade em sua descrição. A tecnologia traz novas possibilidades e com ela novos desafios. $O$ foco muda, saindo da materialidade física do objeto concreto para a imaterialidade abstrata de seu conteúdo, novos padrões e protocolos surgem voltados, principalmente, para a interoperabilidade entre sistemas e a formação de repositórios abertos, que preconizam a universalização do conhecimento, característica principal do mundo digital.

Acompanhando o avanço tecnológico e as necessidades face à essa nova realidade da web, a LC vem realizando adaptações no formato MARC. Além das já mencionadas atualizações e criação de novos campos para atendimento aos padrões do Código de Catalogação RDA, foi desenvolvida uma codificação para os registros MARC com o uso da linguagem de marcação EXtensible Markup Language (XML), denominado de MARCXML. Nesse aspecto, Gracio (2002, p. 28) explica que,

Com o avanço da Internet e as necessidades cada vez maiores de interação com os usuários, como no caso do comércio eletrônico, surgiu o XML, resultado dos estudos de um grupo de especialistas do 
World Wide Web Consortium (W3C), que em 1996 propuseram uma linguagem mais simples que o SGML, mais flexível que o HTML, que permitisse a criação de marcas e fosse voltada para as necessidades atuais da Web.

Conforme apontam Okada e Ortega (2009, p. 24), "atualmente, o intercâmbio de registros pode ser realizado com uso da linguagem de marcação EXtensible Markup Language (XML), a qual permite que sejam transportados de um sistema a outro tanto a estrutura quanto o conteúdo dos registros". A linguagem XML indica para o sistema o que os dados significam e descreve como os mesmos devem ser mostrados, "[...] por essas características, o XML tem sido fonte de estudos e projetos na sua utilização com metadados" (GRACIO, 2002, p. 28). Nessa perspectiva, Assumpção (2013, p. 105) argumenta que,

[...] uma vez que os registros convertidos estão de acordo com o MARCXML, uma ampla gama de possibilidades passa a existir, principalmente devido às possibilidades trazidas pela XML [...] e ao papel que os Formatos MARC 21 podem desempenhar como padrões de metadados capazes de intermediar a troca de registros entre diferentes padrões de metadados no domínio bibliográfico.

De acordo com Siqueira (2003, apud ASSUMPÇÃO; SANTOS, 2015), a codificação de um registro MARC $21 \mathrm{com}$ a linguagem XML torna mais simples o desenvolvimento de programas para a importação de dados neste padrão, de modo que o MARCXML traz facilidades para os criadores de softwares.

[...] Além da codificação tradicional sequencial, tem-se a possibilidade de codificar registros nos Formatos MARC 21 utilizando a XML, que está em maior consonância com as tecnologias de informática atuais. Mesmo com essa possibilidade, nota-se que a comunidade de bibliotecas encontra-se ainda presa à codificação da ISO 2709, utilizando uma estrutura sequencial desenvolvida para fitas magnéticas [...] (ASSUMPÇÃO; SANTOS, 2015, p. 65)

Percebe-se, portanto, que a codificação do MARC 21 com o XML representa uma alternativa à codificação com a norma ISO 2709, desempenhando uma função parecida, no sistema, em prol do intercâmbio de registros. Gracio (2002, p. 35) esclarece que, "no contexto da Web a linguagem XML é aquela que permite melhor descrever as informações para a troca de metadados" e enfatiza que o padrão Dublin Core é codificado com essa linguagem. 
Sendo assim, entende-se que o emprego do MARCXML nos sistemas das Bibliotecas não modifica diretamente o trabalho do bibliotecário catalogador, porque os atributos dos materiais necessitam ser registrados na mesma estrutura de descrição já conhecida, ou seja, nos campos e subcampos do MARC 21. A codificação em XML exercerá um papel importante na etapa do layout para o intercâmbio entre sistemas.

Entretanto, Assumpção e Santos (2015, p. 70) ressaltam que a codificação de registros MARC $21 \mathrm{com}$ a XML, ainda "[...] não é suficiente para garantir a adequação dos Formatos MARC 21 ao cenário em que o domínio bibliográfico se encontra no começo do século XXI".

O formato MARC foi pensado para atender às necessidades descritivas de catálogos em papel, transferindo aos computadores as informações contidas nas fichas analógicas, sem, contudo, explorar os recursos tecnológicos que esta linguagem oferece. Esta situação não é coerente com o cenário atual (SERRA, 2013, p. 3).

Diante desse contexto, segundo Silva et al (2017), a LC já vem trabalhando e desenvolvendo um novo formato denominado Bibliographic Framework Initiative (BIBFRAME), com o intuito de que, no futuro, este seja o sucessor do MARC 21, da mesma maneira em que o RDA será o sucessor do AACR2. A iniciativa BIBFRAME incorpora "[...] questões sobre a utilização de tecnologias como o modelo de dados Resource Description Framework (RDF), além da já consolidada XML" (ASSUMPÇÃO; SANTOS, 2015, p. 71). Os autores acrescentam que,

O BIBFRAME, apesar dos avanços já realizados em seu desenvolvimento, ainda encontra-se em fase inicial, sendo conduzidos os primeiros testes e realizados os ajustes necessários. Assim, entende-se que, para o intercâmbio de dados no domínio bibliográfico, os Formatos MARC 21 - apesar de suas críticas - ainda perdurarão como padrões de metadados amplamente utilizados pelos próximos anos (ASSUMPÇÃO; SANTOS, 2015, p. 71).

Nesse sentido, Serra (2013, p. 8) destaca que, dentre as atribuições do grupo de trabalho designado para a iniciativa BIBFRAME "[...] figura a preocupação na transição do MARC 21 para este novo formato, preservando os esforços e investimentos que vêm sendo feitos há décadas". A autora destaca ainda que a transição do MARC 21 para um novo formato não pode ocorrer de uma hora para 
outra sem o reaproveitamento dos dados já existentes, além disso, esta mudança demandará exaustivos testes de validação, além de esforços em capacitação. 


\section{O PERCURSO METODOLÓGICO}

A presente pesquisa, quanto às suas fontes, revela-se como bibliográfica, por ter sido realizada a partir de consulta à literatura já existente sobre os formatos de intercâmbio. De acordo com Marconi e Lakatos (2003, p. 183), a pesquisa bibliográfica "[...] abrange toda a bibliografia já tornada pública em relação ao tema de estudo, desde publicações avulsas, boletins, jornais, revistas, livros, pesquisas, monografias, teses, material cartográfico, etc. [...]".

Quanto aos objetivos pretendidos, é de natureza descritiva. De acordo com Sampieri, Collado e Lucio (2006, p. 102), a pesquisa descritiva "[...] busca especificar propriedades e características importantes de qualquer fenômeno que se analise". Além disso, os autores argumentam que "os estudos descritivos servem para analisar como é e como se manifestam um fenômeno e seus componentes" (SAMPIERI; COLLADO; LUCIO, 2006, p. 112).

No que se refere à abordagem das pesquisas, Richardson (1999, p. 79), afirma que,

O método qualitativo difere, em princípio, do quantitativo à medida que não emprega um instrumental estatístico como base do processo de análise de um problema. Não pretende numerar ou medir unidades ou categorias homogêneas.

Portanto, considera-se que esta pesquisa possui abordagem qualitativa, visto que não se pretende quantificar dados, mas sim, conhecer e realizar um cotejamento da estrutura de representação descritiva de livros em diferentes formatos de intercâmbio com a estrutura do formato MARC 21 para Dados Bibliográficos.

\subsection{AS ETAPAS DA PESQUISA}

Os autores Bauer e Gaskell (2003, p. 496) definem Corpus da pesquisa como um "[...] conjunto limitado de materiais determinado de antemão pelo analista, com certa arbitrariedade, e sobre o qual o trabalho é feito". Sendo assim, o corpus da presente pesquisa é a estrutura de descrição bibliográfica para livros impressos nos campos variáveis dos seguintes formatos para o intercâmbio de dados entre bibliotecas: formato MARC 21, formato CALCO, formato UNIMARC, formato CCF, formato LILACS, formato CEPAL, formato IBICT e formato Dublin Core. 
Cumpre aqui esclarecer que, ora são cotejados os campos de dados variáveis comumente utilizados para a catalogação de livros, portanto, não dizendo respeito a outros tipos de materiais como periódicos, arquivo eletrônico, etc. Optou-se por cotejar os campos variáveis tendo em vista que estes são os que mais dependem do trabalho do catalogador para o seu correto preenchimento. Sendo assim, o corpus deste trabalho não engloba os campos de controle e campos fixos, os quais incluem, por exemplo, o registro do líder e os demais códigos ou números de controle. No MARC 21 esses campos de controle entram no bloco 0XX, por exemplo: 001- número de controle; 005-data e hora da última intervenção; 008-campos fixos de dados; 040fonte de catalogação, dentre outros. Esses campos em questão, em sua maioria, são preenchidos de forma automática ou passíveis de padronização pelos administradores dos sistemas.

A realização da pesquisa se deu em cinco etapas principais, sendo:

1. primeiramente, por meio de uma revisão da literatura, identificou-se aspectos da trajetória dos principais instrumentos utilizados na representação descritiva da informação em bibliotecas, destacando-se o formato MARC e os Códigos de Catalogação AACR2 e RDA;

2. em seguida, foram identificados e estudados, também por meio de consulta à literatura da área de Biblioteconomia, os outros formatos de intercâmbio, dando enfoque às suas respectivas trajetórias bem como à verificação da existência de manuais que demonstrassem a estrutura para descrição de livros;

3. partiu-se então para a verificação de como as áreas de descrição e os pontos de acesso prescritos no AACR2 são contemplados pelos campos do formato MARC 21 para Dados Bibliográficos e pelos demais formatos. Para tal, foram justapostos, em uma planilha eletrônica, os seguintes dados: 1) as áreas de descrição e os pontos de acesso prescritos no AACR2 para a descrição de livros; 2) os respectivos campos MARC 21 comumente utilizados e que contemplam as áreas e os pontos de acesso prescritos no AACR2; e 3) os campos correspondentes para as mesmas áreas, nos demais formatos aqui estudados; 
4. em seguida, foi realizada a descrição de livros impressos nos campos variáveis do MARC 21 bem como em cada um dos outros formatos estudados, sendo que, para cada formato - CALCO, UNIMARC, CCF, LILACS, CEPAL, IBICT e Dublin Core - utilizou-se um título diferente, totalizando sete livros, escolhidos de forma aleatória;

5. por fim, partiu-se para a observação dos dados e o cotejamento dos campos e subcampos do MARC 21 para Dados Bibliográficos, com cada um dos outros formatos de descrição bibliográfica. 


\section{COTEJANDO O MARC 21 COM OS OUTROS FORMATOS}

Nesta seção, apresenta-se o resultado do cotejamento do MARC $21 \mathrm{com}$ outros formatos de descrição bibliográfica. Destaca-se que, durante a pesquisa, foram encontradas bibliografias abrangendo a correspondência dos campos do MARC 21 com alguns dos outros formatos de descrição aqui estudados, conforme mostra o Quadro 8, a seguir.

Quadro 8 - Bibliografias que apresentam correspondência dos campos do Formato MARC 21 com outros formatos de descrição.

\begin{tabular}{|c|c|c|c|}
\hline Referências & Formatos & $\begin{array}{l}\text { Acesso } \\
\text { aberto }\end{array}$ & Idioma \\
\hline $\begin{array}{l}\text { ALVES, Maria das Dores Rosa; SOUZA, Marcia Izabel } \\
\text { Fugisawa. Estudo de correspondência de elementos metadados: } \\
\text { DUBLIN CORE e MARC 21. RDBCI: Revista Digital de } \\
\text { Biblioteconomia e Ciência da Informação, Campinas, SP, v. } 5 \text {, n. } \\
\text { 1, p. } 20-38 \text {, jan. } 2007 \text {. }\end{array}$ & $\begin{array}{l}\text { Dublin } \\
\text { Core e } \\
\text { MARC } 21\end{array}$ & Sim & Português \\
\hline $\begin{array}{l}\text { BETTENCOURT, Angela Monteiro. A representação da } \\
\text { informação na Biblioteca Nacional: do documento tradicional } \\
\text { ao digital. Rio de Janeiro: Fundação Biblioteca Nacional, } 2014 .\end{array}$ & $\begin{array}{l}\text { Dublin } \\
\text { Core e } \\
\text { MARC } 21\end{array}$ & Sim & Português \\
\hline $\begin{array}{l}\text { BIREME. Metodologia LILACS: Manual de Descrição } \\
\text { Bibliográfica. 7. ed. São Paulo: BIREME / OPAS / OMS, } 2008 .\end{array}$ & $\begin{array}{l}\text { LILACS e } \\
\text { MARC } 21\end{array}$ & Sim & Português \\
\hline $\begin{array}{l}\text { CHANDRAKAR, Rajesh. Mapping CCF to MARC 21: an } \\
\text { experimental approach. Cataloging \& Classification Quarterly, } \\
\text { Binghamton, NY, v. 33, n. 1, jun. } 2001 .\end{array}$ & $\begin{array}{c}\text { CCF e } \\
\text { MARC } 21\end{array}$ & Não & Inglês \\
\hline $\begin{array}{l}\text { LIBRARY OF CONGRESS. Dublin Core to MARC Crosswalk. } \\
\text { [Washington]: Library of Congress, } 2008 .\end{array}$ & $\begin{array}{l}\text { Dublin } \\
\text { Core e } \\
\text { MARC } 21\end{array}$ & Sim & Inglês \\
\hline $\begin{array}{l}\text { LIBRARY OF CONGRESS. UNIMARC to MARC 21: conversion } \\
\text { specifications. [Washington]: Library of Congress, } 2001 .\end{array}$ & $\begin{array}{l}\text { UNIMARC } \\
\text { e MARC } \\
21\end{array}$ & Sim & Inglês \\
\hline $\begin{array}{l}\text { SABORÍO-ACUÑA, José Iván; CHINCHILLA-ARLEY, Ricado. } \\
\text { Metodología para la migración de datos bibliográficos entre } \\
\text { programas de software de automatización: de CEPAL a MARC, } \\
\text { e-Ciencias de la Información, San José, Costa Rica, v. 4, n. 2, } \\
\text { jul.-dez., } 2014 \text {. }\end{array}$ & $\begin{array}{l}\text { CEPAL e } \\
\text { MARC } 21\end{array}$ & Sim & Espanhol \\
\hline
\end{tabular}

Fonte: elaboração própria. 
Ao consultar algumas das bibliografias do quadro anterior, percebeu-se que cotejar campos e subcampos de formatos de intercâmbio e descrição bibliográfica requer minuciosa atenção, tendo em vista a grande quantidade de detalhes a serem observados. Ressalta-se que, nos cotejamentos apresentados a seguir, limitou-se a abranger campos de dados variáveis comumente utilizados para a catalogação de livros no formato impresso.

\subsection{O MARC 21 E O FORMATO CALCO}

Tendo em vista que o formato CALCO foi uma adaptação do MARC no Brasil, pressupõe-se que poucas diferenças separam esses dois formatos. Conforme apontado por Barbosa (1972), a princípio, o CALCO destinou-se à descrição de material monográfico no todo, não estabelecendo os campos e subcampos para descrever artigos de periódicos e publicações seriadas, por exemplo. No quadro a seguir foram elencadas áreas de descrição e os tipos de pontos de acesso para a descrição de livros, conforme o AACR2 e, ao lado, foram informados os campos correspondentes comumente usados para a representação descritiva de livros, tanto em formato MARC 21 para Dados Bibliográficos, quanto no formato CALCO.

Quadro 9 - Campos variáveis do MARC 21 e do CALCO para a descrição de livros segundo o AACR2 (continua...)

\begin{tabular}{|c|c|c|}
\hline $\begin{array}{l}\text { Áreas de descrição } \\
\text { AACR2 PARTE I }\end{array}$ & $\begin{array}{l}\text { Campos } \\
\text { para descrição de LIVROS no } \\
\text { MARC } 21 \text { Bibliográfico }\end{array}$ & $\begin{array}{l}\text { Campos } \\
\text { correspondentes no } \\
\text { Formato CALCO }\end{array}$ \\
\hline $\begin{array}{l}\text { Área do título e da } \\
\text { indicação de } \\
\text { responsabilidade }\end{array}$ & $\begin{array}{l}240 \text { - Título uniforme } \\
245 \text { - Indicação de título } \\
246 \text { - Forma variante do título }\end{array}$ & 245 - Título da publicação \\
\hline Área da edição & 250 - Indicação de edição & 250 - Nota da edição \\
\hline $\begin{array}{c}\text { Área da publicação, } \\
\text { distribuição, etc. }\end{array}$ & $\begin{array}{l}260 \text { - Imprenta } \\
264 \text { - Produção, publicação, } \\
\text { distribuição, manufatura e } \\
\text { informação de Copyright }\end{array}$ & $\begin{array}{l}260 \text { - Imprenta ou notas } \\
\text { tipográficas }\end{array}$ \\
\hline $\begin{array}{c}\text { Área da descrição } \\
\text { física }\end{array}$ & 300 - Descrição física & $\begin{array}{l}300 \text { - Colação ou notas } \\
\text { bibliográficas }\end{array}$ \\
\hline
\end{tabular}




\begin{tabular}{|c|c|c|}
\hline Área de série & $\begin{array}{l}490 \text { - Indicação de série } \\
800 \text { - Entrada secundária de } \\
\text { série - Nome pessoal } \\
810 \text { - Entrada secundária de } \\
\text { série - Nome Corporativo } \\
811 \text { - Entrada secundária de } \\
\text { série - Nome de evento } \\
830 \text { - Entrada secundária de } \\
\text { série - Título uniforme }\end{array}$ & $\begin{array}{l}400 \text { - Série - Nomes Pessoais } \\
410 \text { - Série - Entidades Coletivas } \\
411 \text { - Série - Conferências, } \\
\text { Seminários, Congressos, } \\
\text { etc. } \\
440 \text { - Séries - Diretamente pelo } \\
\text { título } \\
\mathbf{4 5 0} \text { - Série adicional }\end{array}$ \\
\hline Área de notas & $\begin{array}{l}\mathbf{5 0 0} \text { - Nota geral } \\
\mathbf{5 0 1} \text { - Nota iniciada por "com" } \\
\mathbf{5 0 4} \text { - Nota de bibliografia } \\
\mathbf{5 0 5} \text { - Nota de conteúdo } \\
\mathbf{5 2 0} \text { - Nota de resumo } \\
\mathbf{5 3 0} \text { - Nota de disponibilidade de } \\
\quad \text { forma física adicional } \\
\mathbf{5 3 4} \text { - Nota de versão original } \\
\mathbf{5 4 6} \text { - Nota de idioma } \\
\mathbf{5 9 X} \text { - Notas locais }\end{array}$ & $\begin{array}{l}500 \text { - Nota Geral } \\
501 \text { - Nota de "Encadernado } \\
\text { com" } \\
504 \text { - Inclusão de Bibliografias } \\
\mathbf{5 0 5} \text { - Indicação de Conteúdo }\end{array}$ \\
\hline $\begin{array}{l}\text { Área de número } \\
\text { normalizado }\end{array}$ & $020-$ ISBN & 020 - Número padronizado do Livro \\
\hline $\begin{array}{l}\text { Pontos de acesso } \\
\text { AACR2 PARTE II }\end{array}$ & $\begin{array}{l}\text { Campos } \\
\text { para descrição de LIVROS no } \\
\text { MARC } 21 \text { Bibliográfico }\end{array}$ & $\begin{array}{l}\text { Campos } \\
\text { correspondentes no } \\
\text { Formato CALCO }\end{array}$ \\
\hline $\begin{array}{l}\text { Cabeçalhos para } \\
\text { Pessoas }\end{array}$ & $\begin{array}{l}100 \text { - Entrada principal - Nome } \\
\text { Pessoal } \\
600 \text { - Assunto - Nome Pessoal } \\
700 \text { - Entrada Secundária - } \\
\text { Nome Pessoal }\end{array}$ & $\begin{array}{l}100 \text { - Entrada principal - Nome } \\
\text { pessoal } \\
600 \text { - Assunto - Nome Pessoal } \\
700 \text { - Entrada Secundária - } \\
\text { Nome Pessoal }\end{array}$ \\
\hline Nomes Geográficos & 651 - Assunto - Nome Geográfico & $\begin{array}{l}651 \text { - Assuntos entrando pelo } \\
\text { local }\end{array}$ \\
\hline $\begin{array}{l}\text { Cabeçalhos para } \\
\text { entidades }\end{array}$ & $\begin{array}{c}110 \text { - Entrada principal - Nome } \\
\text { Corporativo } \\
111 \text { - Entrada principal - Nome } \\
\text { de Evento } \\
\\
610 \text { - Assunto - Nome } \\
\text { Corporativo } \\
611 \text { - Assunto - Nome de Evento } \\
\\
710 \text { - Entrada Secundária - } \\
\text { Nome Corporativo } \\
711 \text { - Entrada Secundária - } \\
\text { Nome de Evento }\end{array}$ & $\begin{array}{l}110 \text { - Entrada principal - } \\
\text { Entidades Coletivas } \\
111 \text { - Entrada principal - } \\
\text { Conferências, Seminários, } \\
\text { Congressos, etc. } \\
\\
610 \text { - Cabeçalhos de assunto - } \\
\text { Entidades Coletivas } \\
611 \text { - Cabeçalhos de assunto - } \\
\text { Conferências, Seminários, } \\
\text { Congressos, etc. } \\
710 \text { - Entrada Secundária - } \\
\text { Entidades Coletivas } \\
711 \text { - Entrada Secundária - } \\
\text { Conferências, Seminários, } \\
\text { Congressos, etc. }\end{array}$ \\
\hline
\end{tabular}




\begin{tabular}{|c|c|c|}
\hline Títulos Uniformes & $\begin{array}{l}130 \text { - Entrada principal - Título } \\
\text { Uniforme } \\
240 \text { - Título uniforme } \\
630 \text { - Assunto - Título Uniforme } \\
730 \text { - Entrada Secundária - Título } \\
\text { Uniforme }\end{array}$ & $\begin{array}{c}130 \text { - Entrada principal - Título } \\
\text { Uniforme } \\
630 \text { - Cabeçalhos de assuntos - } \\
\text { Títulos uniformes } \\
730 \text { - Entrada secundária - } \\
\text { Títulos uniformes }\end{array}$ \\
\hline
\end{tabular}

Fonte: elaboração própria, a partir de Ferreira (2013) e Barbosa (1972).

Para elucidar um pouco mais as semelhanças e as diferenças entre o MARC 21 e o CALCO, apresenta-se também o quadro a seguir, com a descrição de um mesmo livro nos campos variáveis desses dois formatos.

Quadro 10 - Representação descritiva de um livro nos formatos MARC 21 e CALCO

\section{LIVRO:}

ASSIS, Machado de. O Alienista. São Paulo: Cia dos Livros, 2010. (Clássicos da literatura).

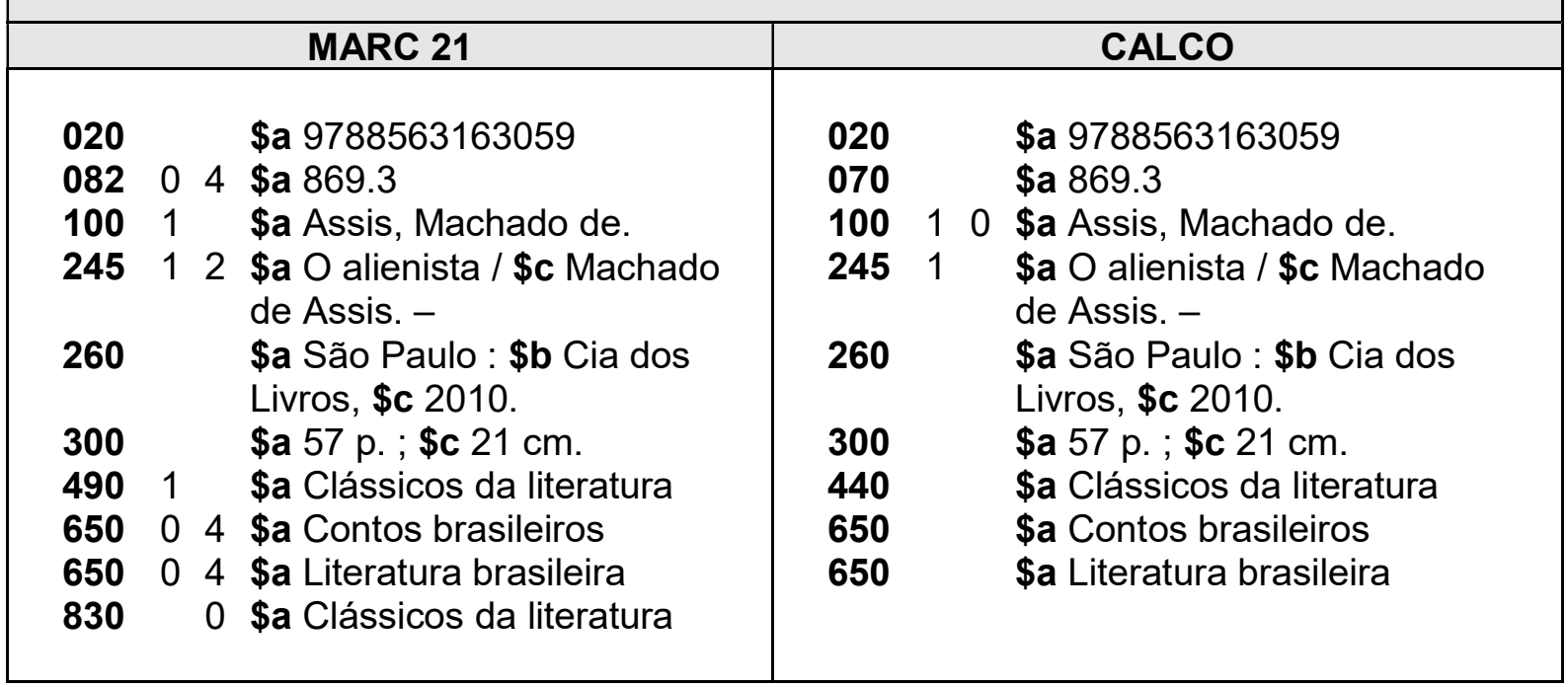

Fonte: elaboração própria, a partir de Ferreira (2013) e Barbosa (1972).

Observando os quadros 9 e 10, notam-se as seguintes semelhanças entre o MARC 21 e o CALCO:

- assim como o MARC 21, os campos do formato CALCO também contemplam todas as áreas de descrição de livros e os pontos de acesso determinados nas partes I e II do Código de Catalogação AACR2; 
- os dois formatos adotam campos identificados com etiquetas de três dígitos numéricos (campo 100, campo 245, etc.), além do uso de indicadores e subcampos para a inserção dos dados do registro;

- nos dois formatos, existem campos não repetíveis, como por exemplo o campo 100 do autor principal, e há campos que podem se repetir, tal como o campo 650 de assuntos temáticos;

- nos dois formatos as informações são divididas em blocos, sendo: 0XX para números de identificação; $1 \mathrm{XX}$ para as entradas principais; 2XX para títulos, edição e imprenta; 3XX para descrição física; 4XX para informação de série; 5XX para notas; 6XX para assuntos e 7XX para entradas secundárias.

$\mathrm{Na}$ observação dos dados acima, destacam-se também algumas diferenças entre os dois formatos:

- o CALCO não possui o bloco de campos 8XX de entradas secundárias de série e outros. No MARC 21 o bloco 9XX é reservado para decisões locais da instituição catalogadora, no CALCO esse bloco foi destinado à recuperação de assuntos;

- na área de título e indicação de responsabilidade, observada no quadro 9 , nota-se que o MARC 21 possui mais opções de descrição, envolvendo, por exemplo, o título uniforme e formas variantes de título, ao passo que o CALCO limitava-se apenas ao campo 245 , destinado ao título principal;

- na área de publicação, distribuição, etc., ainda conforme o quadro 9, notase que o MARC 21 possui, atualmente, a opção do campo 264, possibilitando ao catalogador fazer distinção entre funções: produtor, publicador, distribuidor, manufatureiro ou informação de copyright. No CALCO não havia essa opção, limitava-se ao campo 260;

- na área de série, observada nos dois quadros anteriores, nota-se que há uma diferença entre os dois formatos, visto que o MARC 21 realizou em 2009 uma atualização no bloco de campos 4XX. Nessa atualização, o campo 440 e outros do mesmo bloco deixaram de ser utilizados, ficando apenas o 490, o qual foi designado para a indicação dos dados da série, conforme aparece no material, independentemente do tipo da série. Os desdobramentos passaram a ser feitos 
no bloco 8XX, onde informa-se o cabeçalho controlado da série. No CALCO, usava-se apenas o bloco $4 \mathrm{XX}$ para dados de séries;

- na área de notas, observada no quadro 9, percebe-se que o MARC 21 possui maior quantidade de campos para diferenciados tipos de notas;

- percebe-se também que, no MARC 21 se faz mais uso de indicadores, conforme pode ser observado no quadro 10.

Ao verificar o resultado deste cotejamento entre o MARC 21 e o CALCO, conclui-se que as diferenças apontadas estão basicamente relacionadas com as atualizações pelas quais o MARC 21 vem passando ao longo dos anos e que o CALCO, por ter sido descontinuado, não teve a oportunidade de acompanhar.

\subsection{O MARC 21 E O FORMATO UNIMARC}

Conforme apresentado em capítulos anteriores, o formato UNIMARC surgiu principalmente para resolver problemas de compatibilidade entre sistemas que utilizavam as variações do MARC. Sendo assim, esperava-se encontrar muitas semelhanças entre esses dois formatos, no entanto, foram constatadas algumas diferenças, conforme pode ser visto nos Quadros 11 e 12, a seguir.

Quadro 11 - Campos variáveis do MARC 21 e do UNIMARC para a descrição de livros segundo o AACR2 (continua...)

\begin{tabular}{|c|c|c|}
\hline $\begin{array}{l}\text { Áreas de descrição } \\
\text { segundo o } \\
\text { AACR2 PARTE I }\end{array}$ & $\begin{array}{c}\text { Campos } \\
\text { para descrição de LIVROS no } \\
\text { MARC } 21 \text { Bibliográfico }\end{array}$ & $\begin{array}{l}\text { Campos } \\
\text { correspondentes no } \\
\text { Formato UNIMARC }\end{array}$ \\
\hline $\begin{array}{l}\text { Área do título e da } \\
\text { indicação de } \\
\text { responsabilidade }\end{array}$ & $\begin{array}{l}240 \text { - Título uniforme } \\
245 \text { - Indicação de título } \\
246 \text { - Forma variante do título }\end{array}$ & $\begin{array}{l}200 \text { - Título e menção de } \\
\quad \text { Responsabilidade } \\
\mathbf{5 0 0} \text { - Título uniforme } \\
\mathbf{5 1 7} \text { - Outras formas variantes } \\
\text { de Título }\end{array}$ \\
\hline Área da edição & 250 - Indicação de edição & 205 - Menção de edição \\
\hline $\begin{array}{l}\text { Área da publicação, } \\
\text { distribuição etc. }\end{array}$ & $\begin{array}{c}260 \text { - Imprenta } \\
264 \text { - Produção, publicação, } \\
\text { distribuição, manufatura e } \\
\text { informação de Copyright }\end{array}$ & 210 - Publicação, Distribuição, etc. \\
\hline $\begin{array}{l}\text { Área da descrição } \\
\text { física }\end{array}$ & 300 - Descrição física & 215 - Descrição física \\
\hline
\end{tabular}




\begin{tabular}{|c|c|c|}
\hline Área de série & $\begin{array}{l}490 \text { - Indicação de série } \\
800 \text { - Entrada secundária de } \\
\text { série - Nome pessoal } \\
810 \text { - Entrada secundária de } \\
\text { série - Nome Corporativo } \\
811 \text { - Entrada secundária de } \\
\text { série - Nome de evento } \\
830 \text { - Entrada secundária de } \\
\text { série - Título uniforme }\end{array}$ & $\begin{array}{l}225 \text { - Coleção } \\
410 \text { - Entrada relacionada - } \\
\text { Coleção }\end{array}$ \\
\hline Área de notas & $\begin{array}{l}\mathbf{5 0 0} \text { - Nota geral } \\
\mathbf{5 0 1} \text { - Nota iniciada por "com" } \\
\mathbf{5 0 4} \text { - Nota de bibliografia } \\
\mathbf{5 0 5} \text { - Nota de conteúdo } \\
\mathbf{5 2 0} \text { - Nota de resumo } \\
\mathbf{5 3 0} \text { - Nota de disponibilidade de } \\
\quad \text { forma física adicional } \\
\mathbf{5 3 4} \text { - Nota de versão original } \\
\mathbf{5 4 6} \text { - Nota de idioma } \\
\mathbf{5 9 X} \text { - Notas locais }\end{array}$ & \begin{tabular}{|l}
300 - Notas gerais \\
303 - Notas gerais relativas a \\
informação descritiva \\
317 - Nota de proveniência \\
320 - Notas relativas a \\
Bibliografias e Índices \\
internos \\
324 - Nota do Original \\
325 - Nota de Reprodução \\
327 - Nota de Conteúdo \\
330 - Súmula ou Resumo \\
Reproduzido
\end{tabular} \\
\hline $\begin{array}{l}\text { Área de número } \\
\text { normalizado }\end{array}$ & $020-$ ISBN & $010-$ ISBN \\
\hline $\begin{array}{l}\text { Pontos de acesso } \\
\text { AACR2 PARTE II }\end{array}$ & $\begin{array}{c}\text { Campos } \\
\text { para descrição de LIVROS no } \\
\text { MARC } 21 \text { Bibliográfico }\end{array}$ & $\begin{array}{c}\text { Campos } \\
\text { correspondentes no } \\
\text { Formato UNIMARC }\end{array}$ \\
\hline $\begin{array}{l}\text { Cabeçalhos para } \\
\text { Pessoas }\end{array}$ & $\begin{array}{l}100 \text { - Entrada principal - Nome } \\
\text { Pessoal } \\
600 \text { - Assunto - Nome Pessoal } \\
700 \text { - Entrada Secundária - } \\
\text { Nome Pessoal }\end{array}$ & $\begin{array}{l}600 \text { - Nome de pessoa usado } \\
\text { como assunto } \\
700 \text { - Nome de pessoa - } \\
\text { responsabilidade principal } \\
701 \text { - Nome de pessoa - co-res- } \\
\text { ponsabilidade principal } \\
702 \text { - Nome de pessoa - } \\
\text { responsabilidade } \\
\text { secundária }\end{array}$ \\
\hline Nomes Geográficos & 651 - Assunto - Nome Geográfico & $\begin{array}{l}607 \text { - Nome geográfico usado } \\
\text { como assunto } \\
\text { 617- Nome geográfico } \\
\text { hierarquizado usado como } \\
\text { assunto }\end{array}$ \\
\hline $\begin{array}{l}\text { Cabeçalhos para } \\
\text { entidades }\end{array}$ & $\begin{array}{l}110 \text { - Entrada principal - Nome } \\
\text { Corporativo } \\
111 \text { - Entrada principal - Nome } \\
\text { de Evento } \\
\\
610 \text { - Assunto - Nome } \\
\text { Corporativo } \\
611 \text { - Assunto - Nome de Evento } \\
\\
710 \text { - Entrada Secundária - } \\
\text { Nome Corporativo } \\
711 \text { - Entrada Secundária - } \\
\text { Nome de Evento }\end{array}$ & $\begin{array}{c}601 \text { - Nome de coletividade } \\
\text { usado como assunto } \\
\\
710 \text { - Nome de coletividade - } \\
\text { responsabilidade principal } \\
711 \text { - Nome de coletividade - } \\
\text { co-responsabilidade } \\
\text { principal } \\
712 \text { - Nome de coletividade - } \\
\text { responsabilidade secundária }\end{array}$ \\
\hline
\end{tabular}




\begin{tabular}{|c|c|c|}
\hline Títulos Uniformes & $\begin{array}{l}130 \text { - Entrada principal - Título } \\
\text { Uniforme } \\
240 \text { - Título uniforme } \\
630 \text { - Assunto - Título Uniforme } \\
730 \text { - Entrada Secundária - Título } \\
\text { uniforme }\end{array}$ & $\begin{array}{l}\mathbf{5 0 0} \text { - Título uniforme } \\
\mathbf{5 0 1} \text { - Título coletivo uniforme } \\
\mathbf{5 0 3} \text { - Cabeçalho convencional } \\
\text { uniforme }\end{array}$ \\
\hline
\end{tabular}

Fonte: elaboração própria, a partir de Ferreira (2013) e IFLA (2009).

No próximo quadro, apresenta-se um exemplo de descrição de um mesmo livro impresso, nos campos variáveis dos formatos MARC 21 e UNIMARC.

Quadro 12 - Representação descritiva de um livro nos formatos MARC 21 e UNIMARC

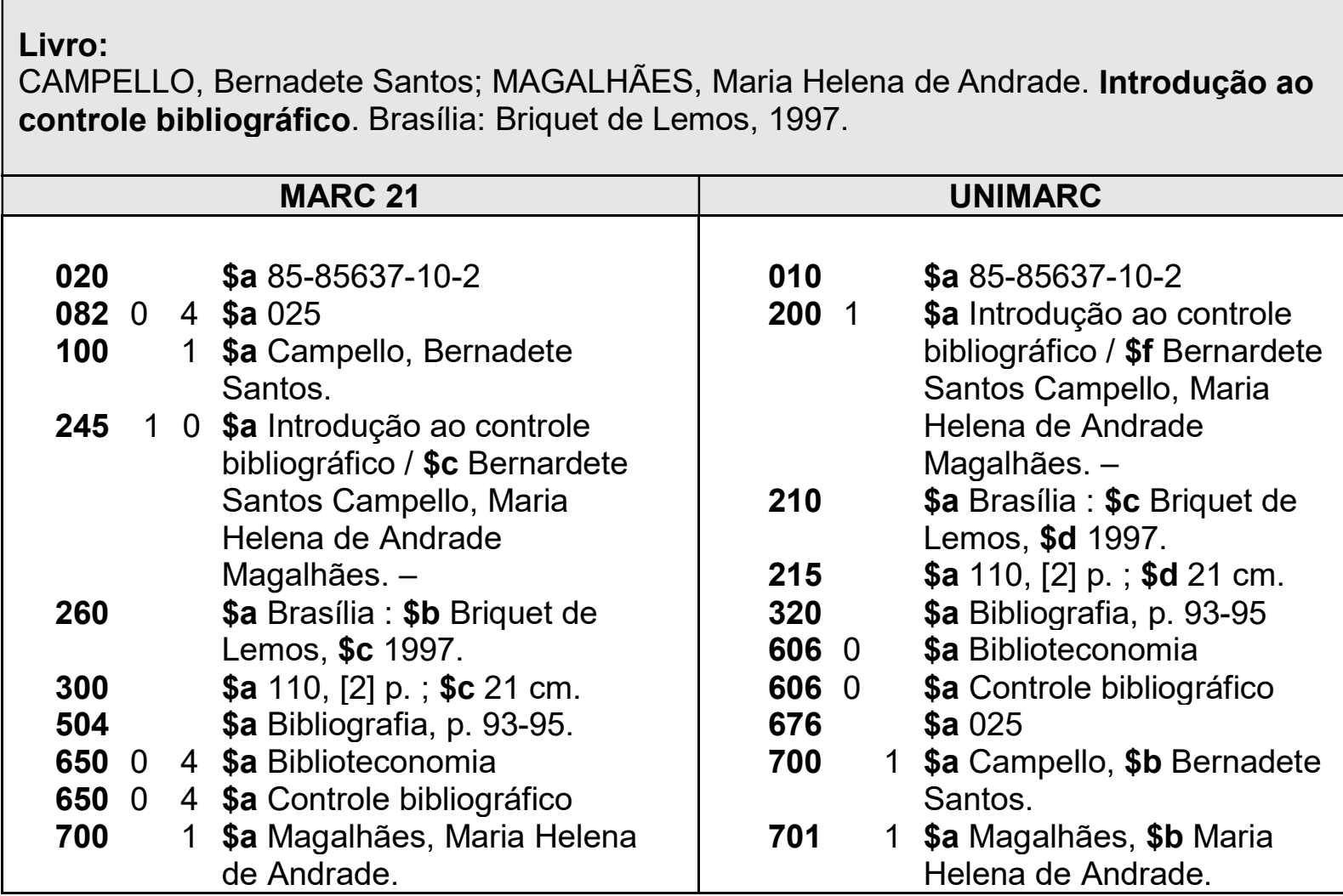

Fonte: elaboração própria, a partir de Ferreira (2013) e IFLA (2009).

Observando os quadros anteriores, notam-se, as seguintes semelhanças entre os MARC 21 e o UNIMARC:

- assim como o MARC 21, os campos do formato UNIMARC também contemplam todas as áreas de descrição de livros, bem como os pontos de acesso, determinados nas partes I e II do Código de Catalogação AACR2; 
- os dois formatos adotam campos identificados com etiquetas de três dígitos numéricos (campo 010, campo 700 etc.), além do uso de indicadores e subcampos para a inserção dos dados do registro;

- nos dois formatos existem campos repetíveis e não repetíveis. Conforme demonstrado no registro de livro (Quadro 12), são exemplos de campos não repetíveis: o campo 100 no MARC 21 e o campo 700 no UNIMARC. São exemplos de campos que podem se repetir: campo 650 no MARC 21 e campo 606 no UNIMARC.

Entretanto, na observação das características destes dois formatos, destacam-se as seguintes diferenças:

- a definição dos conteúdos dos blocos de campos dos dois formatos é diferente. No MARC 21 para Dados Bibliográficos, conforme apresentado anteriormente, os blocos são: OXX- Informação de Controle, Números e Códigos; $1 X X$ - Entradas Principais; $2 X X$ - Títulos, Edição, Imprenta; $3 X X$ Descrição Física; $4 X X$ - Série; $5 X X$ - Notas; $6 X X$ - Entradas De Assunto; $7 X X$ Entradas Secundárias de Nomes de Autores; $8 X X$ - Entradas Secundárias de Série e 9XX-Reservado para Decisões Locais. Já os blocos de campos do formato UNIMARC, de acordo com a IFLA (2009), são: OXX-Números e Códigos de Controle; $1 X X$ - Bloco de Informação Codificada; $2 X X$ - Bloco de Informação Descritiva; $3 X X$ - Bloco de Notas; $4 X X$ - Bloco de Entradas Relacionadas; $5 X X$ - Bloco de Títulos Relacionados; $6 X X$-Bloco de Assuntos e História Bibliográfica; $7 X X-$ Bloco de Responsabilidade; $8 X X-$ Bloco de Uso Internacional e 9XX-Bloco de Uso Nacional;

- conforme mostra o Quadro 11, para a área de título e indicação de responsabilidade, o MARC 21 dedica os campos do bloco $2 X X$, ao passo que, o UNIMARC dedica campos do Bloco 2XX e também 5XX;

- quanto à área de descrição física do livro, conforme apresentado nos dois quadros acima, no MARC 21 é contemplada pelo campo 300. Já no UNIMARC, a descrição física do material é inserida no campo 215;

- quanto à área de Série, observando o Quadro 11, percebe-se que o MARC 21 possui opções para uma descrição mais detalhada dos atributos da série, 
separando-as por tipo no bloco 8XX (série - nome de pessoa, série - nome corporativo, etc.). Ao passo que o UNIMARC não faz essa separação;

- a área de notas, em MARC 21, concentra-se no Bloco de campos 5XX, já no UNIMARC, as notas são incluídas no Bloco 3XX, isto pode ser observado nos dois quadros acima;

- os dois quadros mostram também que, na parte dos pontos de acesso concernentes aos cabeçalhos para pessoas e cabeçalhos para entidades, o MARC 21 designa dois blocos, sendo 1XX e 7XX para entradas primárias e entradas secundárias, respectivamente. Diferentemente, o UNIMARC criou um bloco único, que é o $7 \mathrm{XX}$, onde são inseridas tanto as responsabilidades primárias quanto as secundárias. Nestes campos, nota-se também que, no MARC 21, o nome invertido completo (sobrenome, nome) é lançado no subcampo \$a, ao passo que, no UNIMARC, o sobrenome entra primeiro no subcampo \$a e a outra parte do nome depois, no subcampo \$b;

- o número da classificação segundo a CDD ou CDU, no MARC 21, é inserido no Bloco 0XX destinado à Números e Códigos de Controle. Já no UNIMARC, as informações de classificação ocorrem no bloco $6 \mathrm{XX}$ que é destinado a assuntos e história bibliográfica.

Ao verificar o resultado do cotejamento entre o MARC 21 e o UNIMARC, conclui-se que, no geral, a estrutura dos registros possui semelhanças englobando todas as áreas e pontos de acesso necessários para a descrição de livros, segundo as diretrizes do AACR2. Porém, há diferenças em relação às etiquetas dos campos e subcampos. Isto se dá, principalmente, devido às diferenças no estabelecimento dos conteúdos dos blocos de campos destes dois formatos.

\subsection{O MARC 21 E O FORMATO CCF}

O Formato Comum de Comunicação (CCF), criado pela UNESCO no final da década de 1970, tomou por base características tanto do padrão UNIMARC como também do Manual de referência UNISIST. Percebe-se que o formato CCF sistematizou os seus campos e subcampos com a preocupação de descrever documentos de diferentes segmentos: livros, revistas, artigos de periódicos e outros. 
Isto nos remete aos níveis de descrição definidos pelo manual UNISIST: nível analítico, nível monográfico, nível coleção e nível de publicação seriada.

No quadro a seguir foram listadas áreas de descrição e os tipos de pontos de acesso para a descrição de livros (material monográfico no todo), conforme o AACR2 e, ao lado, foram informados os campos correspondentes comumente usados para a representação descritiva tanto em formato MARC 21 para Dados Bibliográficos quanto no formato CCF.

Quadro 13 - Campos variáveis do MARC 21 e do CCF para a descrição de livros segundo o AACR2 (continua...)

\begin{tabular}{|c|c|c|}
\hline $\begin{array}{l}\text { Áreas de descrição } \\
\text { segundo o } \\
\text { AACR2 PARTE I }\end{array}$ & $\begin{array}{l}\text { Campos } \\
\text { para descrição de LIVROS no } \\
\text { MARC } 21 \text { Bibliográfico }\end{array}$ & $\begin{array}{l}\text { Campos } \\
\text { correspondentes no } \\
\text { Formato CCF }\end{array}$ \\
\hline $\begin{array}{l}\text { Área do título e da } \\
\text { indicação de } \\
\text { responsabilidade }\end{array}$ & $\begin{array}{l}240 \text { - Título uniforme } \\
245 \text { - Indicação de título } \\
246 \text { - Forma variante do título }\end{array}$ & $\begin{array}{l}200 \text { - Título e indicação de } \\
\quad \text { Responsabilidade } \\
210 \text { - Título paralelo e indicação } \\
\text { de responsabilidade } \\
240 \text { - Título uniforme }\end{array}$ \\
\hline Área da edição & 250 - Indicação de edição & 260 - Indicação de Edição \\
\hline $\begin{array}{l}\text { Área da publicação, } \\
\text { distribuição, etc. }\end{array}$ & $\begin{array}{l}260 \text { - Imprenta } \\
264 \text { - Produção, publicação, } \\
\text { distribuição, manufatura e } \\
\text { informação de Copyright }\end{array}$ & $\begin{array}{l}400 \text { - Lugar de publicação e } \\
\text { editor } \\
420 \text { - Lugar e nome do } \\
\text { distribuidor } \\
440 \text { - Data de publicação }\end{array}$ \\
\hline $\begin{array}{l}\text { Área da descrição } \\
\text { física }\end{array}$ & 300 - Descrição física & 460 - Descrição física \\
\hline Área de série & $\begin{array}{l}490 \text { - Indicação de série } \\
800 \text { - Entrada secundária de } \\
\text { série - Nome pessoal } \\
810 \text { - Entrada secundária de } \\
\text { série - Nome Corporativo } \\
811 \text { - Entrada secundária de } \\
\text { série - Nome de evento } \\
830 \text { - Entrada secundária de } \\
\text { série - Título uniforme }\end{array}$ & $\begin{array}{l}480 \text { - Indicação de série e } \\
\text { responsabilidade associada }\end{array}$ \\
\hline Área de notas & $\begin{array}{l}\mathbf{5 0 0} \text { - Nota geral } \\
\mathbf{5 0 1} \text { - Nota iniciada por "com" } \\
\mathbf{5 0 4} \text { - Nota de bibliografia } \\
\mathbf{5 0 5} \text { - Nota de conteúdo } \\
\mathbf{5 2 0} \text { - Nota de resumo } \\
\mathbf{5 3 0} \text { - Nota de disponibilidade de } \\
\quad \text { forma física adicional } \\
\mathbf{5 3 4} \text { - Nota de versão original } \\
\mathbf{5 4 6} \text { - Nota de idioma } \\
\mathbf{5 9 X} \text { - Notas locais }\end{array}$ & $\begin{array}{l}500 \text { - Nota geral } \\
530 \text { - Nota de conteúdo } \\
600 \text { - Nota de resumo }\end{array}$ \\
\hline
\end{tabular}




\begin{tabular}{|c|c|c|}
\hline $\begin{array}{l}\text { Área de número } \\
\text { normalizado }\end{array}$ & $020-I S B N$ & $100-$ ISBN \\
\hline $\begin{array}{l}\text { Pontos de acesso } \\
\text { segundo o } \\
\text { AACR2 PARTE II }\end{array}$ & $\begin{array}{l}\text { Campos } \\
\text { para descrição de LIVROS no } \\
\text { MARC } 21 \text { Bibliográfico }\end{array}$ & $\begin{array}{l}\text { Campos } \\
\text { correspondentes no } \\
\text { Formato CCF }\end{array}$ \\
\hline $\begin{array}{l}\text { Cabeçalhos para } \\
\text { Pessoas }\end{array}$ & $\begin{array}{l}100 \text { - Entrada principal - Nome } \\
\text { Pessoal } \\
600 \text { - Assunto - Nome Pessoal } \\
700 \text { - Entrada Secundária - } \\
\text { Nome Pessoal }\end{array}$ & $300-$ Nome pessoal \\
\hline Nomes Geográficos & 651 - Assunto - Nome Geográfico & 620 - Descritor para o assunto \\
\hline $\begin{array}{l}\text { Cabeçalhos para } \\
\text { entidades }\end{array}$ & $\begin{array}{l}110 \text { - Entrada principal - Nome } \\
\text { Corporativo } \\
111 \text { - Entrada principal - Nome } \\
\text { de Evento } \\
\\
610 \text { - Assunto - Nome } \\
\text { Corporativo } \\
611 \text { - Assunto - Nome de Evento } \\
\\
710 \text { - Entrada Secundária - } \\
\text { Nome Corporativo } \\
711 \text { - Entrada Secundária - } \\
\text { Nome de Evento }\end{array}$ & $\begin{array}{l}310 \text { - Nome da Entidade Coletiva } \\
320 \text { - Nome do Evento }\end{array}$ \\
\hline Títulos Uniformes & $\begin{array}{l}130 \text { - Entrada principal - Título } \\
\text { Uniforme } \\
240 \text { - Título uniforme } \\
630 \text { - Assunto - Título Uniforme } \\
730 \text { - Entrada Secundária - Título } \\
\text { uniforme }\end{array}$ & 240 - Título uniforme \\
\hline
\end{tabular}

Fonte: elaboração própria, a partir de Ferreira (2013) e UNESCO (1994).

O quadro a seguir, traz a representação descritiva de um livro nos dois formatos: MARC 21 e CCF. 
Quadro 14 - Representação descritiva de um livro nos formatos MARC 21 e CCF

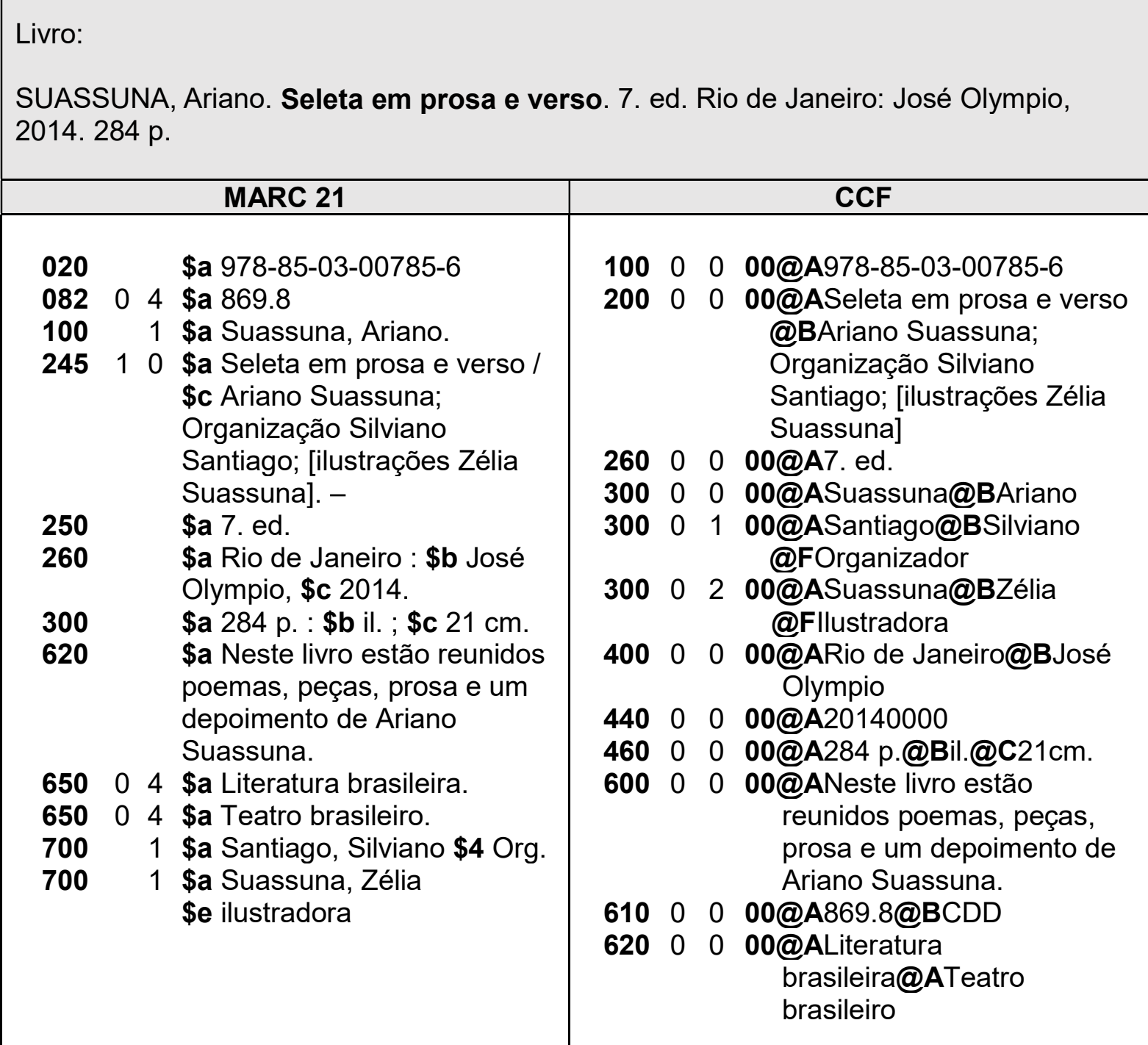

Fonte: elaboração própria, a partir de Ferreira (2013) e UNESCO (1994).

Observando os resultados apresentados acima, nos Quadros 13 e 14, percebe-se as seguintes semelhanças entre o MARC 21 e o CCF:

- assim como o MARC 21, o formato CCF possui campos que permitem a descrição de todas as áreas e pontos de acesso previstos no AACR2 para a descrição de livros, embora o CCF não determine o uso de nenhum código de catalogação em particular; 
- o CCF também foi construído com o uso de campos identificados por três dígitos numéricos, os quais são compostos de indicadores e subcampos para a inserção dos dados dos materiais;

- os dois formatos possuem campos repetíveis e não repetíveis. Por exemplo, o campo destinado ao título principal é um campo classificado como não repetível tanto no MARC 21 como no CCF. Já o campo destinado para autores secundários é repetível nos dois formatos, como observado no Quadro 14.

Notam-se também as seguintes diferenças entre o MARC 21 e o CCF:

- no MARC 21, os subcampos possuem delimitadores que podem ser | ou \$, seguidos de um número ou uma letra minúscula para designar os subcampos. No CCF o princípio é o mesmo, porém é usado o símbolo @ e letras maiúsculas para representar os subcampos, por exemplo: @A, @B;

- no que se refere à área da publicação, distribuição, etc., observa-se que, no CCF, a data de publicação é inserida no campo 440 o qual é separado do campo de local e editora. Neste campo 440 o catalogador tem a opção de inserir a data de publicação normalizada segundo a norma ISO 8601 no subcampo @A ou a data não normalizada no subcampo @B. No MARC 21, a data de publicação é lançada com o local e a editora no campo 260 , sendo que o subcampo de data de publicação não segue normalização ISO, o catalogador deve atribuir a data conforme orientações do Código de Catalogação. No caso do MARC 21, a data normalizada segundo a ISO 8601 é inserida no campo 005, porém, este campo refere-se à data e à hora em que foi realizada a última intervenção no registro e geralmente é lançada automaticamente pelos sistemas.

- os dois quadros acima mostram que, na parte dos pontos de acesso, ou seja, os cabeçalhos para pessoas e os cabeçalhos para entidades, no CCF são todas registradas em um único campo que é o campo 300 , sendo este um campo repetível, conforme mostra o exemplo do quadro 13. Já o MARC 21 designa dois blocos, sendo 1XX e 7XX para entradas primárias e entradas secundárias, respectivamente. Nestes campos, nota-se também que, no MARC 21, o nome invertido completo (sobrenome, nome) do autor é lançado no 
subcampo \$a, ao passo que, no CCF, o sobrenome entra primeiro no subcampo @A e a outra parte do nome depois, no subcampo @B;

- nota-se, no Quadro 14, que, diferentemente do MARC 21, o CCF possui em seus registros duas sequências verticais de números, antes dos indicadores, ficando, por exemplo, o campo do título assim: [200 0000 @ Seleta em prosa e verso]. Essas duas linhas verticais com dígitos numéricos que aparecem na frente dos campos e antes dos indicadores, servem para identificar o segmento e a ocorrência do campo, respectivamente. No exemplo acima, a primeira coluna vertical foi toda preenchida com zeros, isto significa que o material ali descrito engloba apenas um segmento, que no caso é um livro. Se fosse, por exemplo, um registro de artigo de periódico, haveria um campo de ligação com o nome da revista a qual ele pertence. Nesse caso, o título da revista seria um outro segmento dentro do registro do artigo. Os campos referentes a este outro segmento receberiam o número 1 e não o zero na primeira coluna vertical. Ainda considerando o exemplo do Quadro 14, nota-se que a segunda coluna vertical de números possui a numeração 0, 1 e 2 na frente do campo 300 , mostrando que há diferentes ocorrências para este mesmo campo que é repetível;

- no MARC 21, o número da Classificação Decimal de Dewey é inserido no campo 082 e a Classificação Decimal Universal entra no campo 080. Por outro lado, no CCF, as informações de classificação ocorrem todas no campo 610, sendo que, neste campo, o subcampo @B é designado para informação de qual tabela de classificação está sendo utilizada;

- nota-se também, no Quadro 14, que no CCF os assuntos principais entram no mesmo campo 620, visto que dentro deste campo o subcampo @A é repetível. Já no MARC 21 designa-se um novo campo 650 para cada assunto principal visto que o subcampo \$a não é repetível dentro do campo.

Ao verificar os resultados deste cotejamento do MARC 21 com o formato CCF conclui-se que, apesar de terem algumas semelhanças, estes dois formatos se distanciam muito no estabelecimento dos campos de dados e seus subcampos. $O$ MARC 21 possui mais opções de campos, detalhando mais as informações. Já o CCF 
é mais enxuto agrupando diferentes informações em um só campo, como é o caso dos campos 300, 610 e 620.

O fato de o CCF proporcionar a ligação de diferentes segmentos em um único registro revela a preocupação da UNESCO em criar um formato que pudesse atender, na época, a diferentes comunidades que vão desde as bibliotecas tradicionais aos então chamados "serviços secundários" (HOPKINSON, 1985) que envolvem bases de dados de artigos de periódicos, serviços de indexação e resumo, informações de anais de eventos, dentre outros. O MARC em sua evolução passou a contemplar também diferentes segmentos e materiais em diversos tipos de suporte.

\subsection{O MARC 21 E O FORMATO LILACS}

Conforme mencionado em capítulos anteriores, o formato LILACS foi criado na década de 1980, com base nas diretrizes do Manual UNISIST, para atender comunidades bibliográficas de literatura científica e técnica na área da Saúde e, atualmente, atende a instituições em muitos países. A partir de 2006, começou a incorporar alguns elementos do MARC 21. Sendo assim, ao cotejar este formato com o MARC 21, buscou-se identificar os traços advindos destes dois padrões: o UNISIST e o próprio MARC.

No Quadro 15, apresentam-se as áreas e os tipos de pontos de acesso para a descrição de livros, conforme o AACR2, com os campos correspondentes, comumente usados para a representação descritiva de livros, no formato MARC 21 para Dados Bibliográficos e seus correspondentes no formato LILACS.

Quadro 15 - Campos variáveis do MARC 21 e do LILACS para a descrição de livros segundo o AACR2 (continua...)

\begin{tabular}{|c|l|l|}
\hline $\begin{array}{c}\text { Áreas de descrição } \\
\text { segundo o } \\
\text { AACR2 PARTE I }\end{array}$ & $\begin{array}{c}\text { Campos } \\
\text { para descrição de LIVROS no } \\
\text { MARC 21 Bibliográfico }\end{array}$ & $\begin{array}{c}\text { Campos } \\
\text { correspondentes no } \\
\text { Formato LILACS }\end{array}$ \\
\hline $\begin{array}{c}\text { Área do título e da } \\
\text { indicação de } \\
\text { responsabilidade }\end{array}$ & $\begin{array}{c}240 \text { - Título uniforme } \\
245 \text { - Indicação de título } \\
246 \text { - Forma variante do título }\end{array}$ & $\begin{array}{l}18 \text { - Título (nível monográfico) } \\
25 \text { - Título (Nível coleção) }\end{array}$ \\
\hline Área da edição & 250 - Indicação de edição & 63 - Edição \\
\hline
\end{tabular}




\begin{tabular}{|c|c|c|}
\hline $\begin{array}{l}\text { Área da publicação, } \\
\text { distribuição etc. }\end{array}$ & \begin{tabular}{|l}
260 - Imprenta \\
264 - Produção, publicação, \\
distribuição, manufatura e \\
informação de Copyright
\end{tabular} & $\begin{array}{l}62 \text { - Editora } \\
64 \text { - Data de publicação } \\
65 \text { - Data normalizada } \\
66 \text { - Cidade de publicação }\end{array}$ \\
\hline $\begin{array}{l}\text { Área da descrição } \\
\text { física }\end{array}$ & 300 - Descrição física & $\begin{array}{l}20 \text { - Páginas (Nível monográfico) } \\
38 \text { - Informação descritiva }\end{array}$ \\
\hline Área de série & $\begin{array}{l}490 \text { - Indicação de série } \\
800 \text { - Entrada secundária de } \\
\text { série - Nome pessoal } \\
810 \text { - Entrada secundária de } \\
\text { série - Nome Corporativo } \\
811 \text { - Entrada secundária de } \\
\text { série - Nome de evento } \\
830 \text { - Entrada secundária de } \\
\text { série - Título uniforme }\end{array}$ & $\begin{array}{l}25 \text { - Título (Nível coleção) } \\
30 \text { - Título (Nível série) }\end{array}$ \\
\hline Área de notas & $\begin{array}{l}\mathbf{5 0 0} \text { - Nota geral } \\
\mathbf{5 0 1} \text { - Nota iniciada por "com" } \\
\mathbf{5 0 4} \text { - Nota de bibliografia } \\
\mathbf{5 0 5} \text { - Nota de conteúdo } \\
\mathbf{5 2 0} \text { - Nota de resumo } \\
\mathbf{5 3 0} \text { - Nota de disponibilidade de } \\
\quad \text { forma física adicional } \\
\mathbf{5 3 4} \text { - Nota de versão original } \\
\mathbf{5 4 6} \text { - Nota de idioma } \\
\mathbf{5 9 X} \text { - Notas locais }\end{array}$ & $\begin{array}{l}61 \text { - Nota interna } \\
83 \text { - Resumo } \\
500 \text { - Nota geral } \\
505 \text { - Nota formatada de } \\
\quad \text { conteúdo } \\
530 \text { - Nota de disponibilidade de } \\
\quad \text { forma física adicional }\end{array}$ \\
\hline $\begin{array}{l}\text { Área de número } \\
\text { normalizado }\end{array}$ & $020-$ ISBN & $69-$ ISBN \\
\hline $\begin{array}{l}\text { Pontos de acesso } \\
\text { segundo o } \\
\text { AACR2 PARTE II }\end{array}$ & $\begin{array}{l}\text { Campos } \\
\text { para descrição de LIVROS no } \\
\text { MARC } 21 \text { Bibliográfico }\end{array}$ & $\begin{array}{l}\text { Campos } \\
\text { correspondentes no } \\
\text { Formato LILACS }\end{array}$ \\
\hline $\begin{array}{l}\text { Cabeçalhos para } \\
\text { Pessoas }\end{array}$ & $\begin{array}{l}100 \text { - Entrada principal - Nome } \\
\text { Pessoal } \\
600 \text { - Assunto - Nome Pessoal } \\
700 \text { - Entrada Secundária - } \\
\text { Nome Pessoal }\end{array}$ & $\begin{array}{l}16 \text { - Autor pessoal (nível } \\
\quad \text { monográfico) } \\
23 \text { - Autor pessoal (nível coleção) } \\
78 \text { - Indivíduo como tema }\end{array}$ \\
\hline Nomes Geográficos & 651 - Assunto - Nome Geográfico & $\begin{array}{l}82 \text { - Região não DeCS } \\
87 \text { - Descritor Primário }\end{array}$ \\
\hline $\begin{array}{l}\text { Cabeçalhos para } \\
\text { entidades }\end{array}$ & $\begin{array}{l}110 \text { - Entrada principal - Nome } \\
\text { Corporativo } \\
111 \text { - Entrada principal - Nome } \\
\text { de Evento } \\
\\
610 \text { - Assunto - Nome } \\
\text { Corporativo } \\
611 \text { - Assunto - Nome de Evento } \\
\\
710 \text { - Entrada Secundária - } \\
\text { Nome Corporativo } \\
711 \text { - Entrada Secundária - } \\
\text { Nome de Evento }\end{array}$ & $\begin{array}{l}17 \text { - Autor Institucional (Nível } \\
\text { monográfico) } \\
24 \text { - Autor Institucional (Nível } \\
\text { coleção) } \\
52 \text { - Evento - Instituição } \\
\quad \text { Patrocinadora } \\
53 \text { - Evento - Nome } \\
610 \text { - Instituição como tema }\end{array}$ \\
\hline
\end{tabular}




\begin{tabular}{|c|l|l|}
\hline Títulos Uniformes & $\begin{array}{l}130 \text { - Entrada principal - Título } \\
\text { Uniforme } \\
240-\text { Título uniforme } \\
630 \text { - Assunto - Título Uniforme } \\
730 \text { - Entrada Secundária - Título } \\
\text { uniforme }\end{array}$ & \\
\hline
\end{tabular}

Fonte: elaboração própria, a partir de Ferreira (2013) e BIREME (2008).

Para elucidar um pouco mais as semelhanças e diferenças entre estes dois formatos, apresenta-se, a seguir, o Quadro 16 onde foi inserida a descrição de um livro nos formatos MARC 21 e LILACS.

Quadro 16 - Representação descritiva de um livro nos formatos MARC 21 e LILACS

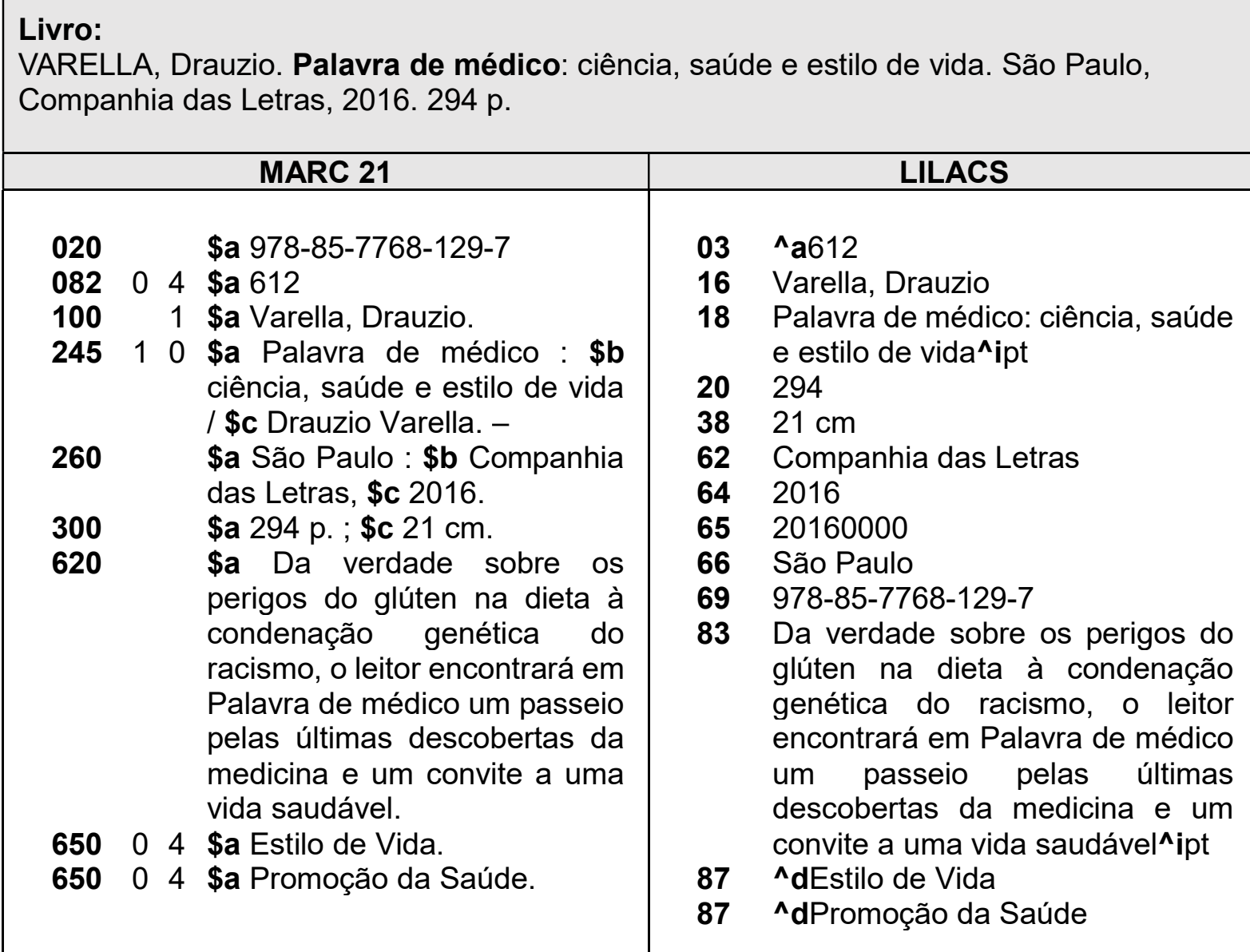

Fonte: elaboração própria, a partir de Ferreira (2013) e BIREME (2008).

Observando os dois quadros apresentados anteriormente, notam-se as seguintes semelhanças entre o MARC 21 e o formato LILACS: 
- assim como o MARC 21, o formato LILACS possui campos que permitem a descrição de todas as áreas e pontos de acesso previstos no AACR2 para a descrição de livros, com exceção apenas para títulos uniformes, sobre os quais o manual do formato LILACS não faz menção;

- o LILACS também foi construído com o uso de campos e subcampos para a inserção dos dados dos materiais, os quais podem ser repetíveis e não repetíveis;

- no Quadro 15, nota-se que os campos 500, 505 e 530 da área de notas do MARC 21, bem como o campo 610 nos cabeçalhos para entidades, foram adaptados também para o formato LILACS.

Analisando os resultados apresentados nos Quadros 15 e 16, são encontradas as seguintes diferenças entre o MARC 21 e o LILACS:

- no formato LILACS a maioria dos campos é identificada com etiquetas de dois dígitos numéricos (16-autor, 18-título, etc.) ao passo que, no MARC, usa-se sempre três dígitos (100-autor, 245-título, etc.);

- no MARC 21, os subcampos possuem delimitadores que podem ser | ou \$, seguidos de um número ou uma letra minúscula para designar os subcampos. No LILACS é usado o símbolo ${ }^{\wedge}$ e letras maiúsculas ou números para representar os subcampos, por exemplo: ^a, ^1;

- conforme pode ser observado no quadro 16, na maioria dos campos do formato LILACS, o delimitador de subcampo só é informado a partir do segundo elemento de dado e, além disso, as pontuações muitas vezes não são consideradas;

- seguindo o Manual UNISIST, o LILACS divide a descrição dos documentos bibliográficos em níveis, sendo: nível analítico, nível monográfico, nível série e nível coleção. No Quadro 15 acima, nota-se que o número do campo para um mesmo tipo de dado muda de acordo com o nível de descrição, por exemplo: o título no nível monográfico entra no campo 18, já o título no nível coleção entra no campo 25. O MARC 21 não faz esta separação, o título principal dos documentos sempre entrará no campo 245, não importando o tipo de documento; 
- observa-se que o LILACS utiliza mais campos e menos subcampos, por exemplo: na área da publicação, distribuição, etc., os elementos local, editora e data de publicação aparecem em campos separados, ao passo que, no MARC, esses três dados entram em um só campo 260. Além disso, no LILACS o catalogador tem a opção de inserir também a data de publicação normalizada segundo a norma ISO 8601 no campo 65, o MARC 21 não dá essa opção em caso de data de publicação;

- os dois quadros acima mostram que, na parte dos pontos de acesso, ou seja, os cabeçalhos para pessoas e os cabeçalhos para entidades, o formato LILACS não designa campos diferentes para entradas primárias e secundárias. Quando um livro possui mais de um autor pessoal, por exemplo, todos são lançados no campo 16, o qual é um campo repetível. Já no MARC 21 , se o documento tiver mais de um autor pessoal, o primeiro autor entra no campo 100 (não repetível), e os demais autores no campo 700 (repetível), e o mesmo ocorre para nomes corporativos e nomes de eventos, sendo cada um com seus respectivos campos.

Ao cotejar os elementos do MARC 21 e do LILACS, percebe-se que a determinação dos campos e subcampos entre os dois padrões é bem diferenciada. A observância do Manual de Referência UNISIST, por parte do LILACS, fez com que a sua estrutura se dividisse em níveis de descrição, e com isto, se diferenciou do padrão MARC. Entretanto, nota-se que alguns campos do MARC foram implantados no LILACS, como por exemplo os campos de notas $(500,505,530)$ e instituição como tema (610). Além disso, no próprio manual do formato LILACS, utilizado para a realização do cotejamento aqui exposto, encontra-se a demonstração da correspondência dos campos LILACS com os campos MARC 21. Isto evidencia que esforços estão sendo feitos para a compatibilização destes dois importantes formatos.

\subsection{O MARC 21 E O FORMATO CEPAL}

Lançado pela Comissão Econômica para a América Latina e o Caribe no início da década de 1980, o formato CEPAL também foi construído segundo as diretrizes do Manual de Referência UNISIST. 
No Quadro 17, apresentam-se as áreas e os tipos de pontos de acesso para a descrição de livros, conforme o AACR2, com os campos correspondentes, comumente usados para livros, no formato MARC 21 para Dados Bibliográficos e seus correspondentes no formato CEPAL.

Quadro 17 - Campos variáveis do MARC 21 e do formato CEPAL para a descrição de livros segundo o AACR2 (continua...)

\begin{tabular}{|c|c|c|}
\hline $\begin{array}{l}\text { Áreas de descrição } \\
\text { segundo o } \\
\text { AACR2 PARTE I }\end{array}$ & $\begin{array}{c}\text { Campos } \\
\text { para descrição de LIVROS no } \\
\text { MARC } 21 \text { Bibliográfico }\end{array}$ & $\begin{array}{l}\text { Campos } \\
\text { correspondentes no } \\
\text { Formato CEPAL }\end{array}$ \\
\hline $\begin{array}{l}\text { Área do título e da } \\
\text { indicação de } \\
\text { responsabilidade }\end{array}$ & $\begin{array}{l}240 \text { - Título uniforme } \\
245 \text { - Indicação de título } \\
246 \text { - Forma variante do título }\end{array}$ & $\begin{array}{l}18 \text { - Título (nível monográfico) } \\
25 \text { - Título (Nível coleção) }\end{array}$ \\
\hline Área da edição & 250 - Indicação de edição & 41 - Edição \\
\hline $\begin{array}{l}\text { Área da publicação, } \\
\text { distribuição etc. }\end{array}$ & \begin{tabular}{|c|}
260 - Imprenta \\
264 - Produção, publicação, \\
distribuição, manufatura e \\
informação de Copyright
\end{tabular} & $\begin{array}{l}38 \text { - Editora } \\
39 \text { - Cidade da Editora } \\
43 \text { - Data de publicação } \\
44 \text { - Data normalizada (ISO) }\end{array}$ \\
\hline $\begin{array}{c}\text { Área da descrição } \\
\text { física }\end{array}$ & 300 - Descrição física & $\begin{array}{l}20 \text { - Páginas (Nível monográfico) } \\
27 \text { - Número de volumes } \\
42 \text { - Informação descritiva }\end{array}$ \\
\hline Área de série & $\begin{array}{l}490 \text { - Indicação de série } \\
800 \text { - Entrada secundária de } \\
\text { série - Nome pessoal } \\
810 \text { - Entrada secundária de } \\
\text { série - Nome Corporativo } \\
811 \text { - Entrada secundária de } \\
\text { série - Nome de evento } \\
830 \text { - Entrada secundária de } \\
\text { série - Título uniforme }\end{array}$ & $\begin{array}{l}23 \text { - Autor pessoal (Nível coleção) } \\
\mathbf{2 4} \text { - Autor Institucional (Nível } \\
\quad \text { Coleção) } \\
\mathbf{2 5} \text { - Título (Nível coleção) } \\
\mathbf{2 7} \text { - Número de volumes }\end{array}$ \\
\hline Área de notas & $\begin{array}{l}\mathbf{5 0 0} \text { - Nota geral } \\
\mathbf{5 0 1} \text { - Nota iniciada por "com" } \\
\mathbf{5 0 4} \text { - Nota de bibliografia } \\
\mathbf{5 0 5} \text { - Nota de conteúdo } \\
\mathbf{5 2 0} \text { - Nota de resumo } \\
\mathbf{5 3 0} \text { - Nota de disponibilidade de } \\
\quad \text { forma física adicional } \\
\mathbf{5 3 4} \text { - Nota de versão original } \\
\mathbf{5 4 6} \text { - Nota de idioma } \\
\mathbf{5 9 X} \text { - Notas locais }\end{array}$ & $\begin{array}{l}68-\text { Notas } \\
72-\text { Resumo } \\
73 \text { - Referências }\end{array}$ \\
\hline $\begin{array}{l}\text { Área de número } \\
\text { normalizado }\end{array}$ & $020-I S B N$ & 47 - ISBN \\
\hline
\end{tabular}




\begin{tabular}{|c|c|c|}
\hline $\begin{array}{l}\text { Pontos de acesso } \\
\text { segundo o } \\
\text { AACR2 PARTE II }\end{array}$ & $\begin{array}{l}\text { Campos } \\
\text { para descrição de LIVROS no } \\
\text { MARC } 21 \text { Bibliográfico }\end{array}$ & $\begin{array}{l}\text { Campos } \\
\text { correspondentes no } \\
\text { Formato CEPAL }\end{array}$ \\
\hline $\begin{array}{l}\text { Cabeçalhos para } \\
\text { Pessoas }\end{array}$ & $\begin{array}{l}100 \text { - Entrada principal - Nome } \\
\text { Pessoal } \\
600 \text { - Assunto - Nome Pessoal } \\
700 \text { - Entrada Secundária - } \\
\text { Nome Pessoal }\end{array}$ & $\begin{array}{l}16 \text { - Autor pessoal (nível } \\
\text { monográfico) } \\
23 \text { - Autor pessoal (nível coleção) }\end{array}$ \\
\hline Nomes Geográficos & 651 - Assunto - Nome Geográfico & $\begin{array}{l}83 \text { - Países primários } \\
84 \text { - Países secundários }\end{array}$ \\
\hline $\begin{array}{l}\text { Cabeçalhos para } \\
\text { entidades }\end{array}$ & $\begin{array}{l}110 \text { - Entrada principal - Nome } \\
\text { Corporativo } \\
111 \text { - Entrada principal - Nome } \\
\text { de Evento } \\
610 \text { - Assunto - Nome } \\
\text { Corporativo } \\
611 \text { - Assunto - Nome de Evento } \\
710 \text { - Entrada Secundária - } \\
\text { Nome Corporativo } \\
711 \text { - Entrada Secundária - } \\
\text { Nome de Evento }\end{array}$ & $\begin{array}{l}17 \text { - Autor Institucional (Nível } \\
\text { monográfico) } \\
\mathbf{2 4} \text { - Autor Institucional (Nível } \\
\text { coleção) } \\
\mathbf{5 2} \text { - Conferência - Instituição } \\
\mathbf{5 3} \text { - Conferência - Nome }\end{array}$ \\
\hline Títulos Uniformes & $\begin{array}{l}130 \text { - Entrada principal - Título } \\
\text { Uniforme } \\
240 \text { - Título uniforme } \\
630 \text { - Assunto - Título Uniforme } \\
730 \text { - Entrada Secundária - Título } \\
\text { uniforme }\end{array}$ & Não encontrado \\
\hline
\end{tabular}

Fonte: elaboração própria, a partir de Ferreira (2013) e Arendt (2003).

Apresenta-se também, no Quadro 18, a descrição de um livro nos campos variáveis dos formatos MARC 21 e CEPAL. 
Quadro 18 - Representação descritiva de um livro nos formatos MARC 21 e CEPAL

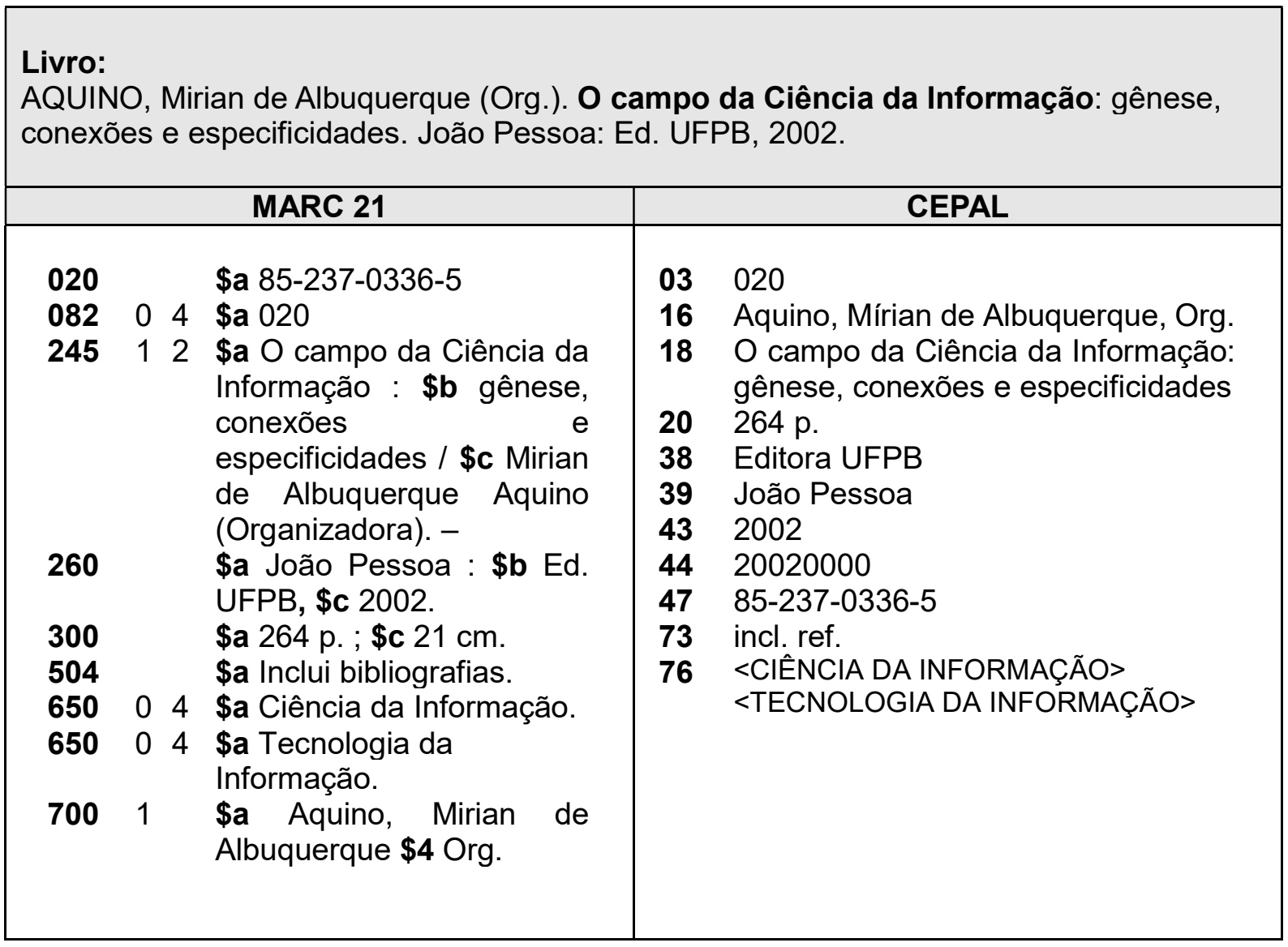

Fonte: elaboração própria, a partir de Ferreira (2013), Arendt (2003) e CEPAL (1989).

Observando os dois quadros apresentados anteriormente, nota-se a seguinte semelhança entre o MARC 21 e o formato CEPAL:

- assim como o MARC 21, o formato CEPAL possui campos repetíveis e não repetíveis que permitem a descrição de todas as áreas e pontos de acesso previstos no AACR2 para a descrição de livros, com exceção para títulos uniformes, dos quais o manual do formato CEPAL não faz menção.

Analisando os resultados apresentados nos quadros 17 e 18, são encontradas as seguintes diferenças entre o MARC 21 e o formato CEPAL:

- no formato CEPAL os campos são identificados com etiquetas de dois dígitos numéricos (16-autor, 18-título, etc.) e não se faz uso de indicadores, ao passo 
que o MARC usa sempre três dígitos (100-autor, 245-título, etc.) e faz uso de indicadores;

- o MARC 21 possui subcampos delimitados por caracteres como | ou \$, e identificados com um número ou uma letra minúscula. Já o formato CEPAL não possui subcampos, é destinado um novo campo para cada elemento de dado, isto pode ser observado, por exemplo, na área da publicação, distribuição, etc., onde cada um dos elementos - local, editora e data de publicação - possui um campo próprio;

- no formato CEPAL o catalogador tem a opção de inserir também a data de publicação normalizada segundo a norma ISO 8601, no campo 44, o MARC 21 não dá essa opção em caso de data de publicação;

- seguindo o Manual UNISIST, o CEPAL divide a descrição dos documentos bibliográficos em níveis, sendo: nível analítico, nível monográfico, nível série e nível coleção. No Quadro 17, nota-se que o número do campo para um mesmo tipo de dado muda de acordo com o nível de descrição, por exemplo: o título no nível monográfico entra no campo 18 , já o título no nível coleção entra no campo 25. O MARC 21 não faz esta separação, o título principal dos documentos, por exemplo, sempre entrará no campo 245, não importando o tipo de documento;

- na parte dos pontos de acesso, ou seja, os cabeçalhos para pessoas e os cabeçalhos para entidades, o formato CEPAL não atribui campos separados para diferenciar autores primários e secundários, por exemplo, quando um livro possui mais de um autor pessoal, todos são lançados no campo 16 o qual é um campo repetível. Já no MARC 21, se o documento tiver mais de um autor pessoal, o primeiro autor entra no campo 100 (não repetível), e os demais autores no campo 700 (repetível) e o mesmo ocorre para nomes corporativos e nomes de eventos, sendo cada um com seus respectivos campos;

- nota-se também, no Quadro 18, que os assuntos relacionados entram no mesmo campo 76, ao passo que no MARC 21 designa-se um novo campo 650 para cada tópico principal.

Com o cotejamento destes dois formatos, percebe-se que o formato CEPAL foi projetado com características mais simples em relação ao MARC 21. Embora faça a distinção de campos para a descrição de materiais em diferentes níveis, o fato de o 
CEPAL não fazer uso dos indicadores nem de subcampos exige menos trabalho do catalogador, tornando-o um padrão mais fácil de utilização.

Entretanto, é necessário lembrar que o formato CEPAL foi criado na década de 1980 e funcionou com os softwares MicrolSIS e WinISIS, os quais cumpriram o seu papel para a época, porém não foram projetados para uso em multiplataformas e deixaram de ser utilizados, visto que o avanço tecnológico impulsionou a busca por soluções mais evoluídas com novas alternativas para projetos de automação, isso foi explicado por Saborío-Acuña e Chinchilla-Arley (2014). Com isso, esses autores apontam uma metodologia para a migração de dados do formato CEPAL para o formato MARC 21 e argumentam que tal migração requer um cuidadoso estabelecimento de equivalência entre os dois formatos e uma revisão minuciosa com o objetivo de diminuir a quantidade de inconsistências e a perda de informações.

\subsection{O MARC 21 E O FORMATO IBICT}

O formato IBICT foi criado para ser o sucessor do CALCO no Brasil. Notase, ao consultar os seus manuais, que o IBICT evoluiu em relação ao CALCO trazendo uma estrutura mais flexível e abrangente, possibilitando a descrição não só de materiais monográficos, mas também de publicações seriadas. O IBICT trouxe a divisão dos níveis bibliográficos: $(A)$ analítico, (M) monografia e (S) publicações seriadas.

Visando o cotejamento do formato IBICT com o formato MARC 21, apresenta-se no Quadro 19, as áreas de descrição de livros e os pontos de acesso segundo o AACR2 e, ao lado, os campos do MARC 21 e seus correspondentes no formato IBICT para a descrição dos dados. 
Quadro 19 - Campos variáveis MARC 21 e do formato IBICT para a descrição de livros segundo o AACR2 (continua...)

\begin{tabular}{|c|c|c|}
\hline $\begin{array}{l}\text { Áreas de descrição } \\
\text { segundo o } \\
\text { AACR2 PARTE I }\end{array}$ & $\begin{array}{c}\text { Campos } \\
\text { para descrição de LIVROS no } \\
\text { MARC } 21 \text { Bibliográfico }\end{array}$ & $\begin{array}{l}\text { Campos } \\
\text { correspondentes no } \\
\text { Formato IBICT }\end{array}$ \\
\hline $\begin{array}{l}\text { Área do título e da } \\
\text { indicação de } \\
\text { responsabilidade }\end{array}$ & $\begin{array}{l}240 \text { - Título uniforme } \\
245 \text { - Indicação de título } \\
246 \text { - Forma variante do título }\end{array}$ & $\begin{array}{l}\mathbf{2 4 0} \text { - Título convencionado para } \\
\text { o arquivamento } \\
\mathbf{2 4 5} \text { - Título e indicação de } \\
\text { responsabilidade } \\
\mathbf{2 4 6} \text { - Variação do título }\end{array}$ \\
\hline Área da edição & 250 - Indicação de edição & 250 - Área de Edição \\
\hline $\begin{array}{l}\text { Área da publicação, } \\
\text { distribuição, etc. }\end{array}$ & \begin{tabular}{|l}
260 - Imprenta \\
264 - Produção, publicação, \\
distribuição, manufatura e \\
informação de Copyright
\end{tabular} & $\begin{array}{c}260 \text { - Área de publicação, } \\
\text { distribuição, etc. } \\
261 \text { - Data de publicação, } \\
\text { distribuição, etc. }\end{array}$ \\
\hline $\begin{array}{l}\text { Área da descrição } \\
\text { física }\end{array}$ & 300 - Descrição física & 300 - Área da colação \\
\hline Área de série & $\begin{array}{c}490 \text { - Indicação de série } \\
800 \text { - Entrada secundária de } \\
\text { série - Nome pessoal } \\
810 \text { - Entrada secundária de } \\
\text { série - Nome Corporativo } \\
811 \text { - Entrada secundária de } \\
\text { série - Nome de evento } \\
830 \text { - Entrada secundária de } \\
\text { série - Título uniforme }\end{array}$ & \begin{tabular}{|l}
400 - Série com nome \\
pessoal \\
410 - Série com o nome de uma \\
entidade \\
411 - Série com nome de um \\
congresso, conferência, \\
seminário, etc. \\
440 - Série com o nome do título \\
800 - Entrada secundária de \\
série com nome pessoal \\
810 - Entrada secundária de \\
série com o nome de uma \\
entidade \\
811 - Entrada secundária de \\
série com nome de um \\
congresso, conferência, \\
seminário, etc. \\
840 - Entrada secundária de \\
série com o nome do título
\end{tabular} \\
\hline Área de notas & $\begin{array}{l}\mathbf{5 0 0} \text { - Nota geral } \\
\mathbf{5 0 1} \text { - Nota iniciada por "com" } \\
\mathbf{5 0 4} \text { - Nota de bibliografia } \\
\mathbf{5 0 5} \text { - Nota de conteúdo } \\
\mathbf{5 2 0} \text { - Nota de resumo } \\
\mathbf{5 3 0} \text { - Nota de disponibilidade de } \\
\quad \text { forma física adicional } \\
\mathbf{5 3 4} \text { - Nota de versão original } \\
\mathbf{5 4 6} \text { - Nota de idioma } \\
\mathbf{5 9 X} \text { - Notas locais }\end{array}$ & $\begin{array}{l}\mathbf{5 0 0} \text { - Notas gerais } \\
\mathbf{5 0 1} \text { - Nota de "publicado com" } \\
\mathbf{5 0 3} \text { - Nota de conteúdo } \\
\mathbf{5 0 4} \text { - Nota de bibliografia, } \\
\quad \text { apêndice e/ou índice } \\
\mathbf{5 0 5} \text { - Nota de resumo } \\
\mathbf{5 2 0} \text { - Nota para inclusão em } \\
\quad \text { bibliografias } \\
\mathbf{5 9 0} \text { - Nota específica sobre o } \\
\text { documento na instituição }\end{array}$ \\
\hline $\begin{array}{l}\text { Área de número } \\
\text { normalizado }\end{array}$ & $020-I S B N$ & $020-$ ISBN \\
\hline
\end{tabular}




\begin{tabular}{|c|c|c|}
\hline $\begin{array}{l}\text { Pontos de acesso } \\
\text { segundo o } \\
\text { AACR2 PARTE II }\end{array}$ & $\begin{array}{l}\text { Campos } \\
\text { para descrição de LIVROS no } \\
\text { MARC } 21 \text { Bibliográfico }\end{array}$ & $\begin{array}{l}\text { Campos } \\
\text { correspondentes no } \\
\text { Formato IBICT }\end{array}$ \\
\hline $\begin{array}{l}\text { Cabeçalhos para } \\
\text { Pessoas }\end{array}$ & $\begin{array}{l}100 \text { - Entrada principal - Nome } \\
\text { Pessoal } \\
600 \text { - Assunto - Nome Pessoal } \\
700 \text { - Entrada Secundária - } \\
\text { Nome Pessoal }\end{array}$ & $\begin{array}{l}100 \text { - Entrada principal pelo nome } \\
\text { pessoal } \\
600 \text { - Nome pessoal como } \\
\text { assunto } \\
700 \text { - Entrada secundária pelo } \\
\text { nome pessoal }\end{array}$ \\
\hline Nomes Geográficos & 651 - Assunto - Nome Geográfico & $\begin{array}{l}651 \text { - Nome geográfico como } \\
\text { assunto }\end{array}$ \\
\hline $\begin{array}{l}\text { Cabeçalhos para } \\
\text { entidades }\end{array}$ & $\begin{array}{l}110 \text { - Entrada principal - Nome } \\
\text { Corporativo } \\
111 \text { - Entrada principal - Nome } \\
\text { de Evento } \\
\\
610 \text { - Assunto - Nome } \\
\text { Corporativo } \\
611 \text { - Assunto - Nome de Evento } \\
\\
710 \text { - Entrada Secundária - } \\
\text { Nome Corporativo } \\
711 \text { - Entrada Secundária - } \\
\text { Nome de Evento }\end{array}$ & \begin{tabular}{|c}
110 - Entrada principal pelo nome \\
de uma entidade \\
111 - Entrada principal pelo \\
nome de um congresso, \\
conferência, seminário, etc. \\
\\
610 - Nome de uma entidade \\
como assunto \\
611 - Nome de um congresso, \\
conferência, seminário, etc. \\
como assunto \\
710 - Entrada secundária pelo \\
nome de uma entidade \\
711 - Entrada secundária pelo \\
nome de um congresso, \\
conferência, seminário, etc.
\end{tabular} \\
\hline Títulos Uniformes & $\begin{array}{l}130 \text { - Entrada principal - Título } \\
\text { Uniforme } \\
240 \text { - Título uniforme } \\
630 \text { - Assunto - Título Uniforme } \\
730 \text { - Entrada Secundária - Título } \\
\text { uniforme }\end{array}$ & $\begin{array}{l}130 \text { - Entrada principal pelo título } \\
\text { uniforme } \\
240 \text { - Título convencionado para } \\
\text { o arquivamento } \\
630 \text { - Título uniforme como } \\
\text { assunto } \\
730 \text { - Entrada Secundária pelo } \\
\text { Título uniforme }\end{array}$ \\
\hline
\end{tabular}

Fonte: elaboração própria, a partir de Ferreira (2013) e IBICT (1987).

Visando facilitar o cotejamento do formato IBICT com o MARC 21 apresenta-se também o Quadro 20, com a catalogação de um livro nos campos e subcampos dos dois formatos. 
Quadro 20 - Representação descritiva de um livro nos formatos MARC 21 e IBICT

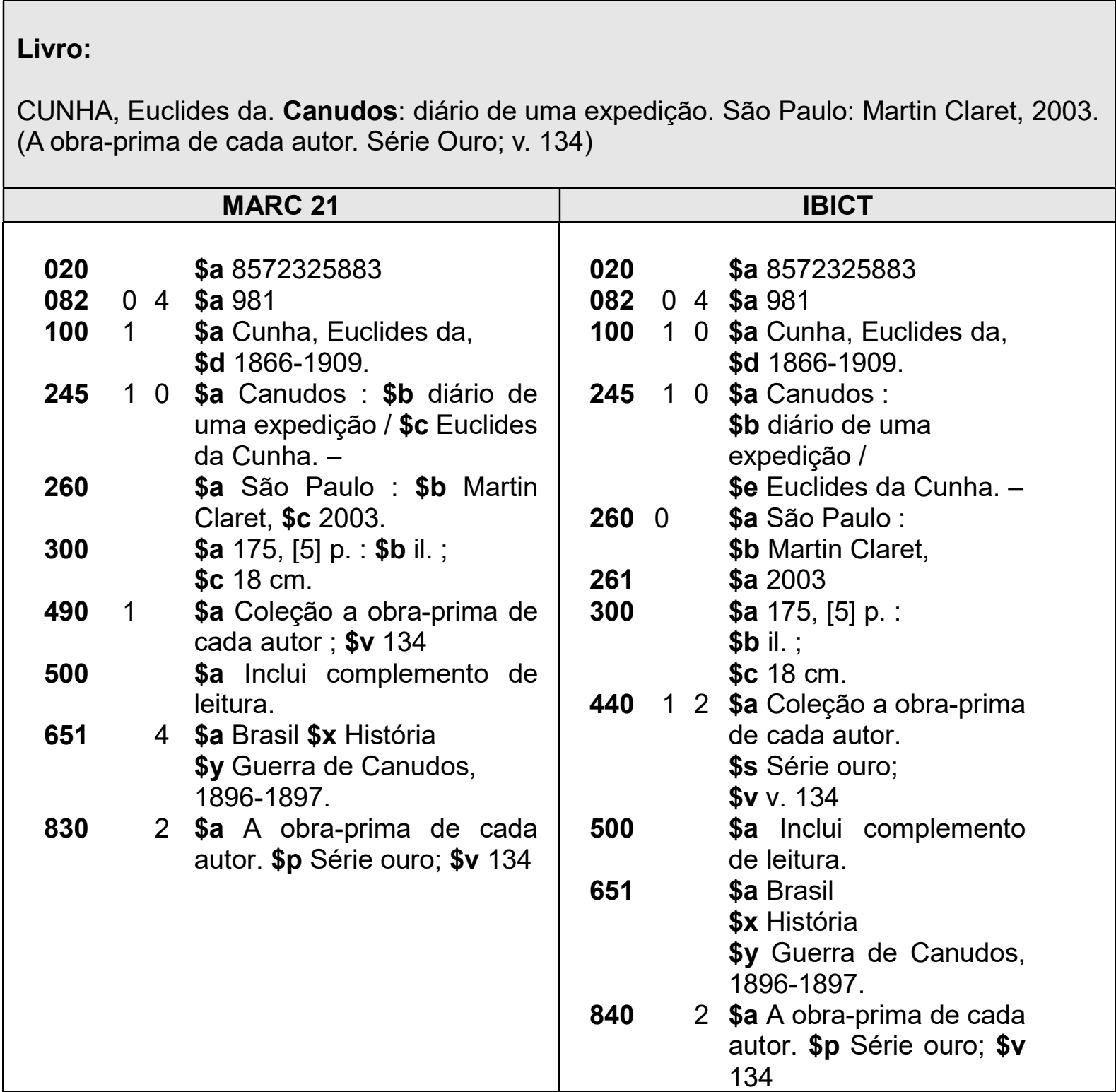

Fonte: Elaboração própria, a partir de Ferreira (2013) e IBICT (1987).

Observando os Quadros 19 e 20, bem como os manuais referentes aos dois formatos, notam-se as seguintes semelhanças entre o MARC 21 e o formato IBICT:

- assim como o MARC 21, os campos do formato IBICT contemplam todas as áreas e os pontos de acesso determinados nas partes I e II do Código de Catalogação AACR2 para a descrição de livros; 
- os dois formatos adotam campos identificados com etiquetas de três dígitos numéricos (campo 100, campo 245, etc.), além do uso de indicadores e subcampos para a inserção dos dados do registro;

- os dois formatos são compostos de campos não repetíveis, como o campo 100 do autor principal, e campos que podem se repetir, como o campo 700 das entradas secundárias de pessoas;

- nos dois formatos as informações são divididas em blocos, sendo: 0XX para números de identificação (por exemplo o ISBN); 1XX para as entradas principais; $2 X X$ para títulos, edição e imprenta; $3 X X$ para descrição física; $4 X X$ para informação de série; $5 X X$ para notas; $6 X X$ para assuntos; $7 X X$ para entradas secundárias e 8XX para entradas secundárias de série;

- tanto no MARC 21 como no IBICT é permitido fazer entradas secundárias de séries no bloco 8XX.

Na observação sobre o MARC 21 e o formato IBICT destacam-se também algumas diferenças:

- o IBICT não apresenta o bloco de campos 9XX, o qual é destinado no MARC 21 às decisões locais;

- na área de publicação, distribuição, etc., observada no Quadro 19, notase que o MARC 21 possui a opção de campo 264, permitindo ao catalogador fazer distinção entre funções: produtor, publicador, distribuidor, manufatureiro ou informação de copyright. No IBICT não havia essa opção. Na mesma área nota-se ainda que o IBICT separa a data de publicação no campo 261;

- na área de série, observada nos dois quadros anteriores, nota-se que há uma diferença entre os dois formatos, visto que o MARC 21 realizou, em 2009, uma atualização e eliminou campos do bloco 4XX, deixando apenas o campo 490 para a indicação da série conforme ela aparece no material, independentemente do tipo da série, sendo que os desdobramentos passaram a ser feitos no bloco $8 \mathrm{XX}$, onde informa-se o cabeçalho controlado da série. Já o formato IBICT, prevê o uso de todos os campos do bloco $4 \mathrm{XX}$, além de permitir as entradas secundárias no campo $8 X X$. 
Ao verificar o resultado do cotejamento do MARC 21 com formato IBICT conclui-se que são formatos bastante parecidos. Assim como o MARC 21, o formato IBICT apresenta-se como um padrão rico em detalhes descritivos fazendo uso de campos numéricos, indicadores e subcampos. Além disso, evoluiu em relação ao seu antecessor no Brasil, o CALCO, abrangendo a descrição de materiais em diferentes níveis. Nota-se que as diferenças básicas apontadas entre o MARC 21 e o IBICT estão relacionadas com questões de atualizações. Com o avanço tecnológico, a partir de meados da década de 1990 a Rede Bibliodata, que hoje é de responsabilidade do IBICT, passou a adotar softwares que utilizam os formatos desenvolvidos pela LC, sendo primeiro o formato USMARC e atualmente o próprio MARC 21, conforme já destacado em seções anteriores.

\subsection{O MARC 21 E O PADRÃO DUBLIN CORE}

O Dublin Core é um padrão de metadados que chegou com a era da web e que permite o compartilhamento de dados em diferentes contextos e, inclusive, tem sido usado de forma integrada com o MARC 21. De acordo com Alves e Souza (2007, p. 20), "a maximização de esforços na integração e intercâmbio de dados, bem como a sistematização das relações entre esses padrões, propiciam o reuso de conjuntos de metadados na mesma organização". Para exemplificar, de maneira geral, significa dizer que, se uma biblioteca ou rede de bibliotecas possui no seu banco de dados o cadastro de publicações eletrônicas, como teses e dissertações, descritas em formato MARC 21, dependendo do software utilizado, é possível que se realize a conversão desses registros para o padrão Dublin Core, com o propósito de reaproveitar esses mesmos dados, por exemplo, para a disponibilização em um repositório institucional de dados abertos que funcione com o Dublin Core, evitando assim o retrabalho. Isso envolve questões técnicas e planejamentos que não vão ao encontro dos objetivos desta pesquisa, mas é certo que uma das etapas necessárias é o mapeamento dos campos do MARC 21 para o padrão Dublin Core, de acordo com as necessidades da instituição e de seus usuários.

Encontra-se, na literatura, a experiência de instituições que trabalharam na correspondência dos campos do formato MARC 21 com os elementos do Dublin Core, compatibilizando esses dois formatos em seus sistemas com o intuito de otimizar o compartilhamento de informações bibliográficas. Dentre essas iniciativas destacam- 
se: a Empresa Brasileira de Pesquisa Agropecuária (EMBRAPA), que teve sua experiência relatada por Alves e Souza (2007), e também a BNDigital, cuja experiência foi mencionada por Bettencout (2014).

Ao cotejar o formato MARC 21 com o padrão de metadados Dublin Core, foi possível ter uma noção de como ocorre este mapeamento entre os elementos dos dois formatos. No Quadro 21, a seguir, são apontadas áreas e os pontos de acesso para a descrição de livros impressos, conforme o AACR2, juntamente com os campos em MARC 21 e uma sugestão para correspondência no padrão Dublin Core.

Quadro 21 - Campos variáveis do MARC 21 e do Dublin Core para a descrição de livros segundo o AACR2

\begin{tabular}{|c|c|c|}
\hline $\begin{array}{l}\text { Áreas de descrição } \\
\text { segundo o } \\
\text { AACR2 PARTE I }\end{array}$ & $\begin{array}{c}\text { Campos } \\
\text { para descrição de LIVROS no } \\
\text { MARC } 21 \text { Bibliográfico }\end{array}$ & $\begin{array}{l}\text { Elementos } \\
\text { correspondentes no } \\
\text { Formato Dublin Core }\end{array}$ \\
\hline $\begin{array}{l}\text { Área do título e da } \\
\text { indicação de } \\
\text { responsabilidade }\end{array}$ & $\begin{array}{l}240 \text { - Título uniforme } \\
245 \text { - Indicação de título } \\
246 \text { - Forma variante do título }\end{array}$ & Title (título) \\
\hline Área da edição & 250 - Indicação de edição & Não encontrado \\
\hline $\begin{array}{l}\text { Área da publicação, } \\
\text { distribuição etc. }\end{array}$ & $\begin{array}{l}260 \text { - Imprenta } \\
264 \text { - Produção, publicação, } \\
\text { distribuição, manufatura e } \\
\text { informação de Copyright }\end{array}$ & $\begin{array}{l}\text { Publisher (editor) } \\
\text { Date (data) }\end{array}$ \\
\hline $\begin{array}{c}\text { Área da descrição } \\
\text { física }\end{array}$ & 300 - Descrição física & Format (formato) \\
\hline Área de série & $\begin{array}{c}490 \text { - Indicação de série } \\
800 \text { - Entrada secundária de } \\
\text { série - Nome pessoal } \\
810 \text { - Entrada secundária de } \\
\text { série - Nome Corporativo } \\
811 \text { - Entrada secundária de } \\
\text { série - Nome de evento } \\
830 \text { - Entrada secundária de } \\
\text { série - Título uniforme }\end{array}$ & Relation (relação) \\
\hline Área de notas & $\begin{array}{l}\mathbf{5 0 0} \text { - Nota geral } \\
\mathbf{5 0 1} \text { - Nota iniciada por "com" } \\
\mathbf{5 0 4} \text { - Nota de bibliografia } \\
\mathbf{5 0 5} \text { - Nota de conteúdo } \\
\mathbf{5 2 0} \text { - Nota de resumo } \\
\mathbf{5 3 0} \text { - Nota de disponibilidade de } \\
\quad \text { forma física adicional } \\
\mathbf{5 3 4} \text { - Nota de versão original } \\
\mathbf{5 4 6} \text { - Nota de idioma } \\
\mathbf{5 9 X} \text { - Notas locais }\end{array}$ & Description (descrição) \\
\hline
\end{tabular}




\begin{tabular}{|c|c|c|}
\hline $\begin{array}{l}\text { Área de número } \\
\text { normalizado }\end{array}$ & $020-$ ISBN & Identifier (identificador) \\
\hline $\begin{array}{l}\text { Pontos de acesso } \\
\text { segundo o } \\
\text { AACR2 PARTE II }\end{array}$ & $\begin{array}{l}\text { Campos } \\
\text { para descrição de LIVROS no } \\
\text { MARC } 21 \text { Bibliográfico }\end{array}$ & $\begin{array}{l}\text { Campos } \\
\text { correspondentes no } \\
\text { Formato Dublin Core }\end{array}$ \\
\hline $\begin{array}{l}\text { Cabeçalhos para } \\
\text { Pessoas }\end{array}$ & $\begin{array}{c}100 \text { - Entrada principal - Nome } \\
\text { Pessoal } \\
600 \text { - Assunto - Nome Pessoal } \\
700 \text { - Entrada Secundária - } \\
\text { Nome Pessoal }\end{array}$ & $\begin{array}{l}\text { Creator (autor) } \\
\text { Contributor (colaborador) } \\
\text { Subject (assunto) }\end{array}$ \\
\hline Nomes Geográficos & 651 - Assunto - Nome Geográfico & $\begin{array}{l}\text { Subject (assunto) } \\
\text { Coverage (cobertura) }\end{array}$ \\
\hline $\begin{array}{l}\text { Cabeçalhos para } \\
\text { entidades }\end{array}$ & $\begin{array}{l}110 \text { - Entrada principal - Nome } \\
\text { Corporativo } \\
111 \text { - Entrada principal - Nome } \\
\text { de Evento } \\
\\
610 \text { - Assunto - Nome } \\
\text { Corporativo } \\
611 \text { - Assunto - Nome de Evento } \\
\\
710 \text { - Entrada Secundária - } \\
\text { Nome Corporativo } \\
711 \text { - Entrada Secundária - } \\
\text { Nome de Evento }\end{array}$ & $\begin{array}{l}\text { Creator (autor) } \\
\text { Contributor (colaborador) } \\
\text { Subject (assunto) }\end{array}$ \\
\hline Títulos Uniformes & $\begin{array}{l}130 \text { - Entrada principal - Título } \\
\text { Uniforme } \\
240 \text { - Título uniforme } \\
630 \text { - Assunto - Título Uniforme } \\
730 \text { - Entrada Secundária - Título } \\
\text { uniforme }\end{array}$ & $\begin{array}{l}\text { Title (título) } \\
\text { Subject (assunto) }\end{array}$ \\
\hline
\end{tabular}

Fonte: elaboração própria, a partir de Ferreira (2013) e Alves e Souza (2007).

Para melhor exemplificar a correspondência entre os dois formatos, apresenta-se no Quadro 22 a representação descritiva, tanto em MARC 21 como também em Dublin Core, de um livro impresso. 
Quadro 22 - Representação descritiva de um livro impresso nos formatos MARC 21 e Dublin Core.

Livro:

BRENNAND, Edna Gusmão de Góes; ALBUQUERQUE, Maria Elizabeth Baltar Carneiro de; MACIEL, João Wandemberg Gonçalves (Org.). Formação docente e tecnologias digitais. João Pessoa: Editora UFPB, 2011. 253 p.

\begin{tabular}{|c|c|c|c|}
\hline & & MARC 21 & DUBLIN CORE \\
\hline $\begin{array}{l}260 \\
\\
300 \\
504 \\
650 \\
650 \\
700 \\
700 \\
700\end{array}$ & $\begin{array}{ll}0 & 4 \\
0 & 4 \\
1 & \\
& \\
1 & \end{array}$ & $\begin{array}{l}\text { \$a 978-85-7745-821-9 } \\
\text { \$a 371.3 } \\
\text { \$a Formação docente e } \\
\text { tecnologias digitais / \$c Edna } \\
\text { Gusmão de Góes Brennand, } \\
\text { Maria Elizabeth Baltar Carneiro } \\
\text { de Albuquerque, João } \\
\text { Wanderbemberg Gonçalves } \\
\text { Maciel (Organizadores). - } \\
\text { \$a João Pessoa : \$b Ed. UFPB, } \\
\text { \$c } 2011 . \\
\text { \$a } 253 \text { p. : \$b il. } \\
\text { \$a Inclui bibliografia. } \\
\text { \$a Formação docente. } \\
\text { \$a Ensino à distância. } \\
\text { \$a Brennand, Edna Gusmão de } \\
\text { Góes \$4 Org. } \\
\text { \$a Albuquerque, Maria Elizabeth } \\
\text { Baltar Carneiro de \$4 Org. } \\
\text { \$a Maciel, João Wandemberg } \\
\text { Gonçalves \$4 Org. }\end{array}$ & $\begin{aligned} & \text { Título } \begin{array}{l}\text { Formação docente } \\
\text { tecnologias digitais }\end{array} \\
& \text { Colaborador } \begin{array}{l}\text { Brennand, Edna Gusmão } \\
\text { de Góes }\end{array} \\
& \text { Colaborador } \begin{array}{l}\text { Albuquerque, Maria } \\
\text { Elizabeth Baltar Carneiro } \\
\text { de }\end{array} \\
& \text { Colaborador } \text { Maciel, João } \\
& \text { Wandemberg Gonçalves } \\
& \text { Assunto } 371.3 \\
& \text { Assunto } \text { Formação docente } \\
& \text { Assunto } \text { Ensino à distância } \\
& \text { Descrição Inclui bibliografia } \\
& \text { Publicador } \text { Ed. UFPB } \\
& \text { Data } 2011 \\
& \text { Tipo } \text { livro } \\
& \text { Formato } 253 \text { p. : il. } \\
& \text { Identificador } 978-85-7745-821-9 \\
& \text { Idioma } \text { Português }\end{aligned}$ \\
\hline
\end{tabular}

Fonte: elaboração própria, a partir de Ferreira (2013) e Alves e Souza (2007).

Analisando os Quadros 21 e 22 constata-se as seguintes semelhanças entre os MARC 21 e o Dublin Core:

- os dois formatos contemplam as áreas de descrição referentes a livros e aos pontos de acesso constantes no AACR2, sendo que há uma exceção no caso da área de edição, para a qual não foi encontrado um campo correspondente no padrão Dublin Core;

- assim como no MARC 21, o Dublin Core também permite que os elementos sejam repetidos dentro do mesmo registro. Isto pode ser observado no exemplo 
do Quadro 22, onde são descritos mais de um colaborador e mais de um assunto para o mesmo material.

Dentre as diferenças encontradas entre os dois formatos, destacam-se:

- diferentemente do MARC 21, o Dublin Core não utiliza campos com etiquetas numéricas, subcampos nem indicadores;

- os elementos do Dublin Core são designados com termos ou palavras tornando o preenchimento dos dados mais fácil, podendo ser preenchidos por qualquer usuário do sistema, sendo que o padrão MARC 21, por utilizar uma estrutura mais complexa - com uso de campos numéricos, indicadores e subcampos - necessita de catalogadores treinados;

- o MARC 21 divide as informações em blocos de campos com diversas possibilidades de descrição, já o Dublin Core, de forma simplificada, utiliza apenas um conjunto de elementos cuidadosamente selecionados para representar os principais dados de qualquer item a ser descrito, que são: título, autor, assunto, descrição, editor, colaborador, data, tipo, formato, identificador, fonte, língua, relação, cobertura e direitos.

O cotejamento entre esses dois formatos favorece a confirmação de que o MARC 21, sendo um formato altamente rico para o domínio bibliográfico, possui uma estrutura complexa e muito mais detalhada em relação ao Dublin Core. Além disso, o MARC 21 baseia-se em regras de catalogação bem estabelecidas para o campo da Biblioteconomia e isto é fundamental, tendo em vista a diversidade de materiais que podem fazer parte de um acervo e, em consequência, a grande quantidade de atributos a serem descritos. No entanto, isto não impede a sua interoperabilidade com um padrão mais simples e geral para a web, como o Dublin Core. Nesse sentido, Alves e Souza (2007, p. 28) argumentam que uma das principais características do Dublin Core é sua extensibilidade, que "[...] permite sua adaptação às necessidades adicionais de descrição".

Percebe-se, portanto, que o padrão Dublin Core, apesar de não ser um padrão específico para o domínio bibliográfico, pode ser adaptado para o uso em conjunto com o formato MARC 21 e, assim, seus elementos acabam por contemplar grande parte das regras de descrição previstas no AACR2. 
Os elementos do Dublin Core são praticamente autoexplicativos, tornandoo um padrão fácil de ser utilizado. No caso dos repositórios digitais, por estarem os itens disponíveis na internet, não necessitam de uma catalogação muito detalhada para que sejam recuperados e, dependendo da política institucional, muitas vezes os próprios autores ficam incumbidos de depositar suas produções bibliográficas. Isto ajuda a explicar o fato de o padrão Dublin Core ser bastante utilizado por repositórios na disponibilização de documentos bibliográficos. 


\section{CONSIDERAÇÕES FINAIS}

Para desenvolver a pesquisa foi preciso direcionar um olhar para meados da década de 1960, uma época marcada pelo avanço tecnológico e pelos processos de informatização. Naquele período iniciava-se, nas bibliotecas, a transposição dos catálogos bibliográficos em papel para os catálogos automatizados. No decorrer do estudo mostrou-se que essa transição gerou um movimento mundial no âmbito das instituições voltadas para a organização, o acesso e o uso de informações. O pioneirismo da LC em tornar dados bibliográficos legíveis por máquina desencadeou uma corrida dos países em prol de uma padronização ideal que tornasse possível o compartilhamento e o intercâmbio de suas informações bibliográficas, por meio do computador.

Assim, nas décadas de 1970 a 1980, as regras contidas nos Códigos de Catalogação foram tomando forma no meio automatizado com a implantação e com o uso dos formatos de intercâmbio. Nesse período, o padrão MARC da LC e o Manual de Referência UNISIST da UNESCO, se destacaram como principais guias no desenvolvimento de formatos de intercâmbio e descrição bibliográfica para uso em bases de dados e sistemas de gerenciamento de bibliotecas.

Este estudo levou à compreensão de que os formatos de intercâmbio são constituídos de uma estrutura de entrada de dados que é legível pelo ser humano, precisando o catalogador conhecer os seus campos e subcampos, etc., para representar descritivamente os materiais do acervo. Em paralelo a essa estrutura, o formato de intercâmbio envolve também um padrão de codificação para a transmissão dos dados máquina a máquina e entre sistemas, o que torna os registros bibliográficos legíveis por computador. Nesse aspecto, foi destacada na pesquisa a codificação ISO 2709, adotada pela maioria dos formatos criados a partir de 1960 e, mais recentemente, a codificação em XML, adotada pelos padrões de metadados.

A literatura da área de Biblioteconomia destaca a forte presença do formato MARC 21 nos atuais sistemas de gerenciamento de bibliotecas, mas também abrange, de forma um tanto quanto fragmentada, a existência de outros formatos. $O$ intuito de reunir em um único estudo o panorama da trajetória desses diferentes padrões impulsionou o principal objetivo da pesquisa, que foi conhecer as características de diferentes tipos de formatos de Intercâmbio de dados bibliográficos por meio de um cotejamento destes com o Formato MARC 21. Reunir as particularidades de vários 
padrões de descrição em uma única pesquisa foi um desafio, mas acredita-se que o objetivo geral tenha sido alcançado na medida em que se avançou em torno dos três objetivos específicos pré-estabelecidos.

O primeiro objetivo específico tratou da identificação dos formatos de descrição e intercâmbio de dados utilizados em bibliotecas e seus princípios norteadores. Ao olhar para décadas anteriores, foram encontrados muitos formatos de intercâmbio, alguns dos quais deixaram de ser atualizados ou foram descontinuados e outros que permaneceram em vigor nos sistemas mais modernos. Em suma, além do MARC 21, a consulta à literatura sobre os formatos de intercâmbio direcionou para a identificação dos seguintes formatos:

- Formato CALCO: criado pela Fundação Getulio Vargas, em 1973, a partir do padrão MARC e em consonância com as regras do AACR2. Codificado para intercâmbio com a norma ISO 2709. Na época foi a implementação do padrão MARC no Brasil e, de forma similar, muitos outros países implementaram seus próprios formatos. Constatou-se que o CALCO foi descontinuado a partir da década de 1990, tendo sido substituído pelo MARC 21;

- Formato UNIMARC: criado pela IFLA, em 1977, a partir do padrão MARC e em consonância com as regras do AACR2. Codificado para o intercâmbio com a ISO 2709. Foi desenvolvido com vistas ao Controle Bibliográfico Universal (CBU). Observou-se que o UNIMARC permanece, atualmente, em vigor;

- Formato CCF: criado pela UNESCO, na década de 1970, a partir do UNIMARC e do Manual UNISIST. O CCF não seguiu um código de catalogação específico, porém foi codificado para o intercâmbio com a ISO 2709. Não foram encontrados relatos recentes de instituições que ainda estejam utilizando este formato. Percebeu-se, portanto, que o mesmo está em desuso;

- Formato LILACS: criado pela BIREME, em 1982, a partir do Manual de Referência UNISIST e em conformidade com o AACR2. Codificado para intercâmbio com a norma ISO 2709. O formato LILACS continua, atualmente, em vigor, sendo amplamente utilizado na área da saúde;

- Formato CEPAL: criado pela CEPAL, em 1984, a partir do Manual de Referência UNISIST e em concordância com o AACR2. Codificado para o intercâmbio com a norma ISO 2709. O formato CEPAL não está mais sendo atualizado e passa por processo de substituição pelo MARC 21; 
- Formato IBICT: criado pelo IBICT, em 1987, a partir do CALCO e em conformidade com o AACR2. Codificado para o intercâmbio com a norma ISO 2709. Foi o sucessor do CALCO e chegou a ser considerado o formato oficial do Brasil, entretanto, não foram encontrados relatos recentes de instituições que ainda o estejam utilizando. Percebeu-se, portanto, que o mesmo está em desuso;

- Padrão Dublin Core: criado pela DCMI, em 1995, a partir do MARC. Por não ser específico do domínio bibliográfico, não é fundamentado em normas de catalogação específicas, porém é flexível e extensível podendo ser adaptado para atender diferentes contextos na web. Faz uso de codificação para intercâmbio com linguagens de marcação, tal como a XML. O Dublin Core encontra-se, atualmente, em vigor.

Com o desenvolvimento da pesquisa, foi possível observar que as regras de catalogação foram fundamentais para a implementação dos formatos de intercâmbio e, consequentemente, para a criação das redes de catalogação cooperativas. Com a publicação das ISBDs e do Código de Catalogação AACR2, as regras de descrição foram, de certa forma, internacionalizadas, contribuindo para o compartilhamento em grande escala e a organização dos dados bibliográficos, principalmente com a popularização da internet.

A partir da década de 1990, os acervos que outrora eram organizados e sistematizados para uso interno nas instituições passaram a ser expostos ao mundo em catálogos on-line de acesso público. Desde então, a atuação das bibliotecas em rede se fortalece a cada dia. Com isso, o desafio de padronizar a descrição dos itens dos acervos para a divulgação na web se torna ainda maior. Nessa perspectiva, considera-se ter sido alcançado o segundo objetivo específico da pesquisa, o qual consistia em enfatizar a importância de adotar as regras de descrição bibliográfica e os formatos de intercâmbio em sistemas de bibliotecas.

No início do Século XXI, o MARC 21 se mantém em constante evolução, ganhando força e destaque como um padrão rico para o domínio bibliográfico. Assim, muitas instituições passaram a adotá-lo, migrando os seus dados e abandonando os formatos mais antigos.

O avanço na disponibilização e no compartilhamento de informações levou as comunidades bibliotecárias a mudarem o foco, colocando no centro das suas 
atenções o próprio usuário e suas necessidades de informação. Surgiu então o modelo conceitual FRBR e também a necessidade de atualização das regras do Código de catalogação AACR2. Com o lançamento do código RDA, em 2010, uma nova fase de mudança se iniciava, e segue avançando.

Paralelamente a tudo isso, surgem também muitos novos padrões de metadados para diferentes contextos no ambiente digital e inclusive para o domínio bibliográfico - tal como Metadados para Teses e Dissertações (MTD-BR). Mais uma vez o que se vê é uma proliferação de novos tipos de padrões, levando certos domínios a terem mais de uma opção para a padronização de dados na web. Assim, constantemente, as instituições necessitam avaliar e escolher o padrão que melhor Ihe atende, chegando inclusive a adotar diferentes padrões num mesmo sistema, ou ainda, a fazer "conversar" diferentes padrões de diferentes sistemas.

Com a atuação em rede cada vez mais presente no âmbito das bibliotecas, e diante do crescente volume de dados bibliográficos produzidos diariamente, mais distante e mais difícil fica o ideal de uma padronização perfeita ou única. Em meio a tudo isso, o bibliotecário precisa tomar decisões importantes no momento da escolha de um sistema de gerenciamento de acervo e torna-se fundamental priorizar sistemas ou softwares que utilizem padrões reconhecidos internacionalmente e que facilitem a observância das regras de catalogação. Assumpção (2013, p. 102) argumenta que as bibliotecas que não adotam os padrões internacionalmente aceitos ‘[...] poderão estar impossibilitadas de participarem de programas de catalogação cooperativa e estarão sujeitas a problemas e a retrabalhos durante a migração entre sistemas de gerenciamento de bibliotecas". Desse modo, espera-se que esta pesquisa possa contribuir para a reflexão sobre a responsabilidade do profissional da informação no momento da escolha de sistemas de gerenciamento para as bibliotecas e unidades de informação.

O terceiro objetivo específico visava apresentar as estruturas de dados em formatos de intercâmbio que se assemelham ou se diferenciam do formato MARC 21. Considera-se que este objetivo foi alcançado e os resultados apresentados na oitava seção. Ao analisar cada um dos formatos e seu cotejamento, foi possível ter uma noção de como é (e como era) a estrutura da representação descritiva de livros em cada um dos formatos estudados. Embora alguns já não estejam mais em uso, considerou-se importante mencioná-los no cotejamento com o MARC 21 para que se 
pudesse compreender a evolução e a trajetória dos formatos de intercâmbio como um todo.

O cotejamento revelou que, embora a maioria dos formatos mais antigos tenha feito ou faça uso da codificação ISO 2709 para o intercâmbio, não significa que os mesmos sejam totalmente compatíveis entre si. Ficou evidente que cada um dos formatos estudados possui particularidades que podem dificultar os processos de migração e ou reutilização de dados bibliográficos.

$\mathrm{Na}$ sociedade contemporânea, torna-se cada vez mais comum o uso de catálogos coletivos proporcionando a união de acervos de bibliotecas distintas em uma única página na web, facilitando a ação do usuário na realização das buscas. A catalogação em rede, ou catalogação cooperativa, poupa tempo e esforços dos profissionais, tendo em vista que o trabalho de representação descritiva dos mais diversificados tipos de materiais não é um processo simples. Sendo assim, um ponto importante que fica como recomendação para a continuidade da pesquisa seria a verificação de padrões de metadados mais recentes - tal como a iniciativa BIBFRAME - e seu uso em bibliotecas com a aplicação da norma RDA.

Por fim, confirma-se que o universo da representação da informação envolve muitas questões e muitas particularidades. Falar especificamente da representação descritiva e de formatos de intercâmbio bibliográfico, pode parecer um tema bastante técnico/operacional, e realmente o é. Porém, toda técnica e toda prática só existe quando há pessoas envolvidas nos processos e, onde há pessoas, há vida em sociedade e consequentemente, há desenvolvimento histórico e social. Portanto, conhecer, por meio do presente estudo, o caminho percorrido pelos formatos de intercâmbio, desde o seu início na década de 1960 até o princípio do Século XXI, possibilitou fazer um passeio também pela trajetória das bibliotecas enquanto "organismos em crescimento" e nos seus esforços e na sua busca por oferecer à sociedade contemporânea o acesso às informações registradas de forma organizada e padronizada. 


\section{REFERÊNCIAS}

AGANETTE, Elisângela Cristina; TEIXEIRA, Livia Marangon Duffles; AGANETTE, Karina de Jesus Pinto. A representação descritiva nas perspectivas do século XXI um estudo evolutivo dos modelos conceituais. Encontros Bibli, Florianópolis, v. 22, n. 50, set. 2017. Disponível em: https://periodicos.ufsc.br/index.php/eb/article /view/1518-2924.2017v22n50p176. Acesso em: 09 fev. 2018.

ALMEIDA JÚNIOR, Oswaldo Francisco de. Mediação da informação e múltiplas linguagens. Tendências da Pesquisa Brasileira em Ciência da Informação, Brasília, v. 2, n. 1, p. 89-103, 2009. Disponível em:

http://www.brapci.inf.br/index.php/article/download/7871. Acesso em: 31 jan. 2019.

ALVES, Maria das Dores Rosa; SOUZA, Marcia Izabel Fugisawa. Estudo de correspondência de elementos metadados: DUBLIN CORE e MARC 21. RDBCI:

Revista Digital de Biblioteconomia e Ciência da Informação, Campinas, SP, v. 5, n. 1, p. 20-38, jan. 2007. Disponível em:

https://periodicos.sbu.unicamp.br/ojs/index.php/rdbci/article/view/2019/2140.

Acesso em: 16 jan. 2019.

ALVES, Rachel Cristina Vesú. Metadados como elementos do processo de catalogação. Tese (Doutorado em Ciência da Informação) - Faculdade de Filosofia e Ciências, Universidade Estadual Paulista, Marília, 2010. Disponível em: https://repositorio.unesp.br/handle/11449/103361. Acesso em: 30 jan. 2019.

AMORIM, Eli Regina da Silva; PEREIRA, Ana Maria. Resource Description And Access: estudo sobre viabilidade. In: ENCONTRO NACIONAL DE PESQUISA EM CIÊNCIA DA INFORMAÇÃO - ENANCIB, 18., 2017, Marília, SP. Anais [...]. Marília: UNESP, 2017. Disponível em:

http://enancib.marilia.unesp.br/index.php/xviiienancib/ENANCIB/paper/viewFile/113/1 165. Acesso em: 03 dez. 2018.

AQUINO, Mirian de Albuquerque; SILVA, Fernanda Mirelle de Almeida. A recuperação do conteúdo freireano como um aprendizado colaborativo na construção da Biblioteca Digital Paulo Freire. In: BRENNAND, E.G. de G.; ALBUQUERQUE, M. E. B. C de. (Org.). Paulo Freire: diálogos e redes digitais. João Pessoa: Editora da UFPB, 2011.

ARAÚJJ, Carlos Alberto Ávila. Fundamentos da Ciência da Informação: Correntes teóricas e o conceito de informação. Perspectivas em Gestão \& Conhecimento, João Pessoa, v. 4, n. 1, p. 57-79, jan./jun. 2014. Disponível em: http://www.periodicos.ufpb.br/index.php/pgc/article/view/19120/10827. Acesso em: 14 dez. 2017.

ARENDT, Carmen Vera. Sistema de Información Bibliográfica de la CEPAL: manual de referência. Santiago: CEPAL, 2003. Disponível em:

http://archivo.cepal.org/pdfs/2003/S0390586.pdf. Acesso em: 23 abr. 2018. 
ASSUMPÇÃO, Fabrício Silva. Conversão de registros em XML para MARC 21: um modelo baseado em folhas de estilo XSLT. Dissertação (Mestrado em Ciência da Informação) - Faculdade de Filosofia e Ciências, Universidade Estadual Paulista, Marília, 2013. Disponível em: https://www.marilia.unesp.br/Home/PosGraduacao/Cienciadalnformacao/Dissertacoes/assumpcao_fs_me_mar.pdf. Acesso em: 25 jan. 2018.

ASSUMPÇÃO, Fabrício Silva; SANTOS, Plácida Leopoldina Ventura Amorim da Costa. Conversão de registros em XML para MARC 21: um modelo baseado em XSLT. In: ENCONTRO NACIONAL DE PESQUISA EM CIÊNCIA DA INFORMAÇÃO (ENANCIB), 15., 2014, Belo Horizonte. Anais [...]. Belo Horizonte: ECI/UFMG, 2014. p. 3802-3821. Disponível em:

http://enancib2014.eci.ufmg.br/documentos/anais/anais-gt8. Acesso em: 05 nov. 2017.

ASSUMPÇÃO, Fabrício Silva; SANTOS, Plácida Leopoldina Ventura Amorim da Costa. Representação no domínio bibliográfico: um olhar sobre os formatos Marc 21. Perspectivas em Ciência da Informação, v. 20, n. 1, 2015. Disponível em: http://portaldeperiodicos.eci.ufmg.br/index.php/pci/article/download/2054/1582. Acesso em: 20 jan. 2018.

ASSUMPÇÃO, Fabrício Silva; SANTOS, Plácida Leopoldina Ventura Amorim da Costa; ZAFALON, Zaira Regina. O controle de autoridade no domínio bibliográfico: os catálogos digitais. Biblios, v. 68, p. 21-33, 2017. Disponível em: https://doi.org/10.5195/biblios.2018.342. Acesso em: 13 jan. 2018.

BAUER, Martin W.; GASKELL, George (Ed.). Pesquisa Qualitativa com Texto, Imagem e Som: um manual prático. 2. ed. Petrópolis: Vozes, 2003.

BARBOSA, Alice Príncipe. Projeto CALCO: adaptação do MARC II para implantação de uma Central de Processamento da Catalogação Cooperativa. Rio de Janeiro, 1972. 80 f. Dissertação (Mestrado) - Universidade Federal do Rio de Janeiro, 1972. Disponível em: http://ridi.ibict.br/handle/123456789/163. Acesso em: 10 jan. 2018.

BETTENCOURT, Angela Monteiro. A representação da informação na Biblioteca Nacional: do documento tradicional ao digital. Rio de Janeiro: Fundação Biblioteca Nacional, 2014. 216 p. Disponível em: http://bndigital.bn.gov.br/acervodigital. Acesso em: 28 dez. 2018.

BIREME. Metodologia LILACS: Manual de Descrição Bibliográfica. 7. ed. São Paulo: BIREME / OPAS / OMS, 2008. 150 p. Disponível em:

http://metodologia.lilacs.bvsalud.org/download/P/LILACS-2-ManualDescricao-pt. pdf. Acesso em: 29 nov. 2017.

BIBLIOTECA NACIONAL (Portugal). Cooperação PORBASE. Disponível em: http://www.bnportugal.gov.pt/index.php?option=com_content\&view=article\&id=145\% 3Acooperacao\&catid=39\%3Abibliotecarios\&ltemid=185\&lang=pt. Acesso em: 09 abr. 2018. 
CAMPELLO, Bernadete. Introdução ao controle bibliográfico. 2. ed. Brasília: Briquet de Lemos, 2006. 94 p.

CAPLAN, Priscilla. Metadata fundamentals for all librarians. Chicago: American Library Association, 2003. 192 p.

CASTRO, Alisson de; BARBOZA, Tatiana Lúcia. Família ISIS: do Microisis ao ABCD. In: CONGRESSO BRASILEIRO DE BLIOTECONOMIA, DOCUMENTAÇÃO E CIÊNCIA DA INFORMAÇÃO, 24., 2011, Maceió. Anais [...]. Maceió: UFAL, 2011. Disponível em:

http://www.abcdlibrary.com/docs/artigo_alisson_tatiana_winisis_ao_abcd.pdf. Acesso em: 02 jan. 2019.

CEPAL. Sistema de información bibliográfica: manual para uso de Micro CDS/ISIS. Santiago: Nações Unidas, 1989. Disponível em:

https://repositorio.cepal.org/bitstream/handle/11362/9093/S8900116_es.pdf;sequenc e=1. Acesso em: 16 jan. 2019.

CÓDIGO de catalogação anglo-americano. 2. ed., rev. 2002. São Paulo: FEBAB, 2004.

CÔRTE, Adelaide Ramos et al. Avaliação de softwares para bibliotecas e arquivos: uma visão do cenário nacional. 2. ed. rev. e ampl. São Paulo: Polis, 2002.

COYLE, Karen. FRBR Before and After: a Look at Our Bibliographic Models. Chicago: American Library Association, 2016. Disponível em:

http://kcoyle.net/beforeAndAfter/. Acesso em: 16 jan. 2018.

DCMI. History of the Dublin Core Metadata Initiative (DCMI). c2017. Disponível em: http://dublincore.org/about/history/. Acesso em: 19 jan. 2018.

DIERICKX, Harold. The UNISIST Reference Manual for machine readable bibliographic descriptions within the context of international exchange formats.

Annals of Library Science and Documentation, v. 32(1-2), 1985. Disponível em: http://nopr.niscair.res.in/handle/123456789/27938. Acesso em: 23 dez. 2018.

FERREIRA, Luciene da Costa; ALBUQUERQUE, Maria Elizabeth Baltar Carneiro de. A representação da informação para a organização do acervo em bibliotecas universitárias. In: ALBUQUERQUE, Maria Elizabeth Baltar Carneiro de et al (Org.). Representação da informação: um universo multifacetado. João Pessoa: Editora da UFPB, 2013. Cap.1. p.15-28.

FERREIRA, Margarida M. (trad.). MARC21: formato internacional para dados bibliográficos. Uma tradução e adaptação de MARC 21: concise format for bibliographic data da Network Development and MARC Standards Office - LC. 3. ed. São Paulo: Fundepe, 2013. 
FORMENTON, Danilo. Identificação de padrões de metadados para preservação digital. 2015. 102 f. Dissertação (Mestrado em Ciência da Informação) -Universidade Federal de São Carlos, São Paulo, 2015. Disponível em: https://repositorio.ufscar.br/handle/ufscar/7221. Acesso em: 02 jan. 2019.

FUNDAÇÃO GETULIO VARGAS. Sistema de Bibliotecas. 2016. Disponível em: https://sistema.bibliotecas-bdigital.fgv.br/bases/rede-bibliodata. Acesso em: 27 dez. 2018.

FUSCO, Elvis. Aplicação dos FRBR na modelagem de catálogos bibliográficos digitais. São Paulo: Cultura Acadêmica, 2011. E-book. Disponível em: http://hdl.handle.net/11449/109186. Acesso em: 17 jan. 2018.

GOMES, Henriette Ferreira; SANTOS, Raquel do Rosário. Representação e organização da informação científica como ações de mediação implícita: compromisso da biblioteca universitária com o ethos da ciência e a afiliação acadêmica. In: ALBUQUERQUE, M. E. B. C. et al. (Org.). Representação da informação: um universo multifacetado. João Pessoa: Editora da UFPB, 2013.

GONDIM, Linda M. P.; LIMA, Jacob Carlos. A pesquisa como artesanato Intelectual: considerações sobre método e bom senso. São Carlos: EdUFSCar, 2006. 88 p.

GRACIO, José Carlos Abbud. Metadados para a descrição de recursos da Internet: o padrão Dublin Core, aplicações e a questão da interoperabilidade. 2002. 127f. Dissertação (Mestrado em Ciência da Informação) - Faculdade de Filosofia e Ciências, Universidade Estadual Paulista, Marília. 2002. Disponível em: https://www.marilia.unesp.br. Acesso em: 19 jan. 2018.

HOPKINSON, Alan. O "Common Communication Format" desenvolvido pela UNESCO. Ci. Inf., Brasília, 14(1): 51-4, jan./jun. 1985. Disponível em: http://revista.ibict.br/ciinf/article/download/227/227. Acesso em: 14 abr. 2018.

IBICT. Formato IBICT: formato de intercâmbio bibliográfico e catalográfico. Brasília, DF: IBICT, 1987. Disponível em: http://livroaberto.ibict.br/. Acesso em: 18 jan. 2018.

IBICT. Rede Bibliodata. Disponível em: http://www.ibict.br/informacao-para-cienciatecnologia-e-inovacao\%20/rede-bibliodata. Acesso em: 15 jan. 2018.

IFLA. Permanent UNIMARC Commitee (PUC). Disponível em: https://www.ifla.org/unimarc/puc. Acesso em: 18 jan. 2018.

IFLA. UNIMARC Formato Bibliográfico. [Versão abrevidada da edição de 2008]. Lisboa: BNP, 2009. Disponível em:

https://www.ifla.org/files/assets/uca/Unimarc_bib_3\%C2\%Aaed_abrev.pdf. Acesso em: 14 fev. 2018.

ISBD Review Committee Working Group. ISBD(G): General International Standard Bibliographic Description. Rev. Ed. München: K.G. Saur; 1992. ISBN 3-598-11084-7. 
JOHNSON, Peggy. Editorial. Library Resources \& Technical Services, Chicago, v. 55, n. 4, p. 178-179, 2011. Disponível em: https://searchproquest.ez15. periodicos.capes.gov.br/docview/896735868?accountid=26611. Acesso em: 16 jan. 2018.

JOUDREY, Daniel N.; TAYLOR, Arlene G.; WISSER, Katherine M. The organization of information. 4rd ed. Santa Bárbara, Califórnia: Libraries Unlimited, 2018.

JSC-RDA. RDA - Resource Description and Access: a prospectus. JSC/RDA, 2009. Disponível em: http://www.rda-jsc.org/rdaprospectus.html. Acesso em: 6 jan. 2018.

KINCY, Chamya Pompey; LAYNE, Sara Shatford. Making the move to RDA: a selfstudy primer for catalogers. Lanham: Rowman \& Littlefield, 2014.

LÊDO, Felipe José; SILVEIRA, Naira Christofoletti. A representação do livro em braille em catálogos em linha de acesso público de bibliotecas. Informação \& Sociedade: Estudos, v. 27, n. 2, 2017. Disponível em: http://www.periodicos.ufpb.br/ojs/index.php/ies/article/view/33314. Acesso em: 31 jan. 2019.

LIBRARY OF CONGRESS. Dublin Core to MARC Crosswalk. [Washington]: Library of Congress, 2008. Disponível em: http://www.loc.gov/marc/dccross.html. Acesso em: 28 jan. 2019.

LIBRARY OF CONGRESS. Frequently Asked Questions (FAQ). Washington, 2006a. Disponível em: http://www.loc.gov/marc/faq.html\#definition. Acesso em: 12. fev. 2018.

LIBRARY OF CONGRESS. MARC 21 Bibliographic: introduction. [Washington]: Library of Congress, 2006b. Disponível em: https://www.loc.gov/marc/bibliogra phic/bdintro.html. Acesso em: 23 fev. 2018.

LIBRARY OF CONGRESS. MARC 21: Harmonized USMARC and CAN/MARC [Washington]: Library of Congress, 1998. Disponível em:

http://www.loc.gov/marc/annmarc21.html. Acesso em: 05 mar. 2019.

LIBRARY OF CONGRESS. RDA in MARC. Washington, 2014. Disponível em: http://www.loc.gov/marc/RDAinMARC.html. Acesso em: 23 fev. 2018.

LIBRARY OF CONGRESS. UNIMARC to MARC 21: conversion specifications. [Washington]: Library of Congress, 2001. Disponível em: http://loc.gov/marc/unimarctomarc21.html. Acesso em: 02 jan. 2019.

LIMA, Ida Maria Cardoso et al. Contribuição para o estabelecimento de padrões para o processamento técnico nas bibliotecas Instituições de Ensino Superior (IES) brasileiras. In: SEMINARIO NACIONAL DE BIBLIOTECAS UNIVERSITÁRIAS, 7., 1991, Rio de Janeiro. Anais [...]. Rio de Janeiro: SIBI/UFRJ, 1992., v. 1, p. 163-240. 
LOPES, Tatiane dos Santos de Feitas. FERNEDA, Edberto. Padrão especial de disseminação de dados (SDDS): uma introdução. Pesquisa Brasileira em Ciência da Informação e Biblioteconomia, João Pessoa, v. 11, n. 1, p. 151-168, 2016. Disponível em: http://www.periodicos.ufpb.br/ojs2/index.php/pbcib/article/view/28252. Acesso em: 16 jan. 2019.

LOURENÇO, Cíntia de Azevedo. Análise do Padrão Brasileiro de Metadados de Teses e Dissertações segundo o Modelo Entidade-Relacionamento. 2005. 165 f. Tese (Doutorado em Ciência da Informação) - Universidade Federal de Minas Gerais, Belo Horizonte, 2005. Disponível em: http://www.bibliotecadigital.ufmg.br/dspace/handle/1843/EARM-6ZGNZC. Acesso em: 05 jan. 2019.

MACHADO, Raquel Bernadete; PEREIRA, Ana Maria. Produção científica acerca do novo código de catalogação RDA: análise bibliométrica de 2010 a 2014. Revista Digital de Biblioteconomia \& Ciência da Informação, v. 13, n. 2, 2015. Disponível em:

https://periodicos.sbu.unicamp.br/ojs/index.php/rdbci/article/download/2106/3387. Acesso em: 11 jan. 2018.

MAIMONE, Giovana Deliberali; SILVEIRA, Naira Christofoletti; TÁLAMO, Maria de Fátima G. Moreira. Reflexões Acerca das Relações entre Representação Temática e Descritiva. Informação e Sociedade: Estudos, v. 21, n. 1, p. 27-35, jan./abr. 2011. Disponível em:

http://www.periodicos.ufpb.br/ojs2/index.php/ies/article/download/7367/5596. Acesso em: 13 abr. 2018.

MARCONDES, Carlos Henrique; SAYÃO, Luiz Fernando. Situação brasileira dos formatos de intercâmbio bibliográfico e dos "softwares" de suporte. In: SEMINÁRIO NACIONAL DE BIBLIOTECAS UNIVERSITÁRIAS, 7., 1991, Rio de Janeiro. Anais [...]. Rio de Janeiro: SIBI/UFRJ, 1992. p. 241-255.

MARCONI, Marina de Andrade; LAKATOS, Eva Maria. Fundamentos de metodologia científica. 5. ed. São Paulo: Altas, 2003.

MARTÍNEZ, Ana M.; RAMÓN, Susana. Los formatos bibliográficos usados en bibliotecas argentinas y sus implicaciones para la descripción de contenido en catálogos en línea. Información, Cultura y Sociedad, Buenos Aires, no. 1, p. 27-48, 1999. Disponível em: http://www.scielo.org.ar/pdf/ics/n1/n1a02.pdf. Acesso em: 29 nov. 2017.

MELGAÇO, Leda Maria Louzada. Formato IBICT: formato de intercâmbio bibliográfico e catalográfico. Revista de Biblioteconomia de Brasília, v. 17, n. 2, p. 349-356, 1989. Disponível em:

http://www.brapci.inf.br/index.php/article/view/0000001763/200383b00da996de1a6dd 781b05c64fb\#pdf. Acesso em: 12 abr. 2018.

MEY, Eliane Serrão Alves; SILVEIRA, Naira Christofoletti. Catalogação no plural. Brasília: Briquet de Lemos, 2009. 
MONTE-MÓR, Janice de Mello; BOTELHO, Marcos. O Controle Bibliográfico Universal, o depósito legal e a Fundação Getulio Vargas. Revista de Administração Pública, Rio de Janeiro, v. 21, n. 1, p. 106 a 118, mar. 1987. Disponível em: http://bibliotecadigital.fgv.br. Acesso em: 28 dez. 2018.

MONTE-MÓR, Jannice de Mello; CYSNEIROS, Luiz Fernando. Bibliodata/Calco Geração de uma base de dados nacional. Revista de Administração Pública, Rio de Janeiro, v. 16, n. 4, p. 131 a 141, set. 1982. ISSN 1982-3134. Disponível em: http://bibliotecadigital.fgv.br. Acesso em: 15 out. 2017.

MOURA, Milene Rosa de Almeida; COSTA, Luzia Sigoli Fernandes. Estudo comparativo do Padrão de Descrição de Informação e MARC 21 em livro. In: SEMINÁRIO EM CIÊNCIA DA INFORMAÇÃO, 6., 2016, Londrina. Anais [...]. Londrina: UEL, 2016. v. 1.

OKADA, Suzana Yuri; ORTEGA, Cristina Dotta. Análise da recuperação da informação em catálogo online de biblioteca universitária. Inf. Inf., Londrina, v. 14, n. 1, p. 18 - 35, jul./jun. 2009. Disponível em: http://www.uel.br/revistas/uel/index.php/informacao/article/view/1854/3011. Acesso em: 27 nov. 2017.

OLIVER, Chris. Introdução à RDA: um guia básico. Brasília: Briquet de Lemos, 2011.

ORTEGA, Cristina Dotta. Microisis: das origens à consolidação numa realidade de informação em mudança. São Paulo: Polis/APB, 1998. 130 p.

ORTEGA, Cristina Dotta. Os registros de informação dos sistemas

documentários: uma discussão no âmbito da Representação Descritiva. São Paulo, 2009. Tese (Doutorado em Ciência da Informação) - Escola de Comunicações e Artes, Universidade de São Paulo (ECA/USP). Disponível em:

http://www.teses.usp.br/teses/disponiveis/27/27151/tde-21092009-211824/pt-br.php. Acesso em: 12 fev. 2018.

RIBEIRO, Fernanda. Organizar e representar informação: apenas um meio para viabilizar o acesso? Revista da Faculdade de Letras: Ciências e Técnicas do Patrimônio, Porto, v.4, p.83-100, 2005. Disponível em:

http://ler.letras.up.pt/uploads/ficheiros/4937.pdf. Acesso em: 10 dez 2018.

RIBEIRO, Fernanda. Organização e uso da informação: conhecer bem para bem representar. Íris, Recife, v.1, n.1, p. 7-16, jul./dez. 2012. Disponível em:

https://repositorio-

aberto.up.pt/bitstream/10216/66267/2/fernandaribeiroorganizacao000191125.pdf. Acesso em:15 jul. 2017.

RICHARDSON, Roberto Jarry. Pesquisa Social: métodos e técnicas. São Paulo: Atlas, 1999. 
ROBREDO, Jaime; CUNHA, Murilo B. da. Documentação de Hoje e de Amanhã: uma abordagem informatizada de biblioteconomia e dos sistemas de informação. 2 . ed. São Paulo: Global, 1994.

ROSENFELD, Louis; MORVILLE, Peter; ARANGO, Jorge. Information architecture for the web and beyond. 4. ed. Sebastopol, CA: O'Relly Media, 2015.

SABORÍO-ACUÑA, José Iván; CHINCHILLA-ARLEY, Ricardo. Metodología para la migración de datos bibliográficos entre programas de software de automatización: de CEPAL a MARC, e-Ciencias de la Información, San José, Costa Rica, v. 4, n. 2, jul.-dez., 2014. Disponível em:

https://www.redalyc.org/articulo.oa?id=476847246006. Acesso em 31 jan. 2017.

SAMPIERI, Roberto Hernandez; COLLADO, Carlos Fernández; LUCIO, María del Pilar Baptista. Metodologia da Pesquisa. 3. ed. São Paulo: McGraw-Hill, 2006.

SARACEVIC, Tefko. Ciência da informação: origem, evolução e relações.

Perspectivas em Ciência da Informação, Belo Horizonte, n. 1, v. 1, p. 41-62, jan./jun., 1996. Disponível em:

http://portaldeperiodicos.eci.ufmg.br/index.php/pci/article/view/235. Acesso em: 20 de ago. 2017.

SERRA, Liliana Giusti. O formato MARC e o RDA: tempos de mudanças? In: ENCONTRO INTERNACIONAL DE CATALOGADORES, 9.; ENCONTRO NACIONAL DE CATALOGADORES, 2., 2013, Rio de Janeiro. Anais [...]. Rio de Janeiro: Fundação Biblioteca Nacional, 2013. Disponível em:

http://www.telescopium.ufscar.br/index.php/eic-enacat/eicenacat/paper/viewFile/13/13. Acesso em: 31 jan. 2019.

SERRA, Liliana Giusti et al. Os princípios de descrição e sua aderência aos formatos MARC 21 e ONIX. Ciência da Informação, Brasília, DF, v. 46 n. 2, p.51-66, maio/ago. 2017. Disponível em:

http://revista.ibict.br/ciinf/article/download/2327/3699. Acesso em 25 jul. 2018.

SILVA, Luciana Candida da et al. O código RDA e a iniciativa BIBFRAME: tendências da representação da informação no domínio bibliográfico. Em Questão, v. 23, n. 3, p. 131-157, 2017. Disponível em:

http://seer.ufrgs.br/index.php/EmQuestao/article/view/69549. Acesso em: 15 Jan. 2018.

SILVA, Luciana Candida da; BAPTISTA, Dulce Maria. Entre a teoria e a prática no ensino do formato MARC 21: a metodologia da Universidade Federal de Goiás. In: ENCONTRO INTERNACIONAL DE CATALOGADORES, 9; ENCONTRO NACIONAL DE CATALOGADORES, 2., 2013, Rio de Janeiro. Anais [...]. Rio de Janeiro:

Fundação Biblioteca Nacional, 2013.

SILVA, Maria Weilanny Pinheiro da; SOUZA, Orinete Costa. Catalogação cooperativa: CALCO e Rede Bibliodata. In: ENCONTRO REGIONAL DOS ESTUDANTES DE BIBLIOTECONOMIA, CIÊNCIA DA INFORMAÇÃO E GESTÃO DA INFORMAÇÃO, 14., 2011, São Luis-MA. Anais [...]. São Luis-MA: EREBD, 2011. 
SMET, Egbert; SPINAK, Ernesto. The abc of ABCD: the reference manual. [s.L. : s. n.], 2009. Disponível em:

http://bvsmodelo.bvsalud.org/download/abcd/manuais/ABCofABCD-ES-

Provisional.pdf. Acesso em: 01 jan. 2019.

SOUSA, Marckson Roberto Ferreira de. O acesso a informações e a contribuição da arquitetura da informação, usabilidade e acessibilidade. Informação \& Sociedade:

Est., João Pessoa, v.22, p. 65-76, Número Especial 2012. Disponível em:

http://www.ies.ufpb.br/ojs/index.php/ies/article/view/13298. Acesso em: 06 ago. 2017.

SOUZA, Marcia Izabel Fugisawa; ALVES, Maria das Dores Rosa. Representação descritiva e temática de recursos de informação no sistema Agência Embrapa: uso do padrão Dublin Core. Revista Digital de Biblioteconomia e Ciência da Informação, Campinas, v.7, n. 1, p. 208-223, jul./dez. 2009. Disponível em: https://periodicos.sbu.unicamp.br/ojs/index.php/rdbci/article/view/1983/2104. Acesso em: 08 fev. 2019.

STORTI, Vivian Rosa; ZAFALON, Zaira Regina; LANDGRAF, Juliana Roberta Morcelli. Estudo dos padrões de metadados em instituições estaduais e municipais de ensino superior: aspectos para a interoperabilidade e para o compartilhamento de recursos. In: ENCONTRO INTERNACIONAL DE CATALOGADORES, 9., 2013, Rio de Janeiro. Anais [...]. Rio de Janeiro: Fundação Biblioteca Nacional, 2013.

Disponível em: http://www.abinia.org/catalogadores/66-229-1-PB.pdf. Acesso em: 22 abr. 2018.

TEIXEIRA, Marcelo Votto. O RDA no controle de autoridades do Sistema De Bibliotecas da Universidade De Caxias Do Sul. In: ENCONTRO INTERNACIONAL DE CATALOGADORES, 9, 2013. In: ENCONTRO INTERNACIONAL DE CATALOGADORES, 9., 2013. Rio de Janeiro. Anais [...]. Rio de Janeiro: Fundação Biblioteca Nacional, 2013. Disponível em:

http://www.telescopium.ufscar.br/index.php/eic-enacat/eic-enacat/paper/view/53/24. Acesso em: 13 dez. 2018.

TEXEIRA, Marcelo Votto et al. Implantação do código de catalogação Resource Description and Access (RDA) na Biblioteca da Pontifícia Universidade Católica do Rio Grande do Sul (PUCRS). In: CONGRESSO BRASILEIRO DE BIBLIOTECONOMIA, DOCUMENTAÇÃO E CIÊNCIA DA INFORMAÇÃO, 27., 2017, Fortaleza (CE). Anais [...]. Fortaleza: [s. n.], 2017. v. 26. Disponível em: https://anaiscbbd.emnuvens.com.br/anais/article/download/1925/1926. Acesso em 13 dez. 2018.

UNESCO. Reference Manual for Machine Readable Bibliographic Descriptions. 2nd ed., edited by H. Dierickx and A. Hopkinson. Paris: UNESCO, 1981. Disponível em: http://unesdoc.unesco.org/images/0004/000478/047859EB.pdf. Acesso em: 18 jan. 2018. 
UNESCO. The Common Communication Format for information on cultural Development: based on the CCF for factual and CCF for bibliographic information. Compilado por Alan Hopkinson. Paris: UNESCO, 1994. Disponível em: https://unesdoc.unesco.org/ark:/48223/pf0000097050?posInSet=1\&queryld=0f6beb1 9-59b7-4094-b1f3-08e1ee1c1252. Acesso em: 11 set. 2017.

VASCONCELLOS, Paulo de Avellar de Góes e. Bibliodata/Calco - informação bibliográfica para o desenvolvimento. Ciência da Informação, v. 25, n. 3, 1996. Disponível em: http://revista.ibict.br/ciinf/article/view/646/650. Acesso em: 18 abr. 2018.

VETTER, Silvana Maria de Jesus; ARAUJO, Leonardo Pinto. Padrão MARC 21 e catalogação em bibliotecas universitárias de São Luis/MA. In: SEMINÁRIO NACIONAL DE BIBLIOTECAS UNIVERSITÁRIAS - SNBU, 17., 2012, Gramado. Anais [...]. Gramado: UFRGS, 2012. Disponível em:

https://lume.ufrgs.br/handle/10183/70710. Acesso em: 09 abr. 2018.

VOSGRAU, Sonia Regina Casselhas et al. Formato MARC 21 bibliográfico para publicações seriadas. ETD - Educação Temática Digital, v. 5, n. 1, p. 106-114, 2003. Disponível em: http://www.brapci.inf.br/index.php/article/download/7494.

Acesso em: 12 fev. 2018.

YAMANE, Gabriela Aparecida da Cunha; CASTRO, Fabiano Ferreira de. O estudo e a identificação dos padrões de metadados para a representação e a recuperação da imagem digital na perspectiva da web. Em Questão, Porto Alegre, v. 24, n. 1, p. 145173, jan./abr. 2018. Disponível em:

https://seer.ufrgs.br/index.php/EmQuestao/article/download/71475/43695. Acesso em: 06 jan. 2019. 